\title{
Final report on the MAGARC software consulting support contract (WFO No. 15904) for ITER magnet safety assessment
}

Brad J. Merrill

June $30^{\text {th }}, 2016$ 


\section{DISCLAIMER}

This information was prepared as an account of work sponsored by an agency of the U.S. Government. Neither the U.S. Government nor any agency thereof, nor any of their employees, makes any warranty, expressed or implied, or assumes any legal liability or responsibility for the accuracy, completeness, or usefulness, of any information, apparatus, product, or process disclosed, or represents that its use would not infringe privately owned rights. References herein to any specific commercial product, process, or service by trade name, trade mark, manufacturer, or otherwise, does not necessarily constitute or imply its endorsement, recommendation, or favoring by the U.S. Government or any agency thereof. The views and opinions of authors expressed herein do not necessarily state or reflect those of the U.S. Government or any agency thereof. 


\title{
Final report on the MAGARC software consulting support contract (WFO No. 15904) for ITER magnet safety assessment
}

\author{
Brad J. Merrill \\ Idaho National Laboratory \\ June $30^{\text {th }}, 2016$ \\ Idaho National Laboratory \\ Nuclear Science and Technology Directorate \\ Fusion Safety Program \\ Idaho Falls, Idaho 83415
}

Prepared for the

U.S. Department of Energy

Office of Science, Office of Fusion Energy Sciences

Under DOE Idaho Operations Office

Contract DE-AC07-05ID14517 


\begin{abstract}
The ITER (not an acronym but Latin for "the Way") International Organization (IO) is building a large-scale scientific experiment that is now under construction in Cadarache, France. The ITER Tokamak fusion reactor aims to demonstrate that it is possible to produce energy from fusion. The ITER's power output goal is to deliver ten times the power it consumes. During its operational lifetime, ITER will test key technologies necessary for the next step: the demonstration fusion power plant that will prove that it is possible to capture fusion energy for commercial use. General information on the ITER project can be found at http://www.iter.org.

The ITER reactor's superconducting magnet systems create $41 \mathrm{GJ}$ of stored magnetic field energy when fully energized. The consequences of such energy dissipating via electrical arcs under faulted conditions gives rise to safety concerns even though these fault events are extremely unlikely. As part of the ITER licensing procedure, and as a result of such safety concerns, this contract was established to benchmark a developing magnet safety analysis tool at Culham Centre for Fusion Energy against the MAGARC computer code.

MAGARC was developed by the U.S. Idaho National Laboratory (INL) under the ITER Engineering Design Activity (EDA) Project and was applied to produce previous analyses, in order to support magnet fault and safety assessment (ITER_D_22HVG6 v1.4) for the ITER design description document.

This contract report documents the completion of requested modifications to the MAGARC code by the ITER IO, a time-step size sensitivity analysis with MAGARC during an unmitigated quench event, a comparison of the modeling approaches taken in developing MAGARC and the CCFE analysis package, and the data required for the benchmarking activity for these codes.
\end{abstract}




\section{CONTENTS}

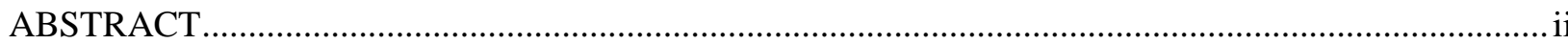

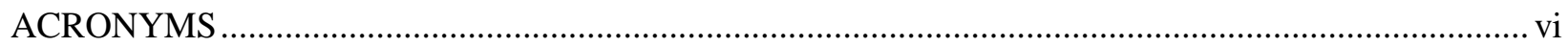

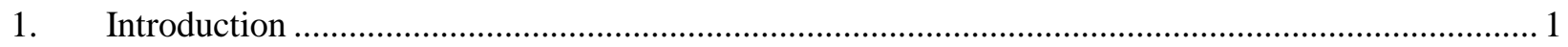

2. Task \#1: Sensitivity study for the MAGARC code ................................................................. 2

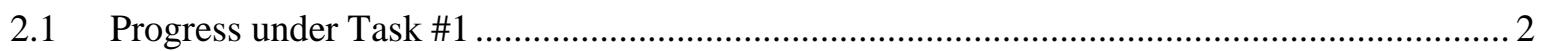

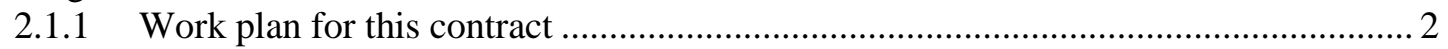

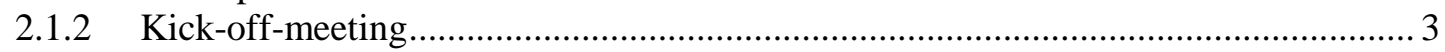

2.1.3 Required code modifications that remedy the problems identified by the

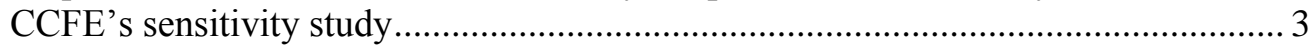

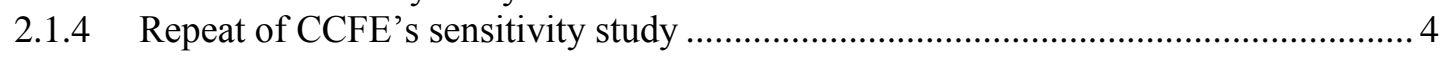

3. Task \#2: Implement additional updates/modifications to the MAGARC code.............................. 10

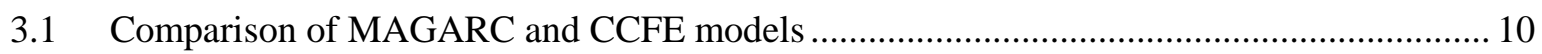

3.1.1 Modeling geometry and numerical solution scheme........................................... 10

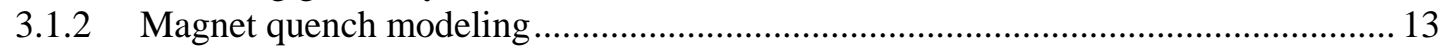

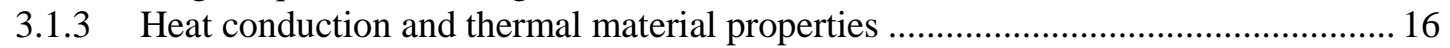

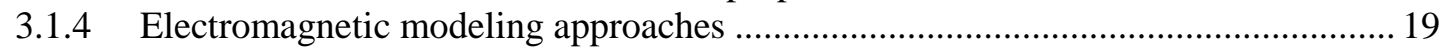

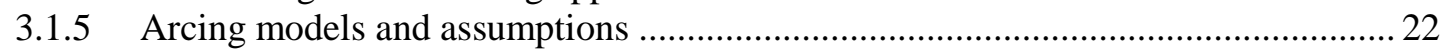

4. Task \#3: Consult with CCFE in performing benchmark activity with MAGARC software.............30

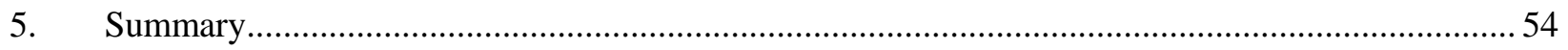

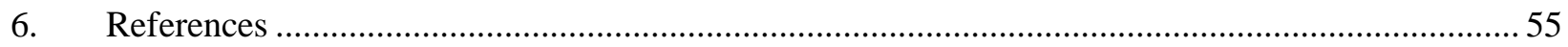

Appendix A Work Plan for the ITER Electromagnetic Assessments of ITER Magnets in Safety-

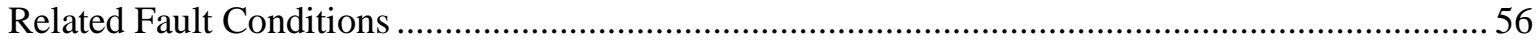

Appendix B Overview of the Magnet Arcing (MAGARC) Computer Code for Toroidal Field Coils Capabilities.

Appendix C MAGARC Computer Code Changes Addressing Time-step Size Sensitivity

Problems

\section{FIGURES}

Figure 1. Number of gap arcs predicted for CCFE sensitivity study.................................................... 6

Figure 2. Number of inline plus bypass arcs predicted for CCFE sensitivity study................................. 6

Figure 3. Voltage drop across magnet leads predicted for CCFE sensitivity study...................................

Figure 4. Quench fraction predicted for CCFE sensitivity study ...........................................................

Figure 5. Total energy $($ resitive + arc) deposited in magnet for CCFE sensitivity study............................ 8

Figure 6. Arc energy deposited in magnet for CCFE sensitivity study ................................................... 8 
Figure 7.Total melt volume predicted for CCFE sensitivity study..................................................

Figure 8. Magnet current predicted for CCFE sensitivity study.................................................... 9

Figure 9. Comparison of MAGARC predicted magnet quench with and without induced eddy

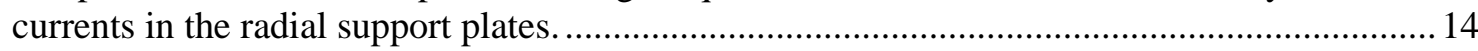

Figure 10. Thermal conduction materials properties comparison between MAGARC and CCFE

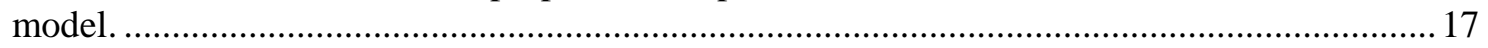

Figure 11. Electrical materials properties comparison between MAGARC and CCFE model.................20

Figure 12. Comparison of arc data for (a) unconfined arcs from Ref [13] and (b) confined arcs

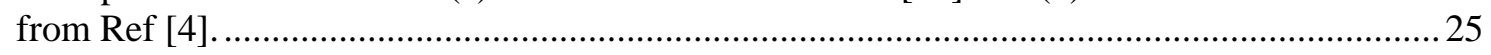

Figure 13. (a) Computed of arc area from Ref [13] data compared to Eq. 2 , and (b) arc electric

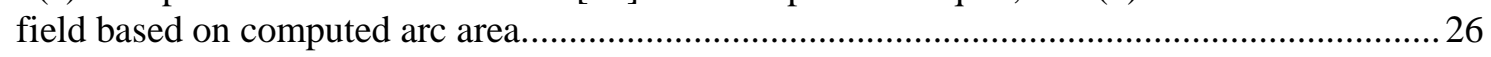

Figure 14. Arc characteristics (a) based on arc area from Eq. 2 used in Kronhardt model [4], and (b) based on arc area derived from arc electric field data from Ref [13] used in Kronhardt model [4].

Figure 15. Number of gap arcs predicted for the base case unmitigated quench event.

Figure 16. Number of inline plus bypass arcs predicted for the base case unmitigated quench event......

Figure 17. Voltage drop across magnet leads predicted for the base case unmitigated quench event.......

Figure 18. Quench fraction predicted for predicted for the base case unmitigated quench event.

Figure 19. Total energy (resistive + arc) deposited in magnet predicted for the base case unmitigated quench event.

Figure 20. Arc energy deposited in magnet predicted for the base case unmitigated quench event........... 35

Figure 21.Total melt volume predicted for the base case unmitigated quench event. ...............................36

Figure 23. MAGARC Cartesian grid mapped to ITER Engineering Design Activity toroidal field coil coordinates, but with the radial and toroidal widths magnified by a factor of two for easier visualization.

Figure 24. MAGARC predicted support plate temperatures at $50 \mathrm{~s}$ for radial cuts through pancakes 1 through 3 .

Figure 25. MAGARC predicted support plate temperatures at $50 \mathrm{~s}$ for radial cuts through pancakes 4 through 6 .

Figure 26. MAGARC predicted support plate temperatures at $50 \mathrm{~s}$ for radial cuts through pancake 7 and voltages for axial cut through magnet midplane.

Figure 27. MAGARC predicted toroidal gap currents between magnet pancakes at $50 \mathrm{~s}$.

Figure 28. MAGARC predicted support plate temperatures at $75 \mathrm{~s}$ for radial cuts through pancakes 1 through 3 .

Figure 29. MAGARC predicted support plate temperatures at $75 \mathrm{~s}$ for radial cuts through pancakes 4 through 6 .

Figure 30. MAGARC predicted support plate temperatures at $75 \mathrm{~s}$ for radial cuts through pancake 7 and voltages for axial cut through magnet midplane. 
Figure 31. MAGARC predicted toroidal gap currents between magnet pancakes at $75 \mathrm{~s}$.

Figure 32. MAGARC predicted support plate temperatures at $100 \mathrm{~s}$ for radial cuts through pancakes 1 through 3 .

Figure 33. MAGARC predicted support plate temperatures at $100 \mathrm{~s}$ for radial cuts through pancakes 4 through 6 .

Figure 34. MAGARC predicted support plate temperatures at $100 \mathrm{~s}$ for radial cuts through pancake 7 and voltages for axial cut through magnet midplane.

Figure 35. MAGARC predicted toroidal gap currents between magnet pancakes at $100 \mathrm{~s}$.

Figure 36. MAGARC predicted support plate temperatures at $125 \mathrm{~s}$ for radial cuts through pancakes 1 through 3 .

Figure 37. MAGARC predicted support plate temperatures at $125 \mathrm{~s}$ for radial cuts through pancakes 4 through 6 .

Figure 38. MAGARC predicted support plate temperatures at $125 \mathrm{~s}$ for radial cuts through pancake 7 and voltages for axial cut through magnet midplane. .52

Figure 39. MAGARC predicted toroidal gap currents between magnet pancakes at $125 \mathrm{~s}$.

\section{TABLES}

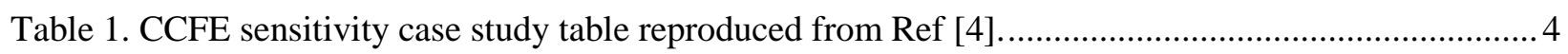

Table 2. Comparison between MAGARC and CCFE analysis package modeling geometries................. 12

Table 3. Comparison of MAGARC and CCFE analysis package quench models. .................................. 15

Table 4. Comparison of MAGARC and CCFE analysis package heat conduction models....................... 18

Table 5. Comparison of MAGARC and CCFE analysis package electrical/magnetic models..................21

Table 6. Comparison of MAGARC and CCFE analysis package arcing models ....................................28

Table 7. Contractor list of required deliverables due after contract effective date of Oct. $16^{\text {th }} 2015 \ldots \ldots . .54$ 


\section{ACRONYMS}

$\begin{array}{ll}\text { CC } & \text { Correction Coils } \\ \text { CCFE } & \text { Culham Centre for Fusion Energy } \\ \text { CS } & \text { Central Solenoid } \\ \text { DEMO } & \text { Demonstration fusion power plant } \\ \text { EDA } & \text { Engineering Design Activity } \\ \text { FSP } & \text { Fusion Safety Program } \\ \text { GE } & \text { Glass Epoxy } \\ \text { GMRES } & \text { Generalized Minimum Residual } \\ \text { GP } & \text { Groupe Permanente } \\ \text { INL } & \text { Idaho National Laboratory } \\ \text { IO } & \text { International Organization } \\ \text { ITA } & \text { Implementing Task Agreement } \\ \text { ITER } & \text { Latin for 'the way" } \\ \text { KoM } & \text { Kick-off-Meeting } \\ \text { MAGARC } & \text { Magnet Arcing } \\ \text { MIT } & \text { Massachusetts Institute of Technology } \\ \text { PF } & \text { Poloidal Field } \\ \text { TF } & \text { Toroidal Field } \\ \text { SS } & \text { Stainless steel } \\ \text { WFO } & \text { Work for Others } \\ \text { 1D } & \text { One dimensional } \\ \text { 3D } & \text { Three dimensional } \\ & \end{array}$




\section{Final report on the MAGARC software consulting support contract (WFO No. 15904) for ITER magnet safety assessment}

\section{Introduction}

The ITER (not an acronym but Latin for "the Way") International Organization (IO) is building a large-scale scientific experiment that is now under construction in Cadarache, France. The ITER Tokamak fusion reactor aims to demonstrate that it is possible to produce energy from fusion. The ITER's power output goal is to deliver ten times more power than it consumes. During its operational lifetime, ITER will test key technologies necessary for the next step: the demonstration fusion power plant (DEMO). DEMO will prove that it is possible to capture fusion energy for commercial use. General information on the ITER project can be found at http://www.iter.org.

The ITER reactor contains a superconducting magnet system that consists of 18 Toroidal Field (TF) coils, 6 Poloidal Field (PF) coils, a Central Solenoid (CS), 18 Correction Coils (CC) and a Feeder System. The amount of magnetic energy stored in the ITER superconducting magnets is up to $41 \mathrm{GJ}$ in the TF coils and $\sim 10 \mathrm{GJ}$ in the PF coils and the CS. The consequences of such energy dissipating via electrical arcs under faulted conditions gives rise to safety concerns even though the fault events are extremely unlikely. As part of ITER licensing procedure, and as a result of such safety concerns, the Groupe Permanente (GP), the advisory experts to the Nuclear Safety Agency (the French regulatory authority) requested a qualified/updated analysis for the electromagnetic safety concerns associated with such arcs.

The ITER contract (ITER/CT/13/4300000813) 'Electromagnetic Assessments of ITER Magnets in Safety-related Fault Conditions' is currently underway at Culham Centre for Fusion Energy (CCFE) in the United Kingdom. One of the objectives of the contract is to develop an analysis package of magnet safety. The MAGARC computer code [1,2,3], which uses 3-D heat conduction equations and a resistive circuit network to account for the arcing, bypass currents, magnet melting, and heat conduction, was developed by the U.S. Idaho National Laboratory (INL) under the ITER Engineering Design Activity (EDA) Project and was applied to produce previous analyses, in order to support magnet fault and safety assessment (ITER_D_22HVG6 v1.4) found in the ITER design description document.

A preliminary benchmark of the CCFE analysis package noted, in some cases, that the MAGARC software calculation results, e.g. the number of arcs, are sensitive to time-step size variation. This indicates that the convergence criterion and control implemented by the MAGARC software should be studied further and perhaps modified in order to enhance the stability of its calculations. Addressing this problem will validate previous analyses and ensure a proper benchmark with the CCFE analysis package.

To this end, an INL Work-for-Others (WFO) contract was developed between the ITER IO and the INL for the purpose of conducting software consulting for the MAGARC code as a supplementary activity to the above referenced ITER contract 'Electromagnetic Assessments of ITER Magnets in Safetyrelated Fault Conditions'. The essential goals of this contract are:

1) To consult and validate the MAGARC code that performed previous analysis for ITER coil fault events and as appropriate update and/or modify the MAGARC code; and

2) For the INL to consult with CCFE on benchmarking and validating of the analysis package developed being developed by CCFE for the assessment of ITER magnet arcing safety.

This consultation contract will proceed under the following three Tasks: 
Task-1: Perform a sensitivity study for the MAGARC code;

Task-2: Implement additional updates to the MAGARC code; and

Task-3: Assist CCFE in performing benchmark activity with MAGARC by supplying CCFE with MAGARC resulting software predictions as performed under this WFO.

This report documents the work conducted under this contract for these Tasks. The following sections are identified by the above task descriptions. The final section contains a summary of the work conducted under this contract.

\section{Task \#1: Sensitivity study for the MAGARC code}

Ref [4] documents the results of a preliminary sensitivity study with the MAGARC toroidal field (TF) coil code. This sensitivity study investigated found convergence issues for the MAGARC code. The findings of this study were that:

1) Decreasing the MAGARC's maximum allowed time-step size produced dramatic changes in calculated results, e.g. the number of arcs,

2) A calculation could halt in the middle of problem execution with the symptom of a large voltage spike reported across the magnet's leads, causing the code to exceed its set limits for that input model and terminating; and

3) Once an in-line arc is initiated, it stays on regardless of what the end time is set to for the calculation or even if the magnet current is predicted to leave the magnet by way of the magnet's busbars.

The agreed upon work-scope under this Task is:

1) Submit a work plan to the ITER IO within 30 days after the initial contact signature date containing the resource distribution estimated for each deliverable,

2) Travel to CCFE in Abingdon, UK for a meeting. At this one week long meeting, provide CCFE with details on MAGARC code's structure and models, and

3) Perform the required code modifications that remedy the problems identified by the CCFE's sensitivity study, and produce a preliminary summary report on the improvements and updates to MAGARC

\subsection{Progress under Task \#1}

\subsubsection{Work plan for this contract}

An initial work-plan was presented at a Kick-off-Meeting (KoM) held November $30^{\text {th }}, 2015$. This work-plan was discussed and revised at the request of the ITER IO. The work plan contains a discussion of the work-scope under this contract, the estimated resources to accomplish this work-scope and a schedule to complete the contract. The work plan has been included as Appendix A to this report. 


\subsubsection{Kick-off-meeting}

During the week of November $30^{\text {th }}$ to December $4^{\text {th }}, 2015$, a KoM was held at CCFE. Besides presenting an initial work-plan for this contract, a PowerPoint presentation was developed and presented at working meetings during the KoM that detailed the capabilities of MAGARC-TF. This presentation has been included as Appendix B of this report. In addition to these meetings, with the help of Dr. Shanliang Zheng of CCFE, work on comparing the MAGARC and CCFE analysis package capabilities was conducted that produced a preliminary side-by-side capabilities comparison table of these computer codes. This Table will be discussed in Section 3 of this report.

\subsubsection{Required code modifications that remedy the problems identified by the CCFE's sensitivity study}

As stated in the introduction, Ref [4] conducted a sensitivity study on the MAGARC-TF code predicted transient results as a function of the adopted time-step size, in particular: 1) the number of predicted arcs (inline and gap arcs) that develop, 2) fraction of magnet quenched and the voltage drop at the magnet's leads (busbars). The MAGARC code allows the user to specify a maximum and minimum time-step size for a given calculation. In between these time-step limits, the code will adjust the time-step to ensure that no more than a $10 \%$ change in material enthalpy occurs during any given time-step. If that occurs, the time-stepping logic cuts the time-step by half and attempts to repeat the time-step. This logic also tries to strive for an optimum time-step size based on the number of iterations required to converge the threedimensional (3D) structural heat conduction solution (i.e., temperatures) for the magnet. If convergence occurs in fewer than 50 iterations, the time-step is increased by $10 \%$ for the next step.

The most challenging problem in modeling unmitigated quench events for the MAGARC code is solving the steady-state voltage equations for the magnet's structure (e.g. the radial support plates and coil case). An added difficulty arises when solving the voltage equations by the large electrical property change produced by simulated arcs. The original strategy adopted to cope with this problem was to dampen the electrical conductance change in time for the grid location containing an arc by taking $90 \%$ of the value at the start of the previous time-step and $10 \%$ of the value at the start of the present time-step to advance the solution to the next time-step. Because the weighting of this time-dampening was not a function of time-step size, forcing MAGARC to take smaller time-steps only produced different results with time. Removing this time dampening may lead to numerical instabilities and would not really solve this time-step size issue because the voltage equations are steady state and produce instantaneous voltage changes in time regardless of the time-step size. To resolve this issue and allow for proper consistency when repeating a time-step, a heuristic approach has now been adopted that allows the arc conductance to change linearly over a user specified time interval. Ref [5] states that "The total ignition time for electric arc lengths of 4-5 mm and gas pressure of 40 mbar is approx. $0.1-0.2 \mathrm{~s}$ ". A natural choice would be 150 ms for an arc initiation model, but for this sensitivity study, a value of $15 \mathrm{~ms}$ was chosen to uncover any additional stability issues associated with taking this approach. The changes made to MAGARC for repeating a time-step and arc initiation time are shown in Appendix C, which contains a side-by-side comparison of the modified and original FORTRAN code.

The test case that halted in the middle of problem execution with a large voltage spike reported across the magnet's leads is symptomatic of the Bi-conjugate iterative method becoming unstable (e.g. dramatically diverges instead of converging) during an attempt to solve the voltage equations. This is a well-known problem associated with this Krylov iterative method that was discovered and remedied by the author when developing a version of MAGARC for busbar arcing predictions. The fix was to apply a 
second Krylov method called the Generalized Minimum Residual (GMRES) method if the Bi-conjugate gradient iterative method failed to converge. GMRES converges much slower than the Bi-conjugate gradient and has a tendency to "stall out" or stop converging after a high number of iterations. But repeated application of these solvers per time-step appears to provide the best solution to these problems. The modifications made to MAGARC to apply these solvers are presented in Appendix C. Like the Biconjugate gradient routines, the GMRES subroutines were also obtained from Ref [6].

The final issue of inline (+ bypass) arcs remaining on in time even after the current is predicted to leave the magnet was a bug in the code. The variable being reported is actually the number of locations of first melt detected along the magnet conductor, which is also taken by MAGARC to be the location where an inline or bypass arc exists, if current is still being applied to the magnet. The code was corrected by setting this variable to zero once the current leaves the magnet. As such, the arc velocity in MAGARC equals that of the conductor melt front. Ref [5] suggests a simple arc velocity which can be considered for implementing in MAGARC instead of the melt front velocity in future work if the Sponsor desires this change.

\subsubsection{Repeat of CCFE's sensitivity study}

As reported in Ref [4], a time-step size sensitivity study was conducted with the previous version of the MAGARC TF code. Table 1 contains the various cases that were investigated. The maximum timestep size was varied between $1 \times 10^{-3}$ to $5 \times 10^{-2} \mathrm{~s}$ for transient time of $150 \mathrm{~s}$, when a current is being applied to the magnet; otherwise, the maximum time-step allowed is $5 \mathrm{~s}$. This table contains a list of end-times that MAGARC stopped on and the number of steps taken to reach that end-time. As can be seen, all of the cases terminated normally for the present modified version of MAGARC code. Where the reported number of steps by CCFE came from is unknown at this time. The number of time-steps taken by MAGARC is printed to screen and doesn't appear in any other output files. It appears that the number being reported by CCFE is the number of output lines found in MAGARC's plot files. Because the plot intervals are every 100 time-steps, a more accurate estimation of the number of time-steps taken by MAGARC would be $\sim 100$ times larger than that reported by CCFE, or more accurately two plus 100 times the number of plot lines minus two (i.e. number of steps $\sim 100 \times(C C F E$ Steps-2) +2$)$. The reported INL quantities highlighted in yellow are those estimated from the plot output files for that case. The INL quantities highlighted in blue are those printed to the computer screen by MAGARC at problem termination.

Table 1. CCFE sensitivity case study table reproduced from Ref [4].

\begin{tabular}{|c|c|c|c|c|c|c|}
\hline Test cases & Dtmin & Dtmax & \multicolumn{2}{|c|}{ Time length (s) } & \multicolumn{2}{|c|}{ Steps } \\
\cline { 4 - 7 } & $(\mathrm{s})$ & $(\mathrm{s})$ & CCFE & INL & CCFE & INL \\
\hline Test1 & $1 \times 10^{-6}$ & $2 \times 10^{-2}$ & 150.10 & 150.02 & 125 & 13402 \\
\hline Test2 & $1 \times 10^{-6}$ & $2 \times 10^{-3}$ & 150.05 & 150.05 & 643 & 40702 \\
\hline Test3 & $5 \times 10^{-7}$ & $2 \times 10^{-2}$ & 150.12 & 150.10 & 124 & 13302 \\
\hline Test4 & $1 \times 10^{-7}$ & $2 \times 10^{-2}$ & 150.87 & 150.10 & 122 & 13302 \\
\hline Test5 & $1 \times 10^{-6}$ & $1 \times 10^{-3}$ & 150.29 & 150.05 & 598 & 77002 \\
\hline Test6 & $1 \times 10^{-6}$ & $5 \times 10^{-3}$ & 29.47 & 150.06 & 62 & 20802 \\
\hline Test7 & $1 \times 10^{-6}$ & $5 \times 10^{-2}$ & 150.07 & 150.01 & 111 & 12002 \\
\hline
\end{tabular}




\begin{tabular}{|l|l|l|l|l|l|l|}
\hline Test8 & $1 \times 10^{-6}$ & $1 \times 10^{-2}$ & 150.03 & 150.25 & 1922 & 15467 \\
\hline
\end{tabular}

Figs 1 through 8 contain the MGARC predicted number of gap arcs, number of inline plus bypass arcs, voltage drop across the magnet, fraction of magnet conductor quenched, energy deposited in the magnet from resistive and arc heating, the energy deposited in the magnet by arc heating, the volume of steel plus copper melt and the predicted magnet current, respectively, for the eight cases examined. As can be seen, the predicted number of inline plus bypass arcs, quench fraction and coil currents are not very time-step sensitive. The number of gap arcs is the most time-step size sensitive prediction, especially prior to $50 \mathrm{~s}$. But this variable appears to have better agreement for maximum time-steps less than or equal to $2 \mathrm{~ms}$, as do all of the other predicted quantities as well. It makes sense that a smaller time-step size would produce more consistent results given the time-explicit heat transfer coupling between the MAGARC magnet conductor and structure heat conduction models (note Section 3.1.3). However, it might also be instructive to assess the impact that the allowed enthalpy-change per time-step and arc initiation-time have on this sensitivity study.

It can also be seen in Fig 3 that there is not a large voltage spike reported by MAGARC for Case 6, indicating that the present modifications have solved this problem. It is also worth noting the connection between this variable and the number of inline plus bypass arcs reported in Fig 2. Once the number of these arcs reaches 14, MAGARC is predicting that there are bypass arcs in all seven pancakes. This means that the preferred current conduction path between the first and seventh pancakes is by way of gap arcs between radial plates of all seven pancakes, that is a short circuit of all of the magnet windings between the first bypass arc and last bypass arc, with the only resistance to ground being that portion of the conductor attached directly to the last bypass arc and the magnet's outlet lead. 


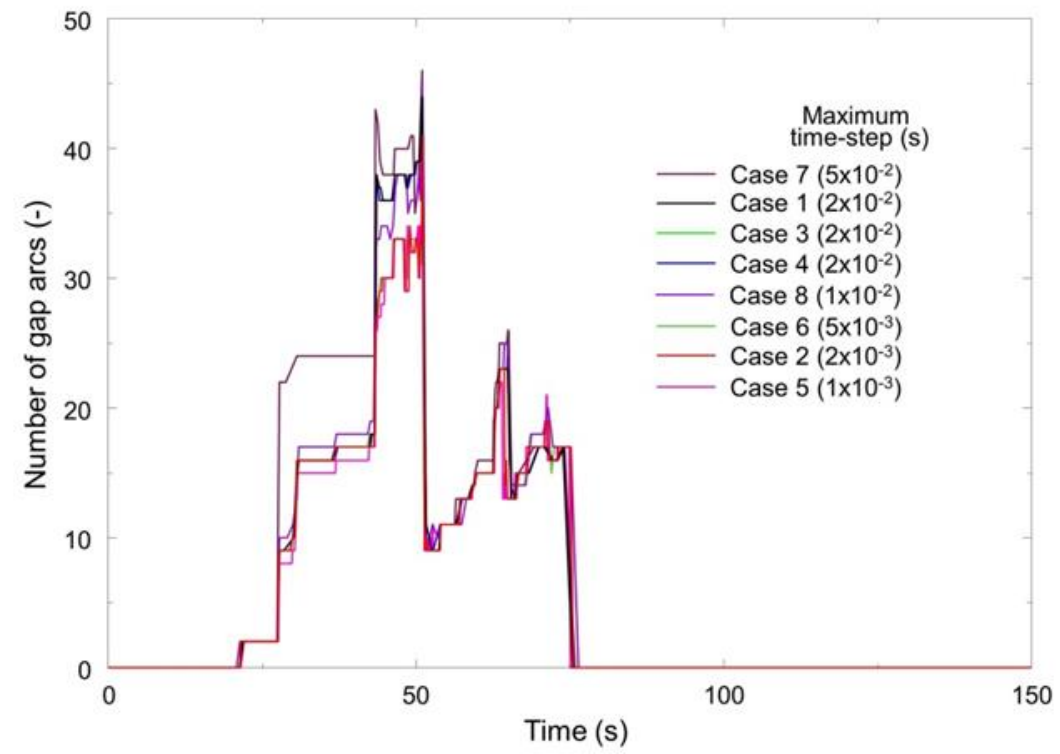

Figure 1. Number of gap arcs predicted for CCFE sensitivity study.

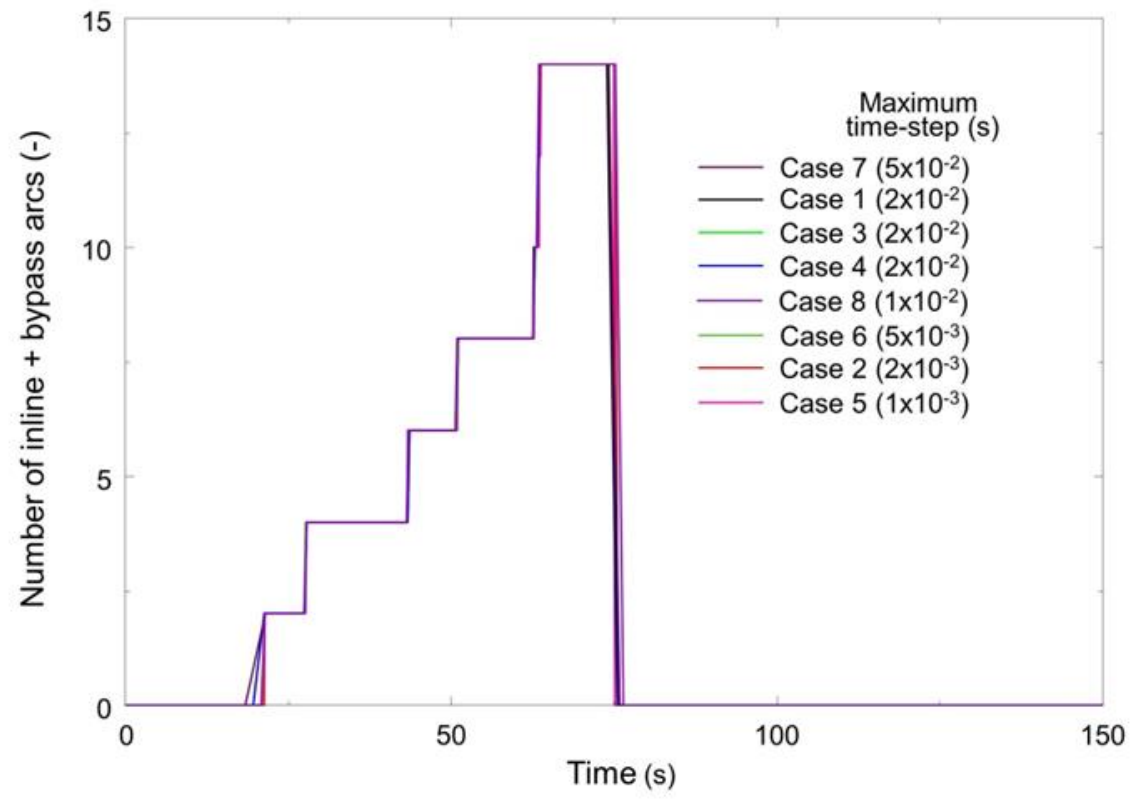

Figure 2. Number of inline plus bypass arcs predicted for CCFE sensitivity study. 


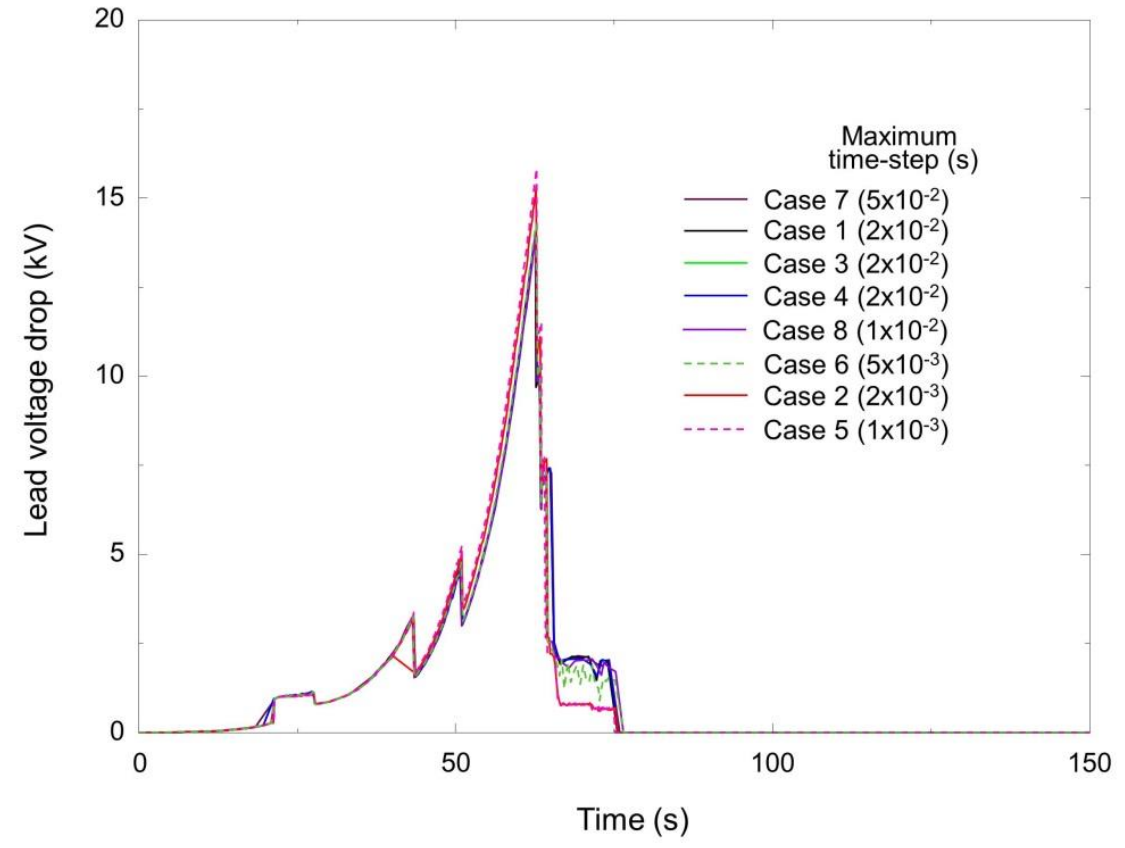

Figure 3. Voltage drop across magnet leads predicted for CCFE sensitivity study.

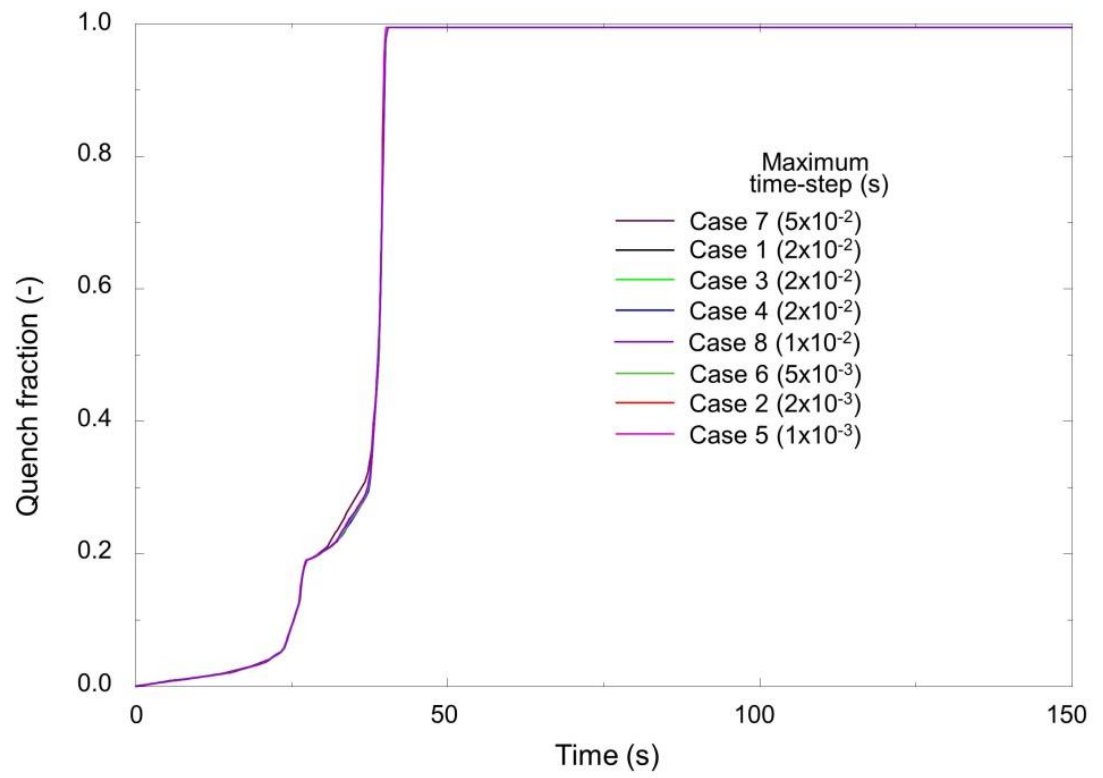

Figure 4. Quench fraction predicted for CCFE sensitivity study. 


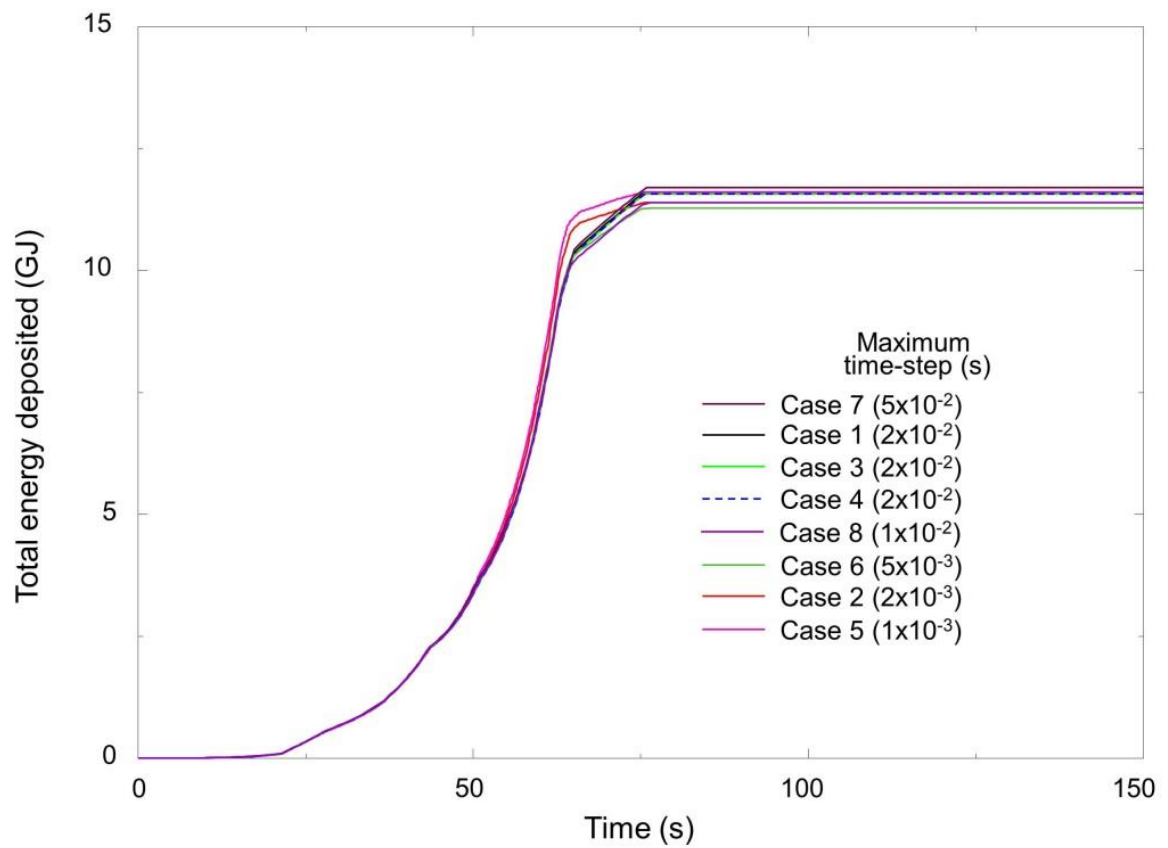

Figure 5. Total energy (resitive + arc) deposited in magnet for CCFE sensitivity study.

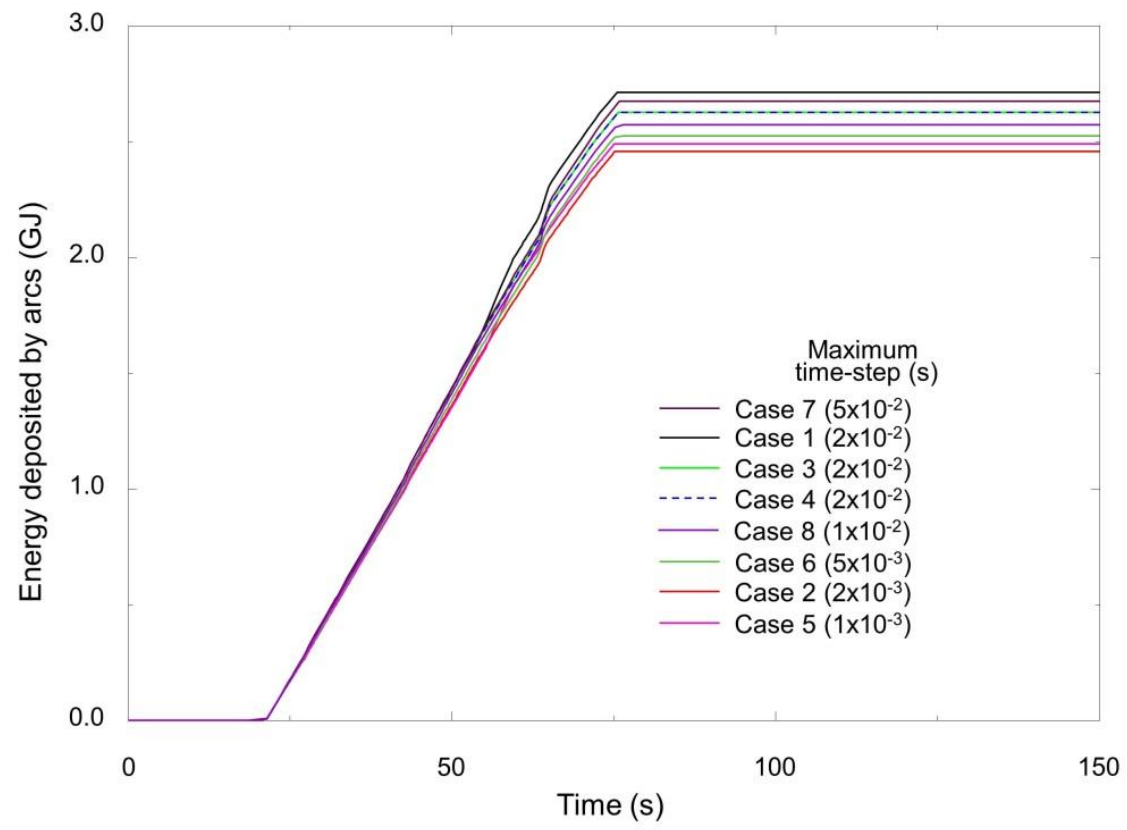

Figure 6. Arc energy deposited in magnet for CCFE sensitivity study. 


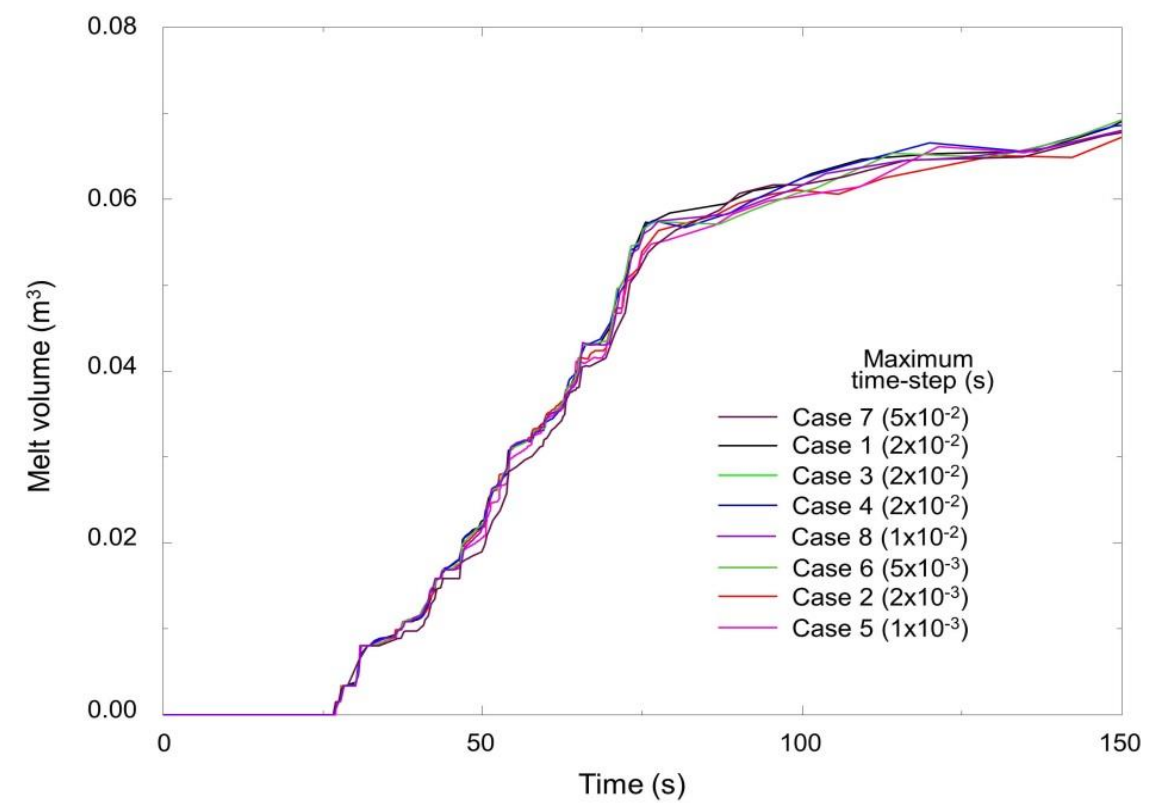

Figure 7.Total melt volume predicted for CCFE sensitivity study.

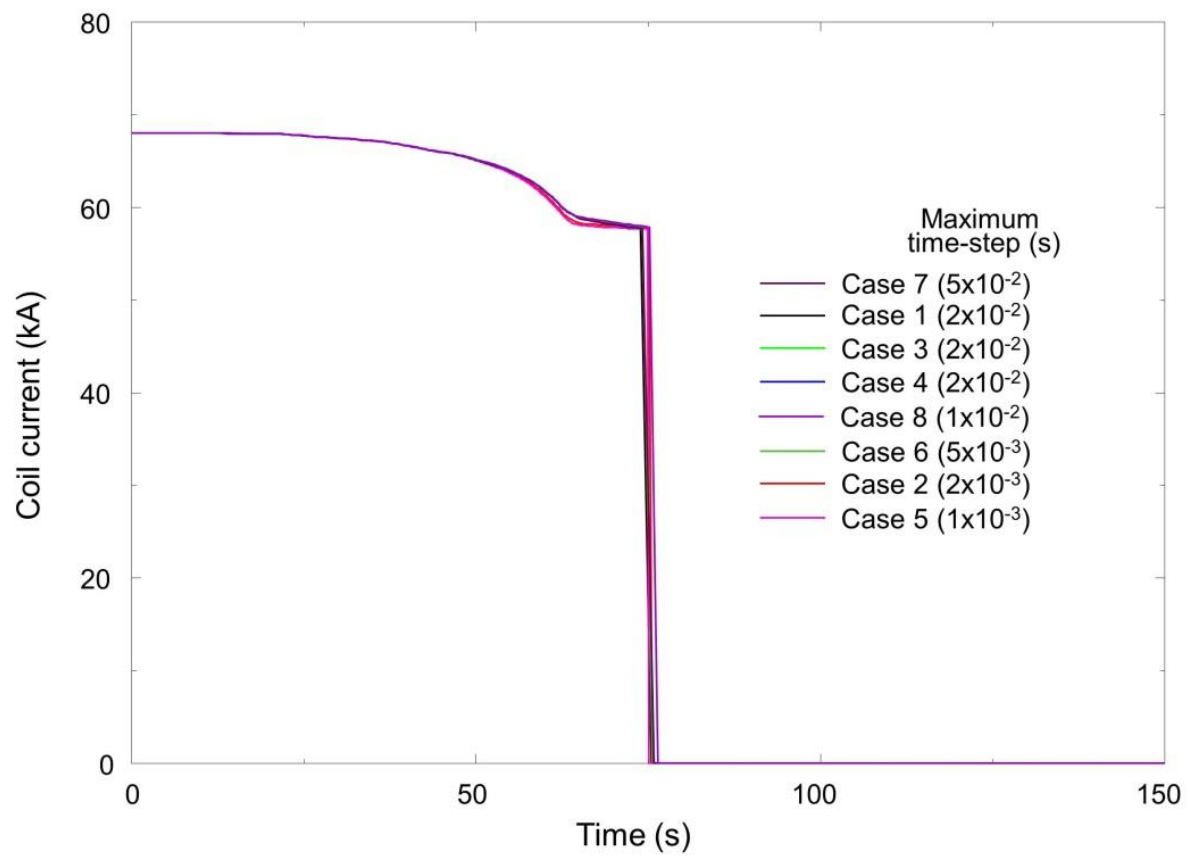

Figure 8. Magnet current predicted for CCFE sensitivity study. 


\section{Task \#2: Implement additional updates/modifications to the MAGARC code}

The primary activities under this task are to:

Become familiar with CCFE analysis package capabilities and report to CCFE on how it compares to the MAGARC code,

1) Propose additional updates/modifications to MAGARC \& CCFE software models that would allow a more correct code comparison,

2) Perform the required code updates/modifications necessary to simulate the latest ITER Toroidal Field magnet's configuration, and

3) Product of this task is to produce a final report comparing MAGARC software and CCFE magnet safety analysis package capabilities and detailing any MAGARC code improvements. This progress report is a preliminary version of this final report that will be delivered at the end of the contract.

During the KoM at CCFE, a modeling or capabilities comparison table was developed, in collaboration with Dr. Shanliang Zheng from CCFE, documenting the modeling approach taken in the MAGARC code and the CCFE analysis package in five areas. This table is included here in the following sub-sections. It is a preliminary comparison at this time; but this information, along with additional reporting found in each sub-section, constitutes the documentation of the comparison of MAGARC and CCFE analysis package capabilities that is required under this contract.

\subsection{Comparison of MAGARC and CCFE models}

\subsubsection{Modeling geometry and numerical solution scheme}

The MAGARC code contains two grid geometries. The first is a one dimensional (1D) computational geometry for the conductor that models the superconducting cable from the location it enters the magnet in the first pancake until it exits the magnet in the last pancake. The conductor model treats:

1) Conductor heat conduction to yield conductor temperature increase and copper melting/vaporization due to resistive heating by the supplied coil current and inline or bypass arcs,

2) Conductor quenching, and

3) The location and movement of inline and bypass arcs.

The second is a three-dimensional (3D) rectangular Cartesian computational geometry that simulates the magnet structure, in particular the magnet's coil case and pancake's radial support plates. The magnet structural grid treats: 
1) Structure heat conduction to predict structural temperature increase from heat transfer with conductor, resistive heating from induced or bypass currents, heat transfer between the conductor and radial plates, gap arcs and steel melting/vaporization,

2) The location of structure insulation failures that allow gap arcs to form,

3) Voltages produced by applied currents, that is the magnet's current resulting by bypass arcs in the pancake's conductor, and gap arcs between pancakes, and

4) Induced currents from the electromagnetic decay of the TF coils magnetic field.

These two models are coupled 1:1 in the axial (along the conductor) direction. And they communicate by passing temperature, heat flux and arc current location information during a transient calculation.

As can be seen from Table 2, the CCFE analysis package has a curvilinear computational geometry. Here the conductor and structure are modeled in the same grid structure in much finer detail than in MAGARC. The applied currents flow in a resistive network that couples with the conductor and structure of the magnet, unlike MAGARC that divided the modeling between the conductor and structure models. Material melting is treated in all computation zones. But it is unclear if material vaporization is included. Gap arcs are included in the resistive network model. An electromagnetic model of induced eddy currents is not included. There is a fundamental difference in logic for arcs between the conductor and structure of the magnet that will be discussed the Section 3.1.5. 
Table 2. Comparison between MAGARC and CCFE analysis package modeling geometries.

\begin{tabular}{|c|c|c|c|}
\hline & MAGARC & CCFE model & Note \\
\hline Geometry & 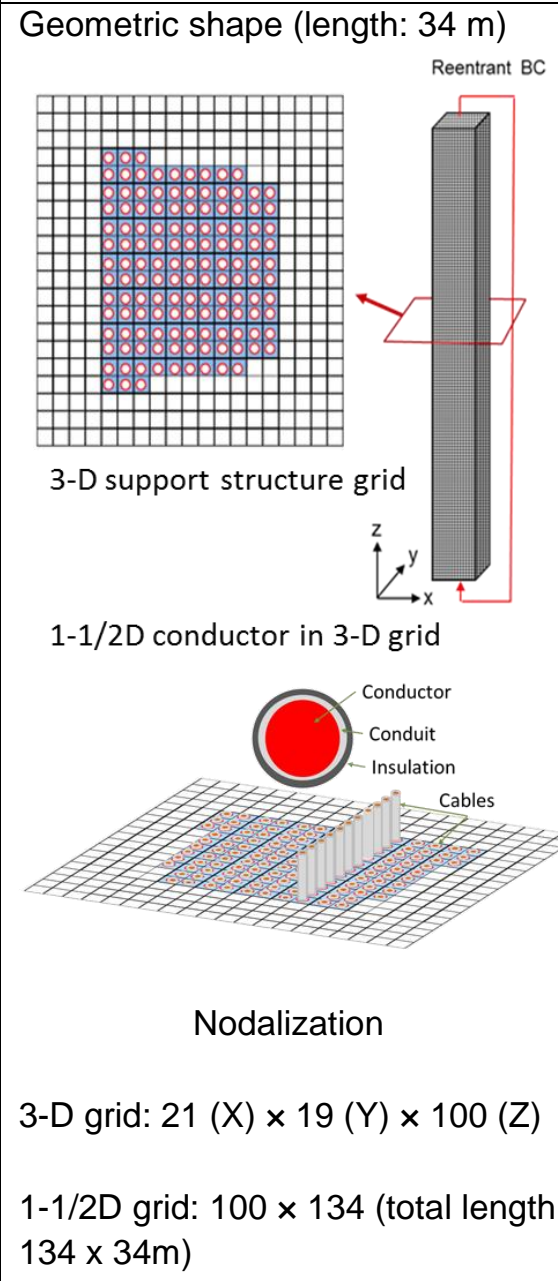 & Geometric shape (length: $34 \mathrm{~m}$ ) & $\begin{array}{l}\text { Cross- } \\
\text { section } \\
\text { dimension } \\
\text { comparable }\end{array}$ \\
\hline Materials & $\begin{array}{l}\text { Cable: volume weighted conduit, } \\
\text { insulation \& stainless steel (SS) } \\
\text { jacket } \\
\text { Radial plate \& coil case: SS \& } \\
\text { insulation } \\
\text { Detailed material properties see } \\
\text { Section } 3.1 .3\end{array}$ & $\begin{array}{l}\text { The CICC conductor materials are } \\
\text { mixed with Nb3Sn, copper with void } \\
\text { fraction to represent helium coolant } \\
\text { tube in the centre. (volume fraction) } \\
\text { The insulation layer outside the } \\
\text { conductor is modelled specifically. } \\
\text { (glass-epoxy) } \\
\text { The radial plate is SS. }\end{array}$ & Comparable \\
\hline Mesh & $\begin{array}{l}\text { 3D structure cells: } \\
\Delta \mathrm{x}=5.1, \Delta \mathrm{y}=5.4, \Delta \mathrm{z}=34 \mathrm{~cm} \text { in } \\
\text { pancakes } \\
\text { 1-1/2D conductor cable: } \\
\text { Radius }=2 \mathrm{~cm}, \Delta \mathrm{z}=34 \mathrm{~cm}\end{array}$ & $\begin{array}{l}\text { Divided in length (poloidal D-shape): } \\
\text { ANSYS meshing? } \\
\text { Different mesh size for thermal and } \\
\text { electrical }\end{array}$ & Comparable \\
\hline $\begin{array}{l}\text { Boundary } \\
\text { conditions }\end{array}$ & $\begin{array}{l}\text { Cable: heat loss to } 3-\mathrm{D} \text { grid } \\
\text { Support structure: re-entrant in } \mathrm{Z} \text {, } \\
\text { radiation to } 4 \mathrm{~K} \text { case surface } \\
\text { (X\&Y) }\end{array}$ & $\begin{array}{l}\text { The boundary condition is applied to } \\
\text { represent the spiral coil winding }\end{array}$ & Comparable \\
\hline
\end{tabular}




\begin{tabular}{|l|l|l|l|}
\hline Time step & $<5 \times 10^{-3} \mathrm{~s}$ & $<0.25 \mathrm{sec}$ & Sensitivity \\
\hline Numerical & Equilibrium electric field at each & Equilibrium electric field sub-stepped & \\
assumption & $\begin{array}{l}\text { ime step. All other variables } \\
\text { advanced implicitly in time, with } \\
\text { heat conduction coupling between } \\
\text { conductor and structure meshes } \\
\text { advanced explicitly in time }\end{array}$ & implit time-step. & \\
\hline
\end{tabular}

\subsubsection{Magnet quench modeling}

MAGARC was originally developed with a numerical quench model that treated heat transfer and fluid flow between the cryogenic helium and the copper cable strands. However given the size and nature of the problem to be addressed during an unmitigated quench event, this model was dropped in favor of a more heuristic model based on a user specified constant quench front propagation velocity. This velocity is taken to be $5 \mathrm{~m} / \mathrm{s}$ based on MAGS computer code simulations found in Ref [7].

At the start of a given problem execution, MAGARC will use a user specified original quench location to calculate the time to quench for the entire magnet, based on the distance a given conductor grid point is from this original quench location, both in the direction of, and opposite to, magnet current flow. If this was the only mechanism that affects conductor quench, then the estimated time for an ITER TF coil to completely quench would be $\sim 400 \mathrm{~s}$. However, 3D heat conduction in the magnet will cause earlier quenching of conductor locations both within the same pancake and in the pancakes adjacent to the original quench location. In addition, the energy transfer by conduction is accelerated by the presence of arcs that not only deposit MW of power locally, but result in high amperage currents flowing in the radial support plates that resistively heat these structures. There is also a third mechanism that accelerates conductor quenching and that is induced eddy currents that resistively heat radial support plates, and there by conductors, in pancakes that are not experiencing arcing as the magnetic field of this magnet decays. Fig. 9 illustrates the predicted impact that these induced currents have on magnet quenching.

To account for these mechanisms during a calculation, at each computation time-step the MAGARC code searches the conductor of each pancake starting at its leads both in the direction of, and opposite to, current flow. If the conductor location is found with the temperature exceeding the super conductor's critical temperature, or the time to quench based on the assumed user specified quench velocity, then from that location, new quench times are calculated based on the distance other conductor locations are in this pancake from these new quench points. Once these criteria for a conductor grid point to quench have been exceeded, then the resistivity of that grid location's conductor changes from zero (a superconducting state) to that of copper at that location's temperature.

The CCFE quench model uses an analytically derived quench propagation velocity based on the work of Ref [8]. The model of Ref [8] was available at the time the decision was made to modify MAGARC's quench model to the one described above. However, the model of Ref [8] was not adopted for MAGARC because of the need for the user to specify an initial quench length for the model of Ref [8]. The initial length seemed arbitrary and could produce any desired result. But perhaps this is a misunderstanding of the model on this author's part; and it would be possible to add the MIT quench velocity in future work if the ITER IO desires this feature added to MAGARC. 


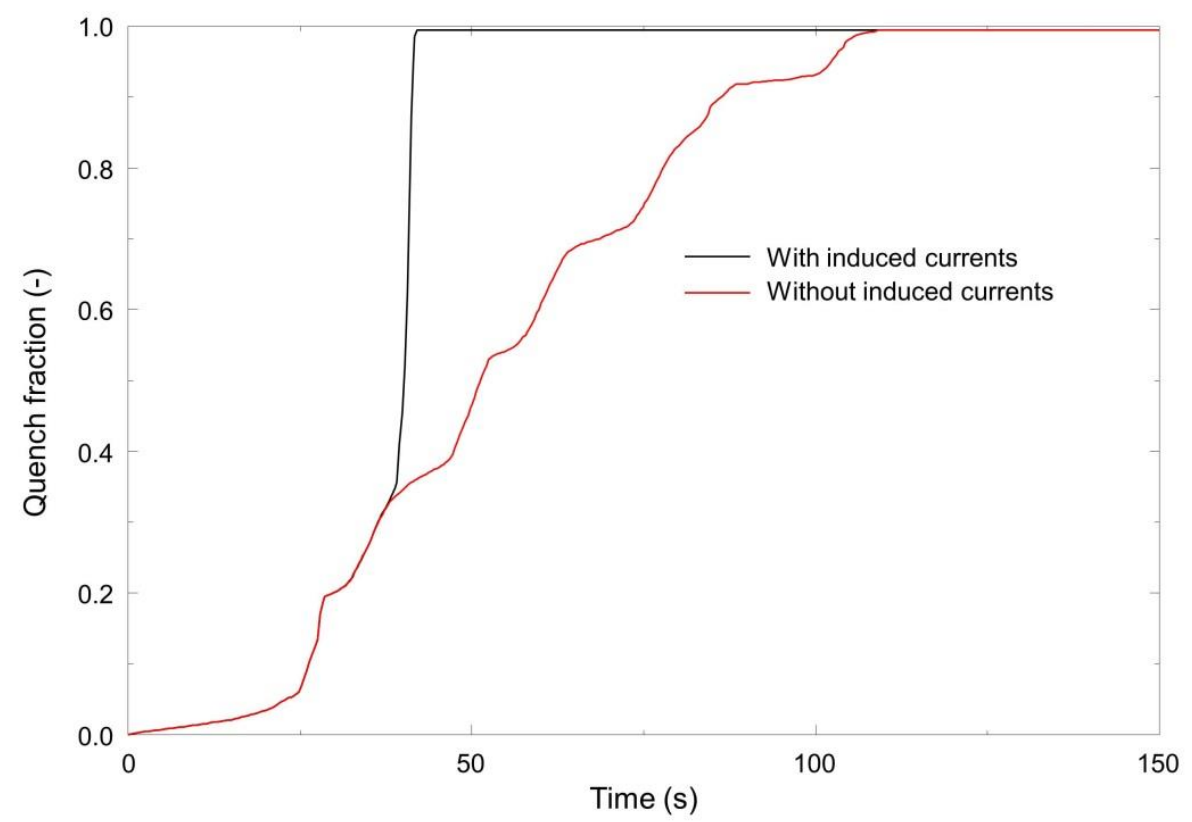

Figure 9. Comparison of MAGARC predicted magnet quench with and without induced eddy currents in the radial support plates. 
Table 3. Comparison of MAGARC and CCFE analysis package quench models.

\begin{tabular}{|c|c|c|c|}
\hline & MAGARC & CCFE model & Note \\
\hline $\begin{array}{l}\text { Quench } \\
\text { physics }\end{array}$ & $\begin{array}{l}\text { Quench velocity } \\
\text { based on detailed } \\
\text { MAGS code } \\
\text { performed by KIT. } \\
\text { This code includes } \\
\text { the physics of } \\
\text { conductor } \\
\text { conduction, helium } \\
\text { convection and } \\
\text { helium mass, } \\
\text { momentum and } \\
\text { energy conservation. } \\
\text { Calculation based on } \\
\text { ITER EDA TF coil } \\
\text { that gave a quench } \\
\text { velocity driven by } \\
\text { helium convection of } \\
\sim 5 \mathrm{~m} / \mathrm{s}\end{array}$ & $\begin{array}{l}\text { the MacQuench analytical approach developed by } \\
\text { MIT. } \\
\text { the conductor is homogenised using a rule of } \\
\text { mixtures calculation based on that same conductor } \\
\text { constituent property namely, copper, } \mathrm{Nb}_{3} \mathrm{Sn} \text { and } \\
\text { helium. As shown in Fig. 10, the enthalpy of the } \\
\text { conductor is calculated from the specific heats and } \\
\text { densities, and the heat of fusion for copper added } \\
\text { over a } 5 \text {-degree temperature change above the } \\
\text { melting temperature (1356K) to account for copper } \\
\text { phase change. }\end{array}$ & \\
\hline $\begin{array}{l}\text { Quench } \\
\text { initiation } \\
\text { criteria }\end{array}$ & $\mathrm{T} \geq 11.7 \mathrm{~K}$ & $\mathrm{~T} \geq 10 \mathrm{~K}$ & $\begin{array}{l}\text { Can be } \\
\text { unified if ITER } \\
\text { desires }\end{array}$ \\
\hline $\begin{array}{l}\text { Initiating } \\
\text { quench } \\
\text { size }\end{array}$ & $\begin{array}{l}\text { Axial dimension of } \\
3 \mathrm{D} \text { cell }=34 \mathrm{~m} / 100 \\
\text { or } 34 \mathrm{~cm}\end{array}$ & Variable: $5 \mathrm{~cm}-3 \mathrm{~m}$ (sensitivity study) & Comparable \\
\hline $\begin{array}{l}\text { Quench } \\
\text { velocity }\end{array}$ & $\begin{array}{l}\text { Constant quench } \\
\text { velocity: } 5 \mathrm{~m} / \mathrm{s}\end{array}$ & $\begin{array}{l}\text { Quench velocity } \\
V_{q}(t)=0.766\left(\frac{2 d_{h}}{f}\right)^{\frac{1}{5}}\left(\frac{R L_{q} \alpha_{o} J^{2}}{c_{o}}\right) \frac{1}{t^{1 / 5}} \\
\mathrm{~d}_{\mathrm{h}} \text { the hydraulic diameter; } \mathrm{f} \text { the friction factor; } \\
\mathrm{C}_{\mathrm{o}} \text { the speed of sound in helium; } \\
\mathrm{R} \text { the gas constant for helium; } \\
\mathrm{L}_{\mathrm{q}} \text { the initial quench length; } \\
\mathrm{J} \text { the current density; } \\
\mathrm{t} \text { the time } \\
\mathrm{\alpha}_{0} \text { a fitting parameter used during the specific heat } \\
\text { linearization step }\end{array}$ & $\begin{array}{l}\text { Can be } \\
\text { unified if ITER } \\
\text { desires, but is } \\
\text { a minor } \\
\text { difference for } \\
\text { unmitigated } \\
\text { quench } \\
\text { events }\end{array}$ \\
\hline $\begin{array}{l}\text { Coupling } \\
\text { method }\end{array}$ & $\begin{array}{l}\text { Time to quench is } \\
\text { calculated from } \\
\text { starting from initial } \\
\text { quench location. } \\
\text { Each } 1-1 / 2 \mathrm{D} \\
\text { location quenches } \\
\text { on time or } T>T_{\mathrm{c}} \\
\text { whichever occurs } \\
\text { first }\end{array}$ & $\begin{array}{l}\text { Quench causes temperature and resistivity change. } \\
\text { Temperature is taken by thermal conduction to } \\
\text { further initiate new quench in adjacent turns; } \\
\text { resistivity change results in increased joule heating } \\
\text { and electrical responses (voltage and current). }\end{array}$ & \\
\hline
\end{tabular}




\begin{tabular}{|c|c|c|} 
Superconducting \\
cable \\
$h=\frac{N u_{\text {lam }} K(\bar{T})}{d_{h}}$
\end{tabular}

\subsubsection{Heat conduction and thermal material properties}

In MAGARC, the heat conduction equations are advanced in time by first solving the 1-1/2D conductor equations to determine conductor temperatures everywhere in the magnet based on the 3D structure grid temperatures at the start of a given time-step (see Appendix B for grid definitions). Once new conductor temperatures are obtained at each 1-1/2D grid location, these temperatures, and those used from the $3 \mathrm{D}$ grid at the start of the time-step, are used to calculate the power exchanged between the corresponding conductor and radial support plate grid locations. This radially conducted power exchange represents the 1/2D designation of the 1D conductor heat conduction model in MAGARC [1]. Based on these power exchange terms, the 3D structure heat conduction equations are advanced in time to obtain the structure temperatures at the end of the time-step. As can be seen, MAGARC contains a semi-implicit scheme for advancing its conduction equations since there is no attempt to converge the energy exchange terms between the 1-1/2D and 3D conduction models in time. However, energy is still being correctly conserved between the two heat conduction models and as long as time-step sizes are small, numerical oscillations or instabilities should not develop.

Resistive heating of copper or stainless steel structures based on applied currents (+ induced currents for steel) are calculated from temperature dependent material resistivity equations and the current at each grid point in both conduction models. The power from arcs into or out of the conductor cable is equally split between the 1-1/2D and 3D conduction models at the predicted arc location. The power from arcs that form at gaps between radial plates is equally split between the adjacent radial plates at the grid locations where the arc is predicted to form.

The material properties used in MAGARC's heat conduction models are shown in Fig. 10, along with those of the CCFE analysis package for comparison. It can be noted that there is good agreement between the material properties below melting, except for the glass epoxy (GE) insulation's thermal conductivity. The GE insulation thermal conductivity used in MAGARC is that measured by Ref [9].

Above melting, heats of fusion and vaporization are accounted in MAGARC for copper and steel. For melting, the heat of fusion is treated as a specific heat capacity over an arbitrary temperature range of $1 \mathrm{~K}$. Prior to the KoM, the heat of vaporization was treated in the same manner at a material temperature of $4500 \mathrm{~K}$. This temperature is approximately the saturation temperature of liquid iron at a pressure of 120 bar based on extrapolating iron saturation pressure information given in Ref [10]. An arc pressure of 
120 bar was measured by Ref [5] for an arc current of 1.5 kA (see Fig. 5.12 in Ref [5]). After the KoM, it was decided that the heat of vaporization should be applied over the range from melting to $4500 \mathrm{~K}$ (120 bar arc pressure) to be more representative of actual time dependent arcing conditions. This change appears in Fig. 10 as a constant specific heat capacity over this temperature range.

CCFE's analysis package iteratively solves all of the magnet temperatures in time, both conductor and magnet structure, when advancing the conduction solution. This should allow this package to take larger time-steps than the MAGARC code. However, it appears that in the CCFE analysis package that the electrical model is advanced by a sub-step method (i.e., smaller time-steps than the heat conduction solution) to avoid numerical instabilities, which is also a time explicit solution method. So this package is not completely implicit either. At this time, the author is not aware of how the CCFE analysis package treats material melting and vaporization. This is a significant difference in the models that must be clarified by CCFE.

Additional side-by-side comparisons of these two thermal models are contained in Table 4.

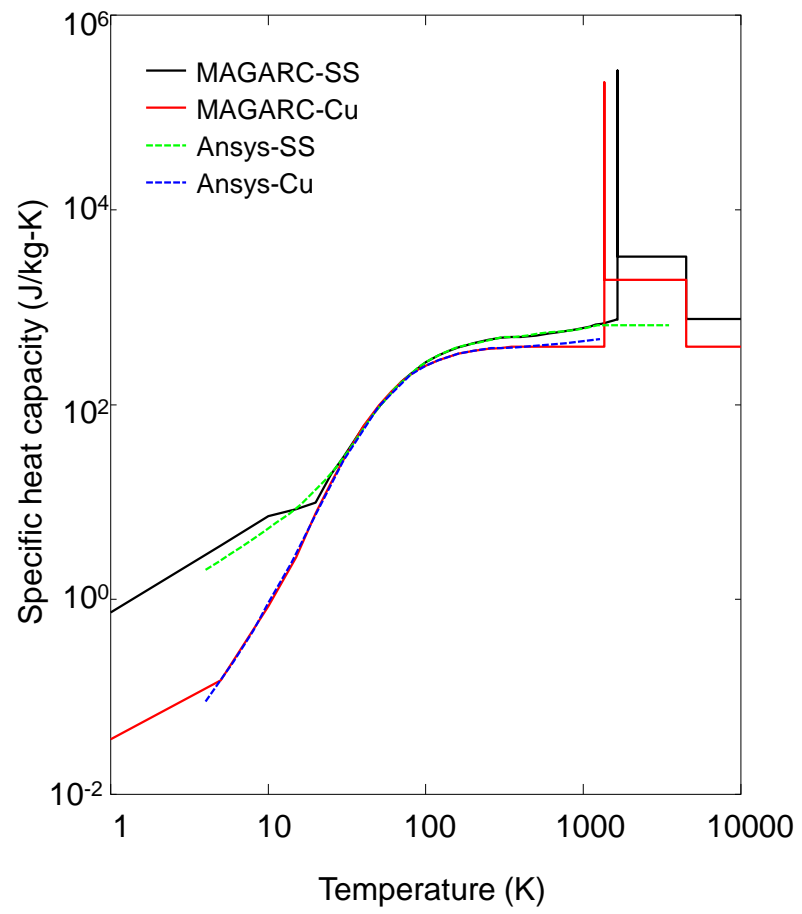

(a)

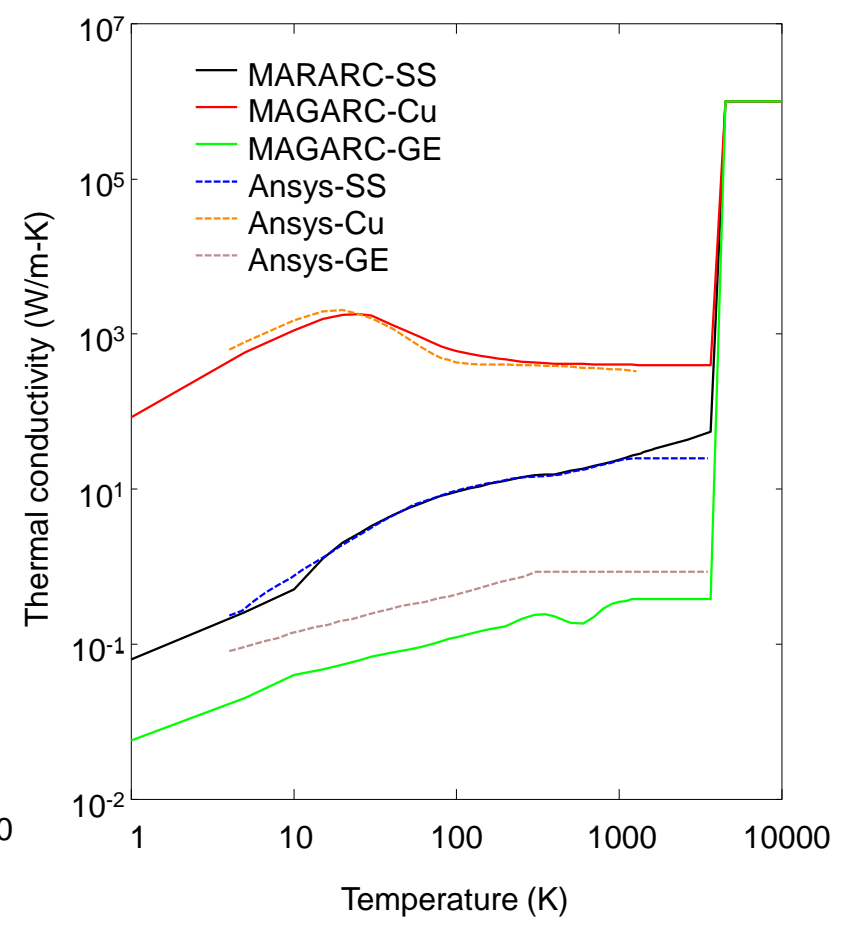

(b)

Figure 10. Thermal conduction materials properties comparison between MAGARC and CCFE model. 
Table 4. Comparison of MAGARC and CCFE analysis package heat conduction models.

\begin{tabular}{|c|c|c|c|}
\hline & MAGARC & CCFE model & Note \\
\hline $\begin{array}{l}\text { Thermal } \\
\text { conduction }\end{array}$ & $\begin{array}{l}\text { 3D conduction in radial plates, coil case } \\
\text { and gap insulation. } 1-1 / 2 \mathrm{D} \text { axial and } \\
\text { radial conduction for cable and cable } \\
\text { insulation }\end{array}$ & $\begin{array}{l}\text { 3D heat conduction } \\
\text { equations to simulate the } \\
\text { thermal response of the } \\
\text { radial plates, coil case, and } \\
\text { associated glass-epoxy (GE) } \\
\text { insulation }\end{array}$ & Comparable \\
\hline $\begin{array}{l}\text { Thermal } \\
\text { power }\end{array}$ & $\begin{array}{l}\text { Resistive heating based on coil current } \\
\text { distribution accounting for quenched } \\
\text { conductor, structure currents and inline, } \\
\text { bypass and gap arcs, and eddy currents } \\
\text { induced by decaying magnetic fields. }\end{array}$ & $\begin{array}{l}\text { Quench \& electrical } \\
\text { Electrical resistivity, which is } \\
\text { a strong function of } \\
\text { temperature, is then } \\
\text { computed at a sub-step level } \\
\text { within the thermal model to } \\
\text { calculate model heating. } \\
\text { Gap arc power between } \\
\text { conductor an structure } \\
\text { modelled }\end{array}$ & $\begin{array}{l}\text { Magnet } \\
\text { arcing } \\
\text { assumptions } \\
\text { are not } \\
\text { comparable }\end{array}$ \\
\hline \multicolumn{4}{|l|}{ Temperature } \\
\hline $\begin{array}{l}\text { Molten } \\
\text { material }\end{array}$ & $\begin{array}{l}\text { Cu and SS heats of fusion at melting } \\
\text { temperatures, respectively. Heat of } \\
\text { vaporization accounted for over } \\
\text { temperature range from melting to } 4500 \\
\mathrm{~K} \text { (approximate Fe saturation pressure at } \\
120 \text { bar seen in Kronhardt's experiments } \\
\text { [5]) }\end{array}$ & $\begin{array}{l}\text { Uncertain how material } \\
\text { melting and vaporization are } \\
\text { treated }\end{array}$ & \\
\hline $\begin{array}{l}\text { Coupling } \\
\text { method }\end{array}$ & $\begin{array}{l}\text { Support structure and cable thermal and } \\
\text { electrical grids are coupled 1:1 through } \\
\text { heat conduction, voltage and } \\
\text { electromagnetics calculations }\end{array}$ & $\begin{array}{l}\text { Temperature transferred to } \\
\text { change resistivity so that } \\
\text { current changes accordingly; } \\
\text { the current changes cause } \\
\text { further temperature change }\end{array}$ & \\
\hline
\end{tabular}




\subsubsection{Electromagnetic modeling approaches}

The MAGARC code solves the vector potential form of Maxwell's equations to predict the magnet's magnetic field and a steady state conservation of current equation to predict the magnet's voltage potential. These equations are finite difference in space and time and are solved on the same grid structure as the heat conduction equations (see Appendix B for grid definitions).

The current source used to advance the magnetic field potentials is the current flowing in the superconducting cables. These potentials are initialized at the start of a calculation by executing a transient until a steady-state-equilibrium has been achieved. During the accident calculation, as the magnet current resistively decays, the associated change in these vector potentials will induce currents in the steel structures of the magnet in an attempt to conserve magnetic field energy. When bypass arcs (Section 3.1.5 contains a discussion on the arc progression logic of the MAGARC code) form between the conductor and radial plates, the current flowing in the radial plates replaces the current source in the magnetic field potential equations, simulating the short circuit of the section of conductor between two bypass arcs.

MAGARC's voltage potential equations only simulate the voltage response of the magnet's winding support structures (i.e., the pancake radial support plates and coil case), and are cast in the form of a resistive network (note Appendix B for an explanation). Arcs are modeled in this voltage network as a current source or sink, or as resistors in the case of arcs that form in the gap between adjacent pancakes where the glass epoxy (GE) insulation fails as a result of high temperatures.

At each time-step, the conductance(s) of the magnetic and voltage potential equations are updated for changing temperature and the presence of arcs. The voltage potential equations are solved first by MAGARC for the new time voltage potentials, which are then used to advance the magnetic vector potential equations. The electrical resistivity of the materials modeled by MAGARC appears in Fig. 11, where they are also compared to those used by the CCFE analysis package. The insulation resistivity equation in MAGARC was developed by Ref [11] based on experimental data. The CCFE analysis package does not consider the resistance of the GE insulation for some unknown reason. MAGARC models only the insulation in the gaps between adjacent pancakes or between pancakes and the coil case. Because MAGARC does not treat electrical conduction between the windings and the support plates, MAGARC and the CCFE model are similar in this area at this time.

The CCFE analysis package also models the voltages that develop in the magnet during this unmitigated quench with a resistive network model. Like MAGARC, an arc is modeled as a time-varying resistor in this package, which resistor has the arc resistance derived from arc voltage-current characteristics equations, such as that proposed by Ref [5]. However, the CCFE package does not include a model for induced currents in the magnet's radial plates. As was shown in Section 3.1.3, magnetically induced currents are an important factor in correctly predicting magnet quench. But it should be possible for CCFE to approximate the induced currents from the CCFE analysis package's electrical circuit model for the TF coil system if CCFE desires to do so.

Additional side-by-side comparisons can be found for these two models in Table 5. 


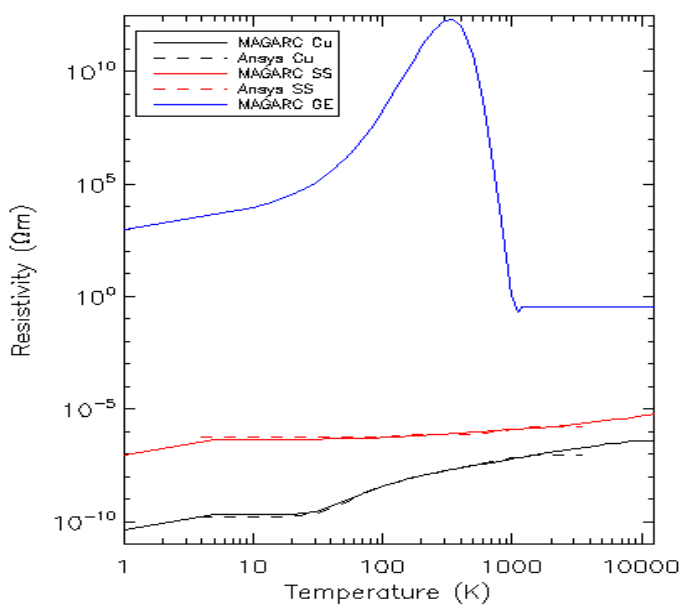

Figure 11. Electrical materials properties comparison between MAGARC and CCFE model. 
Table 5. Comparison of MAGARC and CCFE analysis package electrical/magnetic models

\begin{tabular}{|c|c|c|c|}
\hline & MAGARC & CCFE model & Note \\
\hline $\begin{array}{l}\text { Electrical } \\
\text { network }\end{array}$ & $\begin{array}{l}\text { Maxwell's Equations solved } \\
\text { for induced eddy currents } \\
\text { on 3D support structure } \\
\text { gird. Scalar potential } \\
\text { (voltage) also solved on this } \\
\text { same grid based on } \\
\text { conservation of applied } \\
\text { currents (coil current arcing } \\
\text { into and out of the coil). }\end{array}$ & $\begin{array}{l}\text { General lumped circuit elements are used to } \\
\text { represent the electrical network external to the } \\
\text { magnet system and can be connected with a high } \\
\text { resolution thermal-electric finite element model of a } \\
\text { coil to simulate the coupled field interaction. }\end{array}$ & \\
\hline Voltage & $\begin{array}{l}\text { Voltages included cable } \\
\text { inline and bypass arcs and } \\
\text { radial plate gap arcs } \\
\text { instantaneously change } \\
\text { each time step to match } \\
\text { evolving conditions }\end{array}$ & $\begin{array}{l}\text { Does not model inline or bypass arcs. Gap arcs } \\
\text { between the conductor and radial plates are } \\
\text { modelled. }\end{array}$ & \\
\hline Current & $\begin{array}{l}\text { Structural currents based } \\
\text { on voltage calculations for a } \\
\text { source and sink current } \\
\text { equal to the TF coil's time } \\
\text { dependent applied current } \\
\text { and eddy currents as TF } \\
\text { coil currents decay }\end{array}$ & $\begin{array}{l}\text { Structural currents are calculated by the resistive } \\
\text { network model. Eddy currents are not modelled. }\end{array}$ & \\
\hline $\begin{array}{l}\text { Resistivity } \\
\text { variation }\end{array}$ & $\begin{array}{l}\text { Varies in time and space } \\
\text { based on material } \\
\text { temperature and arcs }\end{array}$ & $\begin{array}{l}\text { The temperature rise in the thermal elements leads } \\
\text { to the resistances variation in the electrical elements } \\
\text { to result in the current change which has a feedback } \\
\text { impact on the thermal elements again. }\end{array}$ & \\
\hline Coupling & $\begin{array}{l}\text { Resistive heating at every } \\
\text { node in } 3 D \text { structure and } 1 \text { - } \\
1 / 2 D \text { cable network is } \\
\text { calculated by } Q=\Delta \mathrm{VI} \text { for } \\
\text { arcs and applied and } \\
\text { induced currents }\end{array}$ & $\begin{array}{l}\text { Shown below, current density rather than joule } \\
\text { heating is selected as the coupling parameter due to } \\
\text { its slow temporal evolution relative to temperature } \\
\text { rises in the conductor; } \\
\text { To ensure continuity of the conductor, electrical and } \\
\text { thermal contacts are made by coupling the voltage } \\
\text { and temperature of neighbouring turn terminals. } \\
\text { Note that this way of "numerically" shorting different } \\
\text { turns is a way to simplify the transition areas that } \\
\text { occurs in the model from turn to turn. The last turn, } \\
\text { which is electrically grounded, is connected to the }\end{array}$ & \\
\hline
\end{tabular}




\begin{tabular}{|c|c|c|}
\hline & & 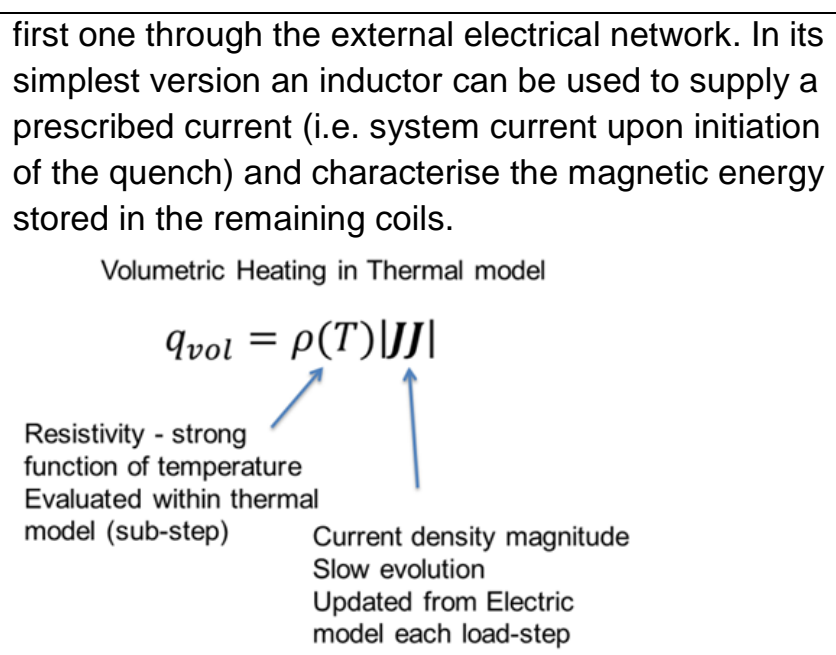 \\
\hline $\begin{array}{l}\text { External } \\
\text { magnetic } \\
\text { field }\end{array}$ & $\begin{array}{l}\text { Electromagnetic equations } \\
\text { solved with boundary } \\
\text { conditions from the Biot- } \\
\text { Savart law }\end{array}$ & Not included in CCFE analysis package \\
\hline $\begin{array}{l}\text { Effect } \\
\text { coupling }\end{array}$ & $\begin{array}{l}\text { Boundary conditions scale } \\
\text { linearly with coil current. No } \\
\text { coupling with electrical } \\
\text { circuit equation models } \\
\text { representing the magnet } \\
\text { system }\end{array}$ & $\begin{array}{l}\text { CCFE analysis package solves electrical circuit } \\
\text { equations to determine the coupling of the quenching } \\
\text { magnet to the remainder of the TF coil set }\end{array}$ \\
\hline
\end{tabular}

\subsubsection{Arcing models and assumptions}

In MAGARC, an arc is assumed to develop once a given cable location begins to melt. Since that arc is between two ends of a failed section of conductor, it has been called an inline arc. As the accident progresses, in theory this inline arc should grow in length, fail the conductor's steel conduit by melting, expand in radius, and contact the radial plate that supports the cable allowing a portion of the arc's current to flow in the radial plate. Because of the larger cross-sectional area of the radial plate, the resistance to current flow in the plate will be less than inside the arc. Thus, this current share arrangement between the arc and radial plate will push more current to flow into the plate as the inline arc grows in length and thereby in its resistance. At a given inline arc length, most of, if not all of, the current will flow through the radial plate bypassing the conductor channel and re-entering the conductor at the other end of the inline are region. At given length, the current flowing in the inline arc will not support plasma and the inline arc will bifurcate into two arcs that are called bypass arcs. This arc behavior was confirmed in experiments conducted by Ref [12]. For MAGARC, two bypass arcs are assumed to form when the voltage drop for an inline arc exceeds that of the combined voltage drop of two bypass arcs with lengths equal to that of the conductor cable's radius.

To illustrate the current sharing potential of the radial plate, from an arc characteristics model used in MAGARC, which is that proposed by Kronhardt [5], the electric field of the arc with a diameter that fills the cable space area, that is a confined arc whose area equals that of the cable space and is constrained by the radial plate, has a current density of $13.6 \mathrm{~A} / \mathrm{mm}^{2}$ and an electric field of $3 \mathrm{~V} / \mathrm{mm}$, which translates into and arc resistivity of $0.22 \Omega-\mathrm{mm}$. In comparison, steel is $1 \times 10^{-3} \Omega-\mathrm{mm}$ (see Fig. 11). Assuming that the 
shared current flows only in the radial plate steel associated with a single turn, then the resistance per length $(\mathrm{R} / \mathrm{l}=\rho / \mathrm{A})$ of the steel is $\sim 6.7 \times 10^{-7} \Omega / \mathrm{mm}$ and that of the arc is $\sim 1.7 \times 10^{-4} \Omega / \mathrm{mm}$ for these resistivity values. This illustrates that the majority of the current will quickly transition from flowing in the arc to flowing in the radial plate where the resistance is $\sim 250$ times less than in the arc.

Regarding bypass arc modeling in MAGARC, the first arc is fed by the intact windings connected to the current inlet lead of the magnet. The second arc returns the current back into the conductor and thereby to ground through the current outlet lead of the magnet by way of the rest of the magnet's intact windings. In MAGARC's resistive voltage network, these two arcs are modeled as a current source and sink, respectively. Two bypass arcs will form in the conductor of the adjacent pancake as the accident progresses. The condition now exists where the current returned by the second arc in the first pancake feeds the first bypass arc in the adjacent pancake by way of the intact windings between these pancake arcs. In the resistive voltage network, the intact windings between these pancakes are simulated by a "bridge resistor" that connects the two arc locations in MAGARC's resistive voltage network. This bridge resistor is set to the resistance of two bypass arcs, plus the resistance of the windings being simulated between these arcs. Now the second bypass arc in the adjacent pancake acts as a current sink in the network, by returning the current to the magnet's outlet lead.

Arcs can also develop in a third location, which is the gap between two adjacent pancakes, when the insulation between the pancakes fails by decomposing at 900 C [11]. In MAGARC, if the voltage drop between the pancakes exceeds $40 \mathrm{~V}$, then a gap arc is initiated based on the Kronhardt arc voltage-current characteristics model. As discussed in Ref [3], according to Kronhardt, the voltage characteristics of a confined arc, which is an arc enclosed within a strong structure, is given by:

$$
\mathrm{V}_{\operatorname{arc}}=\mathrm{V}_{\mathrm{o}}+\Delta_{\operatorname{arc}}\left(1.75+0.012 \mathrm{j}_{\operatorname{arc}}^{1.75}\right)
$$

where $V_{\text {arc }}$ is the arc voltage drop $(\mathrm{V}), V_{o}$ is the minimum voltage required to initiate an arc $(\mathrm{V}), \Delta_{\operatorname{arc}}$ is the length of the $\operatorname{arc}(\mathrm{mm})$ and $j_{\text {arc }}$ is the arc current density $\left(\mathrm{A} / \mathrm{mm}^{2}\right)$. The cross-sectional area of an arc $\left(\mathrm{A}_{\text {arc }}\right.$, $\mathrm{mm}^{2}$ ) is obtained from a simple fit to data found in [5], which is:

$$
\mathrm{A}_{\mathrm{arc}}=63.8+0.07 \mathrm{I}_{\mathrm{arc}}
$$

where the $I_{\text {arc }}$ is the current flowing in the intact cable at the location of the arc, with the constraint that the arc area is not allowed to exceed the cross-sectional area of the cable for in-line or bypass arcs, that is these confined arcs become confined-constrained arcs.

Ref [3] also describes the approach taken in MAGARC to minimize the number of arcs that can develop in a common gap. This approach was proposed by Ref [13] and is based on the empirically derived criterion known as the 'Steenbeck minimum principle', which states that the electric field strength along an arc column assumes a minimum value for a given current and other conditions necessary to maintain the arc discharge. Based on data for arcs in air, Ref [13] suggested that the arcs in a common gap would tend to a minimum current value of $3 \mathrm{kA}$, with electric field from 0.2 to $1.8 \mathrm{~V} / \mathrm{mm}$ as illustrated in Fig. 12 (a). From Eq. 2, a $3 \mathrm{kA}$ arc has a current density of $\sim 11 \mathrm{~A} / \mathrm{mm}^{2}$. Fig. 12 (b) gives an electric field for this arc current density of $\sim 2.5 \mathrm{~V} / \mathrm{mm}$, which is close the upper value of Ref [13] of 1.8 $\mathrm{V} / \mathrm{m}$. However, below an arc current of $3 \mathrm{kA}$, Eq. 2 will not return an arc electric field that follows the data of Ref [13]. To address this inconsistency, the upper curve of Ref [13] was used to generate arc areas from Ref [5]'s arc characteristics model (Eq. 1). This new arc area model is now available in the MAGARC code and is designated as the Kronhardt-Raeder arc model (note Fig. 13). Fig. 14 presents the derived arc electric field vs current from both the Kronhardt and Kronhardt-Raeder arc models. For the 
Kronardt model, an arc with the current of $\sim 17.3 \mathrm{kA}$ has a cross-sectional area that equals that of the cable space and the arc transitions from a confined unconstrained arc to a confined-constrained arc. The arc current is lower for the Kronhardt-Raeder model at $\sim 6 \mathrm{kA}$.

The arcing logic in the CCFE analysis package starts with the assumption that an inline arc cannot physically occur because the molten conductor cable's copper produced during this accident would be held in place against the cable jacket, or the radial plate once the jacket melts [14], by the electromagnetic force produced in the melt when the conductor's current flows across ITER's toroidal magnetic field. Ref [14] also presents a numerical calculation to support this contention. However, as the author has stated in my review of this report, the analysis does not take into account magnetic field gradients that would force the melt to flow or the resistive heating produced by the current that would vaporize (thin) the molten column.

However, the CCFE analysis package does allow bypass arcs to form between the cable conduit and the radial plate once the insulation in this gap fails. But since the condition for these arcs to form requires a combined voltage drop of $80 \mathrm{~V}$, if the Kronhardt arc characteristics model is correct, it appears unlikely that these arcs will form or carry much current even if they do form. My estimate of the length of a molten copper column required to produce $80 \mathrm{~V}(\mathrm{~L}=\mathrm{VA} / \rho \mathrm{I})$, with $68 \mathrm{kA}$ of current flowing in the column, is $\sim 150 \mathrm{~m}$ for a copper resistivity of $1 \times 10^{-8} \Omega-\mathrm{m}$ (note Fig. 12) and a cable area of $1269 \mathrm{~mm}^{2}$. This is $\sim 5$ continuous molten winding turns. Even if these arcs develop, the current sharing with the radial plate steel would not create very large currents to flow in the radial plate since the resistivity of steel is two orders of magnitude higher than copper. It is much more likely that current sharing will start not by bypass arcs but when the liquid copper conductor comes in contact with the solid radial plate. In this configuration current will flow freely flow into the radial plate without bypass arcs, although again the current would be very small given the resistivity difference between copper and steel.

As of the April $19^{\text {th }} 2016$ progress meeting for this contract, gap arcs between pancakes were not being modeled in the CCFE analysis package, although plans to do so were in progress. The plan is to include a gap arc capability only for gaps between the magnet's pancakes, which is in the toroidal direction, but not in the poloidal gaps between the pancakes and coil case, which is the radial direction. The assumption made by CCFE analysis package developers is that $\mathrm{j} x \mathrm{~B}$ forces on the latter arcs will extinguish these arcs. The jxB forces on these arcs will cause them to move in the poloidal direction cutting a poloidal path through the insulation and continue to move in the poloidal direction unabated until extinguished by low gap voltage conditions. While these arcs are continually moving, the assumption in MAGARC is that these are stationary arcs.

Because arcs in MAGARC result in significant heating and produce large resistive currents flowing in the radial plates of the faulting pancakes, it is difficult to see how results of the MAGARC code can be used to benchmark the CCFE analysis package, without significant changes to the arcing logic of the MAGARC code. But if the Sponsor wanted code modifications to MAGARC's arc logic at a future date to simulate that in the CCFE package, this would be possible.

In addition, the CCFE analysis package has two arc characteristics models, the Kronhardt and Holmes models. If the Sponsor wishes the additional Holmes model implemented in the MAGARC code, these modifications could also be attempted at a future date.

Additional side-by-side comparisons of these two arcing models are contained in Table 6. 


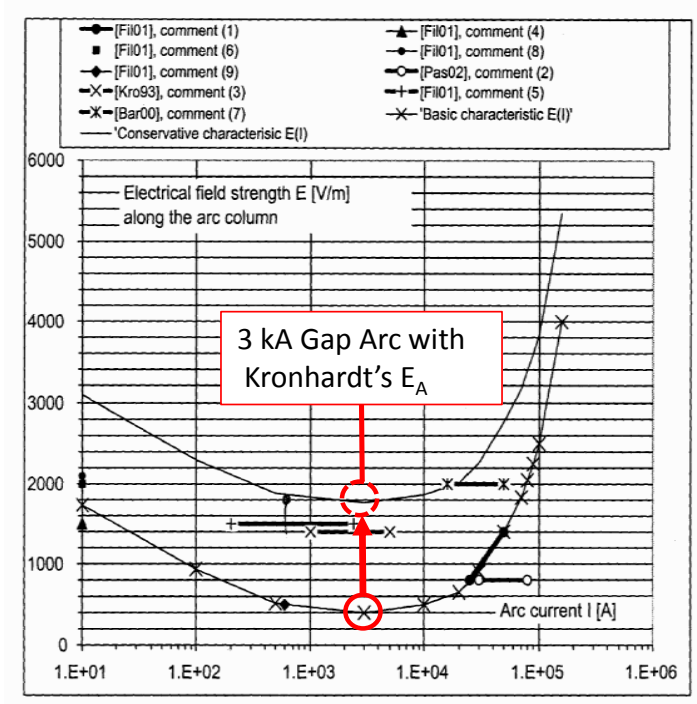

Figure 3-5: 'Conservative characteristic' of an arc (open circles) based on all data in Table 2.1-1. The 'basic characteristic' according to Figure 3-4 and all underlying data are also shown.

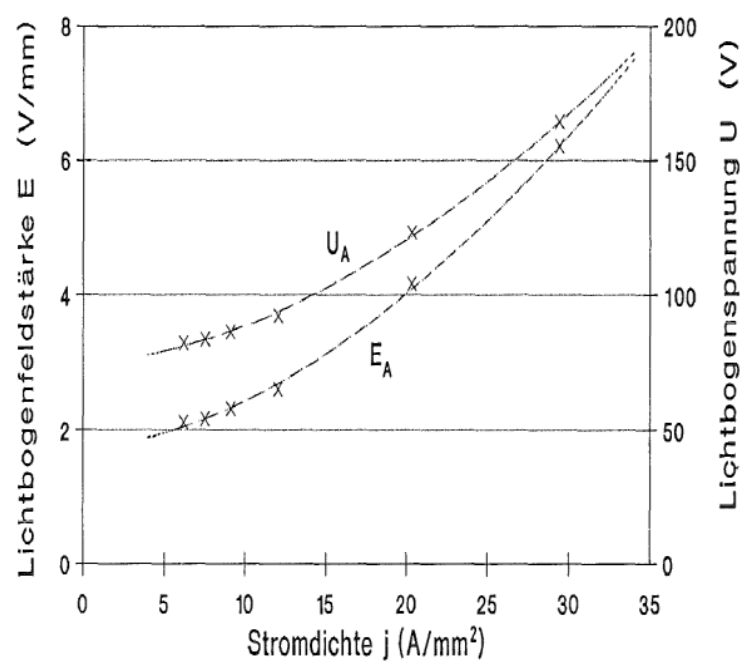

Fig. 5.5 Dependency of the electric arc field strength $\mathrm{E}_{\mathrm{A}}$ and the initial arc voltage $U_{A}$ on the current density: $x$ - measured values, ----- Approximation as per Eq. 5.4.1a,b

(a)

(b)

Figure 12. Comparison of arc data for (a) unconfined arcs from Ref [13] and (b) confined arcs from Ref [4]. 


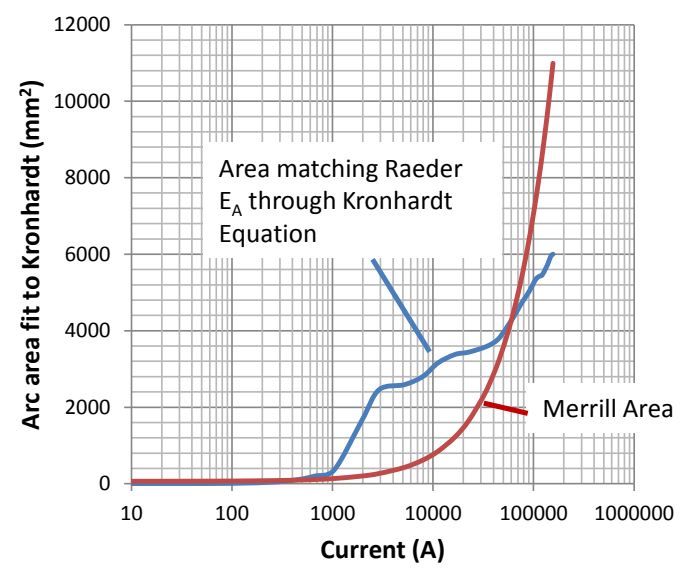

(a)

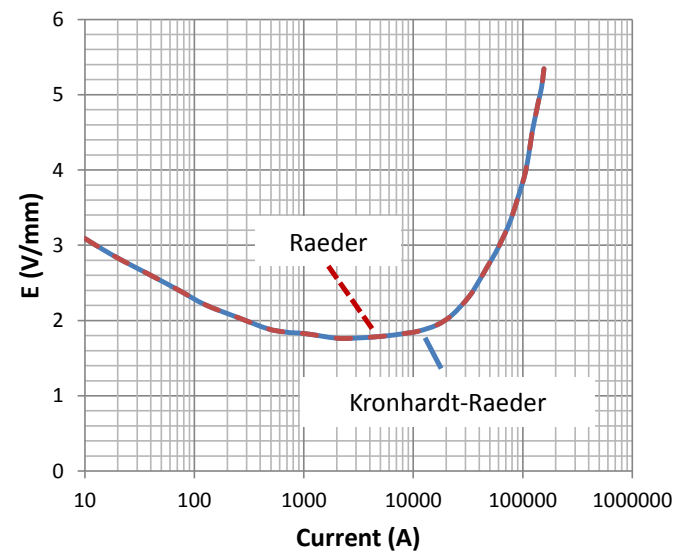

(b)

Figure 13. (a) Computed of arc area from Ref [13] data compared to Eq. 2 , and (b) arc electric field based on computed arc area. 


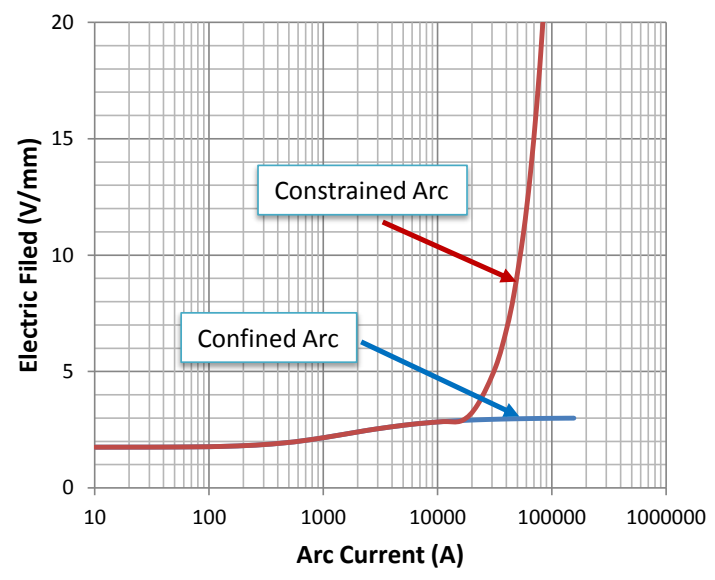

(a)

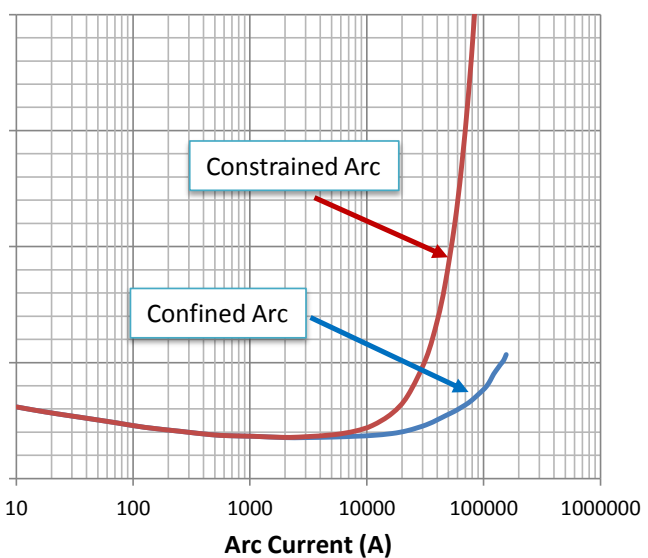

(b)

Figure 14. Arc characteristics (a) based on arc area from Eq. 2 used in Kronhardt model [4], and (b) based on arc area derived from arc electric field data from Ref [13] used in Kronhardt model [4]. 
Table 6. Comparison of MAGARC and CCFE analysis package arcing models

\begin{tabular}{|c|c|c|c|}
\hline & MAGARC & CCFE model & Note \\
\hline Arc initiation & $\begin{array}{l}\text { - Inline arc: Conductor } \\
\text { melting } T>T_{m} \text { for } \mathrm{Cu} \text { (arc } \\
\text { fails cable conduit and } \\
\text { insulation) } \\
\text { - Bypass arc: inline arc } \\
\text { resistance exceeds } \\
\text { voltage of two smaller } \\
\text { bypass arcs plus } \\
\text { conduction in radial plate } \\
\text { (current bypasses failed } \\
\text { conductor) } \\
\text { - Gap arcs: Insulation in } \\
\text { radial plate gap fails ( } \mathrm{T}> \\
900 \mathrm{C} \text { ) and gap voltage } \\
\text { drop exceeds Kronhardt's } \\
\text { minimum voltage for arcs } \\
\text { ( } \Delta \mathrm{V}>40 \mathrm{~V} \text { ) }\end{array}$ & $\begin{array}{l}\text { Currently used in PF } \\
\text { coil: } \\
\text { - } \Delta \mathrm{V}>40 \mathrm{~V} \\
\text { - } T_{\text {ins }}>600 \mathrm{C} \\
\text { - } \quad \text { if steel melts then } \\
\quad R_{\text {arc }}=0\end{array}$ & $\begin{array}{l}\text { Significant differences in } \\
\text { magnet arcing progression } \\
\text { logic }\end{array}$ \\
\hline Arc extinguish & $\begin{array}{l}\text { Complete magnet short circuit } \\
\text { (arcs leave magnet at magnet } \\
\text { leads) or applied current } \\
\text { decays to zero. In addition for: } \\
\text { - Inline arc: current bypasses } \\
\text { arc in favour of two bypass } \\
\text { arcs } \\
\text { - Bypass arc: short circuit of } \\
\text { pancake winding caused by } \\
\text { gap arcs } \\
\text { - Gap arc: Number of arcs } \\
\text { exceeds that sustainable } \\
\text { according to Steenbeck } \\
\text { principle }{ }^{\mathrm{a}} \text { or an arc voltage } \\
\text { drop falls below } 40 \mathrm{~V}\end{array}$ & $\begin{array}{l}\text { Voltage lower than } \\
40 \mathrm{~V}\end{array}$ & Not comparable \\
\hline Arc dimension & $\begin{array}{l}\text { - Inline arc: } 40 \mathrm{~mm} \text { (diameter } \\
\text { of cable) or twice the length } \\
\text { of bypass arcs } \\
\text { - Bypass arc: } 20 \mathrm{~mm} \text { (radius }\end{array}$ & $\begin{array}{l}\text { Insulation layer } \\
\text { thickness } \\
\text { Arc area from data or } \\
\text { analytical modelling } \\
\text { of arc heat balance }\end{array}$ & To be updated!!! \\
\hline
\end{tabular}

${ }^{a}$ Lowest current arcs are extinguished first in a simulation 


\begin{tabular}{|c|c|c|c|}
\hline & $\begin{array}{l}\text { of cable) } \\
\text { - Gap arc: } 4 \mathrm{~mm} \\
\text { - Arc area based on data }\end{array}$ & & \\
\hline Arc model (V-I) & $\begin{array}{l}\text { Kronhardt's voltage equation } \\
\text { with Merrill or Raeder derived } \\
\text { arc areas }\end{array}$ & $\begin{array}{l}\text { Kronhardt model } \\
\text { Holmes model }\end{array}$ & \\
\hline Arc movement & $\begin{array}{l}\text { - Inline arc: stationary } \\
\text { - Bypass arc: move at } \\
\text { conductor melt front } \\
\text { velocity } \text { b, } \\
\text { - Gap arc: stationary }\end{array}$ & $\begin{array}{l}\text { No movement; only } \\
\text { new initiation } \\
\text { according to voltage } \\
\text { and temperature (to } \\
\text { be confirmed??) }\end{array}$ & \\
\hline Arc power & $\begin{array}{l}\mathrm{P}=\Delta \mathrm{VI} \\
\text { - } \text { Voltage: Kronhardt's arc } \\
\text { voltage equation } \\
\text { - Current (I) } \\
\circ \text { Inline arc: coil current } \\
\text { o Bypass arc: coil current } \\
\text { or calculated by } \\
\text { MAGARC when gap arcs } \\
\text { form } \\
\text { Gap arc: calculated by } \\
\text { MAGARC with a max of } 3000 \\
\text { A set as per Raeder's memo } \\
\text { [13]. }\end{array}$ & $\begin{array}{l}\mathrm{P}=\mathrm{VI} \\
\text { current is calculated } \\
\text { in electrical model; } \\
\text { arc voltage is } \\
\text { calculated by the arc } \\
\mathrm{V}-\mathrm{I} \text { model/formula }\end{array}$ & $\begin{array}{l}\text { CCFE analysis package } \\
\text { contains an analytical arc } \\
\text { characteristics model } \\
\text { called the Holmes model } \\
\text { MAGARC contains a gap } \\
\text { arc characteristics model } \\
\text { that combines Kronhardt's } \\
\text { arc characteristics } \\
\text { equation with Raeder } \\
\text { unconfined arc data }\end{array}$ \\
\hline Coupling method & $\begin{array}{l}\text { Set as current sources or } \\
\text { sinks and resistors in } \\
\text { MAGARC voltage network. } \\
\text { Calculate currents and } \\
\text { voltages used to set heat } \\
\text { sources in MAGARC's thermal } \\
\text { calculations }\end{array}$ & $\begin{array}{l}\text { Switches the existing } \\
\text { mesh (electrical) into } \\
\text { an arc element }\end{array}$ & \\
\hline
\end{tabular}

${ }^{\mathrm{b}}$ Could employ implement arcs that move with time according to Kronhardt's arc velocity

${ }^{\mathrm{c}}$ Melt locations searched each time step from both leads of a pancake which has the advantage of capturing an arc that starts in the other winding of a double pancake 


\section{Task \#3: Consult with CCFE in performing benchmark activity with MAGARC software}

The primary activities under this task are to:

1) Use the updated MAGARC code to produce results (code output data) to be used by CCFE to benchmark their magnet analysis package for the purpose of qualifying their package for ITER TF magnet arcing safety assessments,

2) Provide an updated/modified version of MAGARC software by INL to the ITER IO.

The updated version of the MAGARC code will be transmitted to the contract Sponsor at the close out of this contract. MAGARC predictions produced for the purpose of benchmarking the CCFE analysis package are presented in this section.

These MAGARC predictions consist of both time-dependent global and spatial results for an unmitigated TF coil quench event. The location of the initial quench is midway in the inner most winding of the magnet's center pancake ( $4^{\text {th }}$ pancake). To facilitate a comparison with the CCFE analysis package, these MAGARC predictions do not include eddy currents associated with the decay of the magnetic field of this magnet during this event.

The global results are for the:

1) Number of gap arcs,

2) Number of inline plus bypass arcs,

3) Voltage drop across the magnet's current leads,

4) Total energy deposited in the magnet (resistive plus arcs),

5) Energy deposited by arcs,

6) Total magnet melt $(\mathrm{SS}+\mathrm{Cu})$ volume, and

7) Magnet current.

The above list of variables are the same as those examined in the sensitivity study as presented in Section 2.1.4, and presented in this section as Figs 15 through 22.

The spatial variables presented are:

1) $2 \mathrm{D}$ temperature plots obtained by a radial cut though the magnet at the left and right hand windings of each pancake,

2) $2 \mathrm{D}$ voltage distribution in the magnet shown at a horizontal cut in the radial direction at the magnet's axial midplane, and

3) 2D gap arc current plots at the toroidal gaps between the magnet's pancakes.

These data plots are at times of 50, 75, 100 and $125 \mathrm{~s}$ during the event.

When comparing the global results in Figs 15-22 with those from the sensitivity study in Figs 1-7, it can be seen that there are significant differences between the predicted results. Some of these differences are associated with the location of the initial quench, but a large impact is also associated with modifications to MAGARC's arcing models. Fig 15 presents the number of gap arcs that develop during 
the event. The number of gap arcs increase to a maximum of $\sim 70$ arcs by $\sim 120 \mathrm{~s}$. At $50,75,100$ and $125 \mathrm{~s}$, there are 51, 60, 65 and 45 gap arcs, respectively, of which 31, 44, 44 and 25 are in the toroidal gaps at these same times. When compared to the number of gap arcs from the sensitivity study, the new arcing model produces more gap arcs. The modification to the MAGARC code that produced this change is that which forces the gap arc current not to exceed $3 \mathrm{kA}$. It was discovered during the sensitivity study that this current would rise to about $6 \mathrm{kA}$ for the adopted Kronhardt arc characteristics model. The new arcing logic increases the arc's resistivity at each time-step, if necessary, to ensure that the current does not exceed $3 \mathrm{kA}$ even when the gap voltage dictates higher currents based on either the Kronhardt or Kronhardt-Reader arc characteristics model. This assumption should be consistent with the Steenbeck minimum principle as long as arcs in this gap are not being constrained, that is there are more than enough possible locations where arcs can form in a given gap (i.e., locations where the gap insulation has failed). The condition being applied can be seen in Fig 12 (a) when examining the minimum arc electric field between the two curves of this plot. However, at this time the MAGARC arcing logic does not perform a check to guarantee consistency in this regard. It is assumed that there are more than enough locations where the gap insulation has failed.

The magnet lead voltage drop predicted by MAGARC, presented in Fig 17, is directly affected by the predicted arc behavior during this event. This can be seen in comparing the results of Figs 15-17 with those of sensitivity study contained in Figs 1-3.

Another parameter that showed change from the sensitivity study is the magnets quench rate presented in Fig 18. When compared with that for the "without induced current" case of Fig 9, it can be seen that a complete magnet quench occurs within $\sim 80 \mathrm{~s}$ in the Fig 18 compared to $\sim 110 \mathrm{~s}$ in Fig 9. This difference in quench rate is due primarily to updating the thermal conductivity of the GE in the MAGARC model to match that of the CCFE analysis package, which is a higher thermal conductivity than was originally being used in MAGARC [note Fig 10 (b)].

Finally for the global data, there is a noticeable change in the total volume of melt (note Fig 19) and magnet current (note Fig 20) when compared to the sensitivity study results shown in Figs 5 and 6. This difference is attributed to the initial quench location, which has been selected for this analysis to be at a location that produces the maximum time for the first and last bypass arcs to leave the magnet by its electrical leads. This increased time results in a lower final current and a higher fraction of the TF coil set's magnetic field energy being deposited in this shorting magnet by resistive heating during this event.

Regarding the time-dependent spatial data, predictions from the MAGARC code's 3D Cartesian grid were mapped onto a 3D Curvilinear grid that simulates the geometry of an ITER TF magnet to aid in viewing of the 2D spatial parameter plots given in this section. Fig 23 contains a view of the grid used for these plots. The centerline of this grid follows the design equations of that of an Engineering Design Activity's (EDA's) TF magnet because similar information was not made available for the present ITER magnets by the contract Sponsor. In addition, the width of the magnet in the radial and toroidal direction has been arbitrarily scaled in magnitude by a factor of 2 to allow easier visualization of the results.

Figs 24-26 contain 14 2D radial cross-sections at the transient of 50 s showing the temperature of the radial support plate at the locations of the pancake windings. By glancing at these 14 plots, it can be seen that there are hot spots being produced by arcs (maximum temperature of $\sim 4950 \mathrm{~K}$ ) in the failed winding, while temperatures away from these arc locations remain at the initial $4 \mathrm{~K}$ temperature, or quickly decay back to the initial value after the arcs move past a given location. The temperature trend in the toroidal direction (+ and -) away from the initial failing pancake (\#4) show that pancakes without arcs are not yet experiencing these high temperatures. By comparing these figures with those at $75 \mathrm{~s}$ (Figs 28-30), $100 \mathrm{~s}$ (Figs 32-34) and $125 \mathrm{~s}$ (Figs 36-38), one can see how MAGARC predicts the arcing and heating of the magnet structures to change in time. By $125 \mathrm{~s}$, it can be seen by viewing Fig 37 that the $4^{\text {th }}$ pancake's 
radial plate has reached a predicted average temperature of $\sim 1165 \mathrm{~K}$. It can also be seen that while the radial plate in this pancake has reached this temperature that the coil case remains at a low temperature due to the resistance heat conduction afforded by the GE gap insulation.

Figure 26 contains the predicted voltages of the magnet at $50 \mathrm{~s}$. As mentioned previously, the crosssection shown is produced by a radial cut through the magnet at its axial midplane. Because the pancakes of the magnet are electrically isolated from each other, and the coil case, by the GE gap insulation, they appear in this figure as being at a constant voltage in the poloidal direction. This is not exactly true, but to within the resolution of this plot appears to be true. In this figure, it can be seen that pancakes 3 and 5 are the high and low voltage components in the magnet at $50 \mathrm{~s}$, respectively, illustrating that the first bypass arc in the direction of coil current flow occurs in the pancake 3 (i.e., the current source), while the last bypass arc occurs in pancake 5 (i.e., the current sink to ground). The other pancakes show a voltage distribution that varies between the high and low voltage pancakes based on their proximity to the failing pancakes 3, 4 and 5. This picture will change somewhat if current flow through the GE wrap of the intact windings of the unaffected pancakes was to be included in the MAGARC model. If it had been, pancakes 1 and 2 would show an increasing voltage per winding in the direction towards the inlet lead of the magnet (i.e. in the direction opposite to magnet current flow) and pancakes 6 and 7 would show a decrease in voltage per winding in the direction of magnet current flow to ground. It may be possible to correct this in future versions of MAGARC if the Sponsor desires this modification. As the event progresses, the initial and final bypass arcs transition to pancakes 2 and 6 at $75 \mathrm{~s}$ (note Fig 30) and to pancakes 1 and 7 at $100 \mathrm{~s}$ (note Figure 34). The voltage distribution at $125 \mathrm{~s}$ is shown in Fig 38. This is a unique instance in time during this event when the voltage distribution illustrates that the first bypass arc is now transiting out of the magnet and is arcing inside of the coil case as it makes this transition. At this time point, the coil current is flowing from the initial arc in the coil case to ground through the last bypass arc in pancake 7.

The final spatial plots are of the gap arc current distribution in the toroidal gaps between pancakes. By comparing Figs 27, 31, 35 and 39 for times of $50 \mathrm{~s}, 75 \mathrm{~s}, 100 \mathrm{~s}$ and $125 \mathrm{~s}$, respectively, one can see MAGARC's prediction of gap arcs both in location and intensity. It is clear that the gap arcs are at or near the location of high temperatures generated by the bypass arcs in the failing pancakes. 


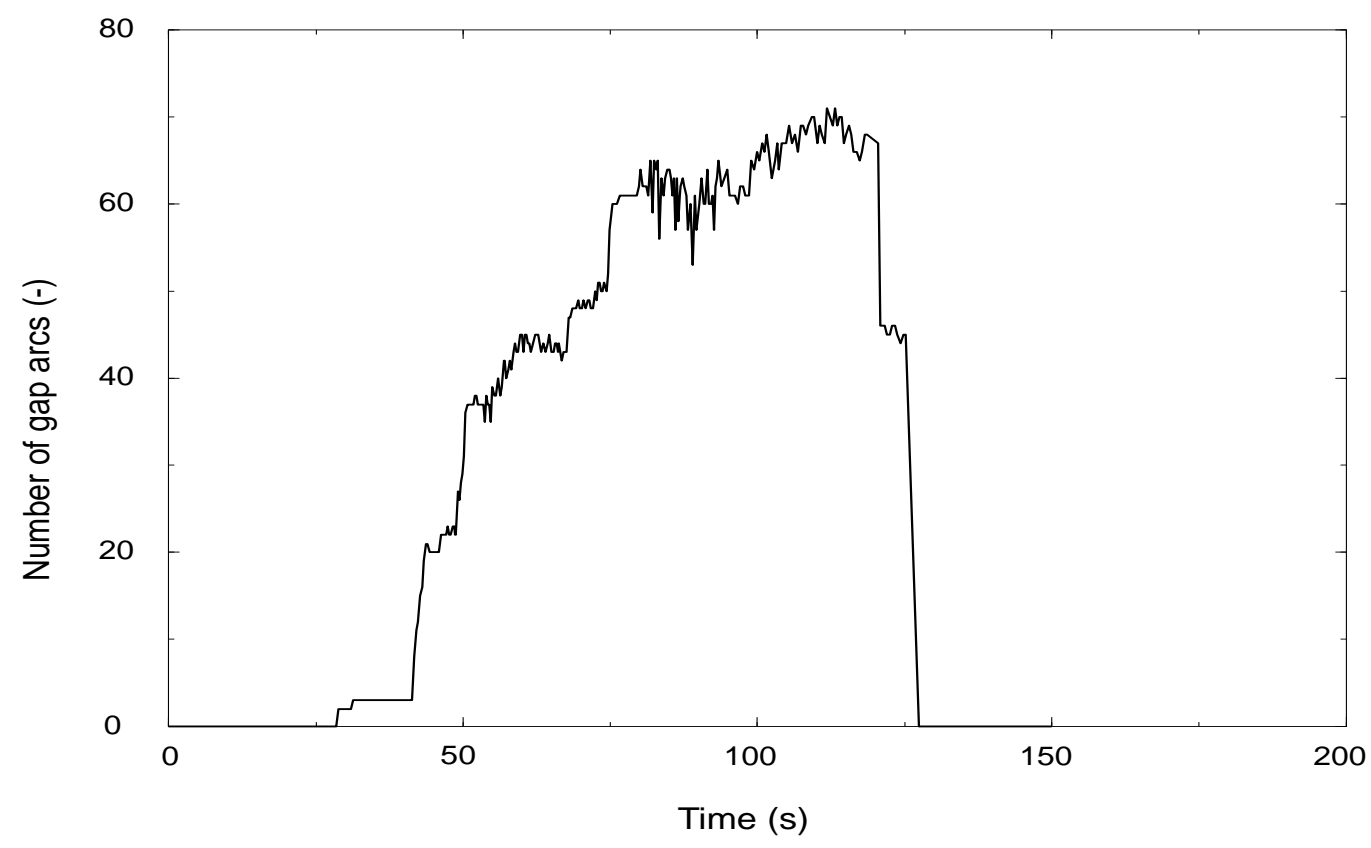

Figure 15. Number of gap arcs predicted for the base case unmitigated quench event.

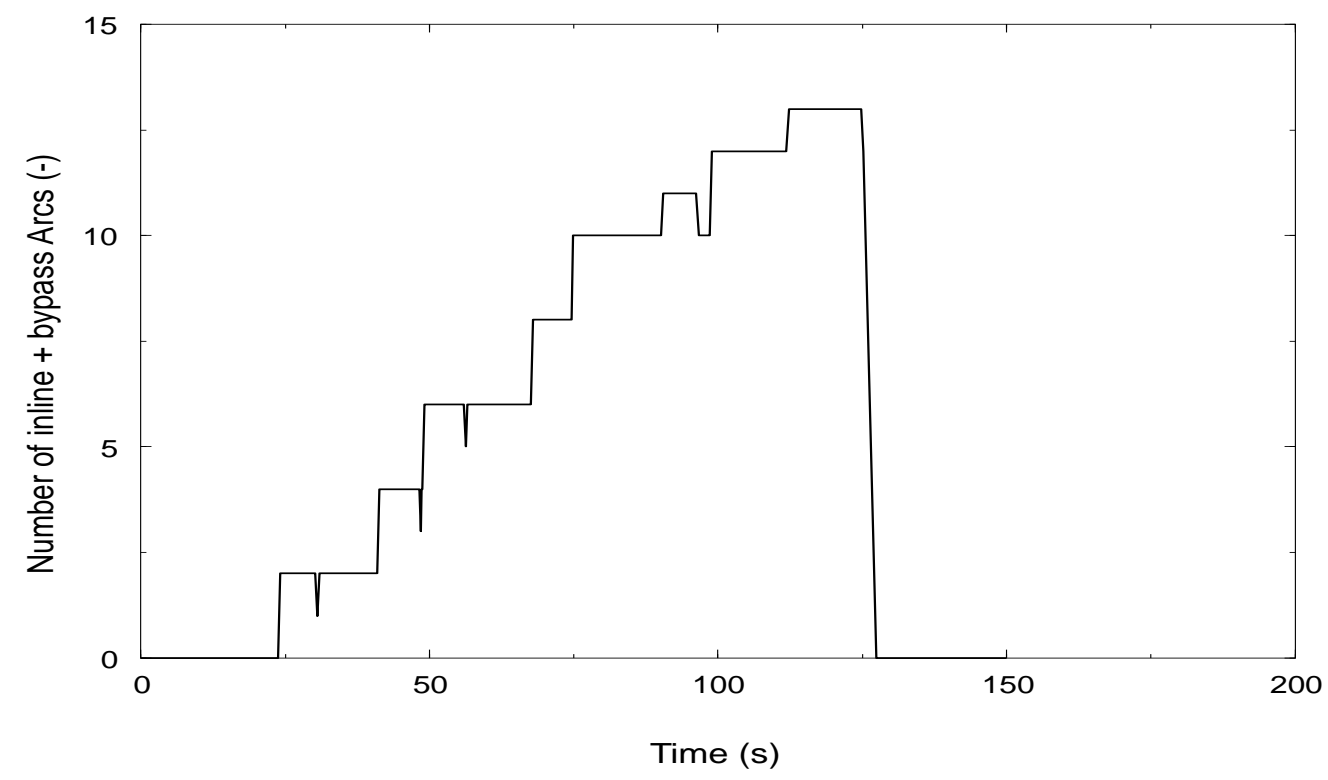

Figure 16. Number of inline plus bypass arcs predicted for the base case unmitigated quench event. 


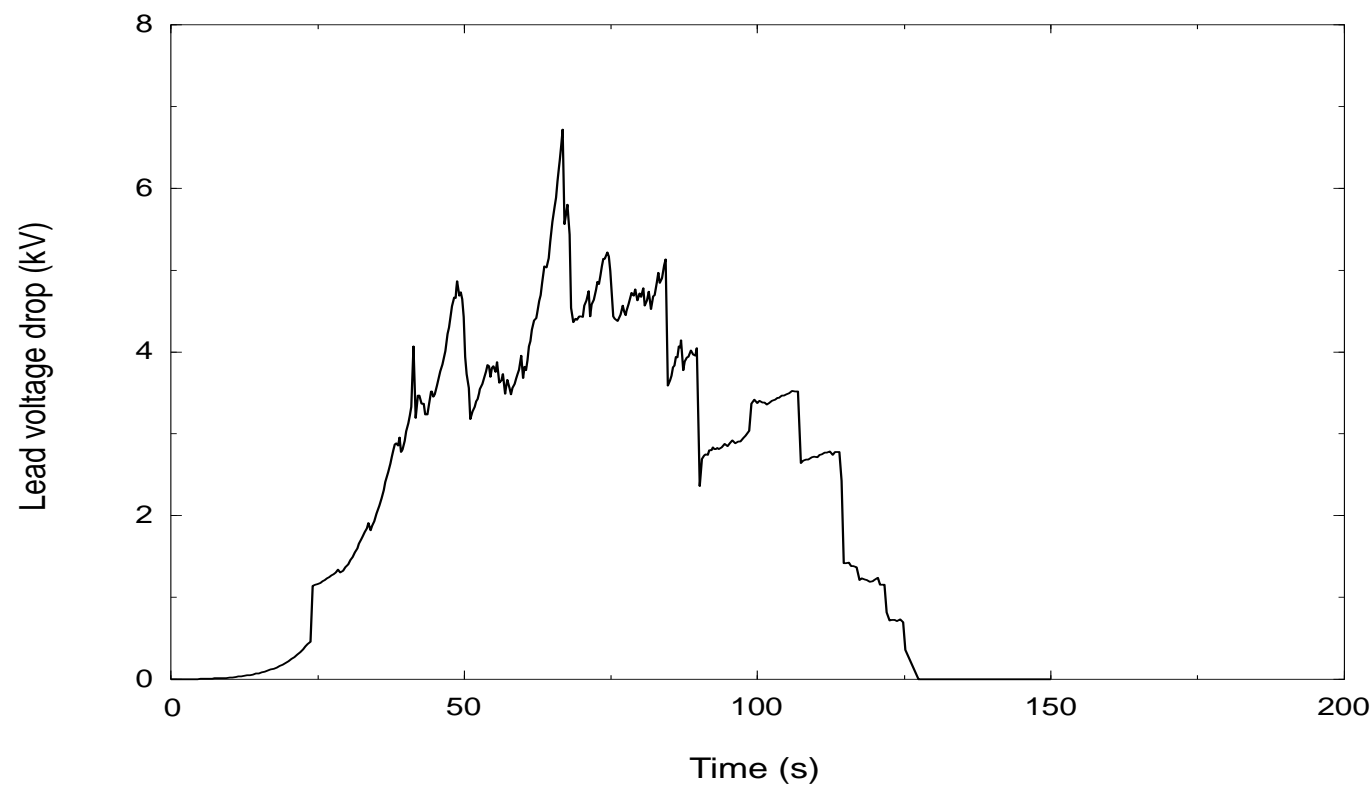

Figure 17. Voltage drop across magnet leads predicted for the base case unmitigated quench event.

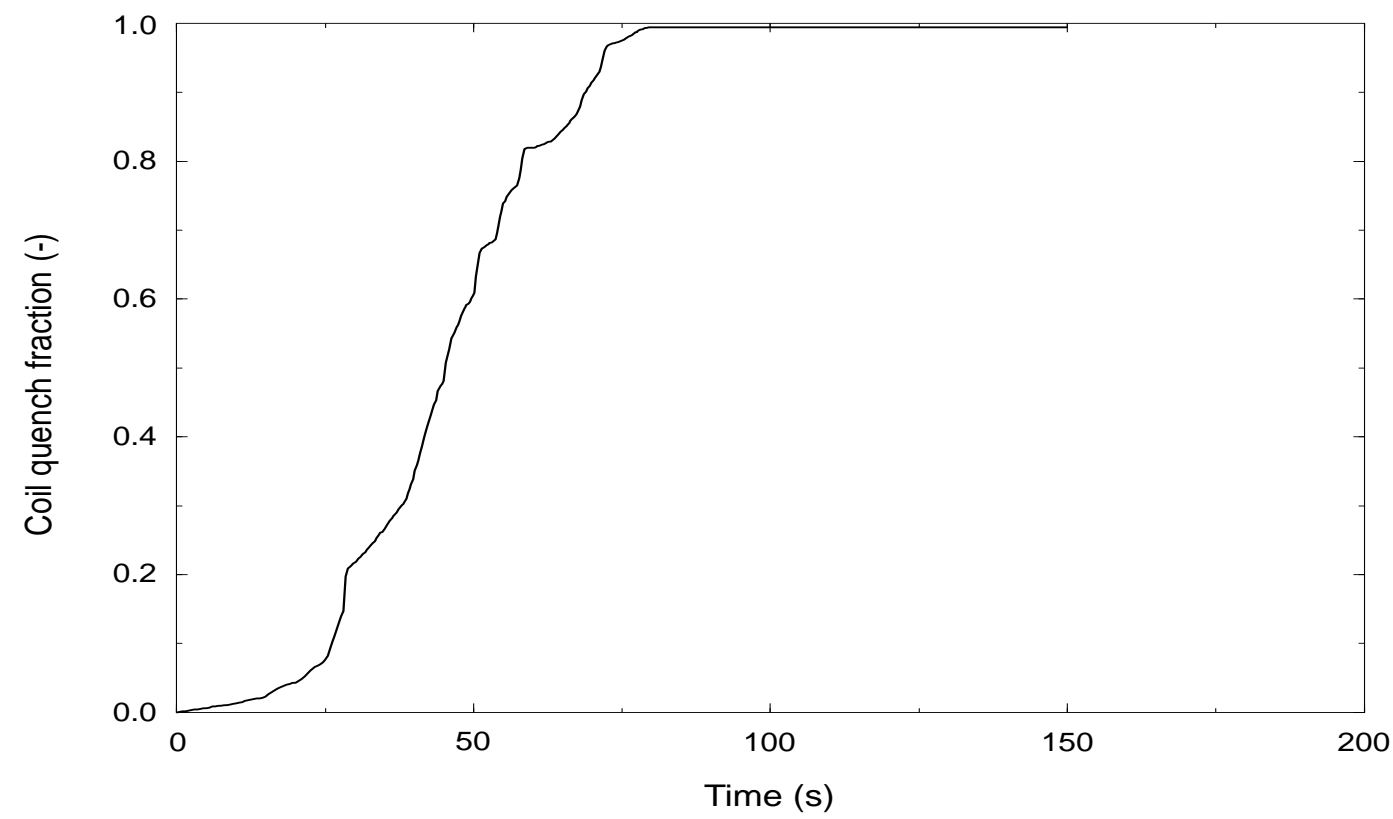

Figure 18. Quench fraction predicted for predicted for the base case unmitigated quench event. 


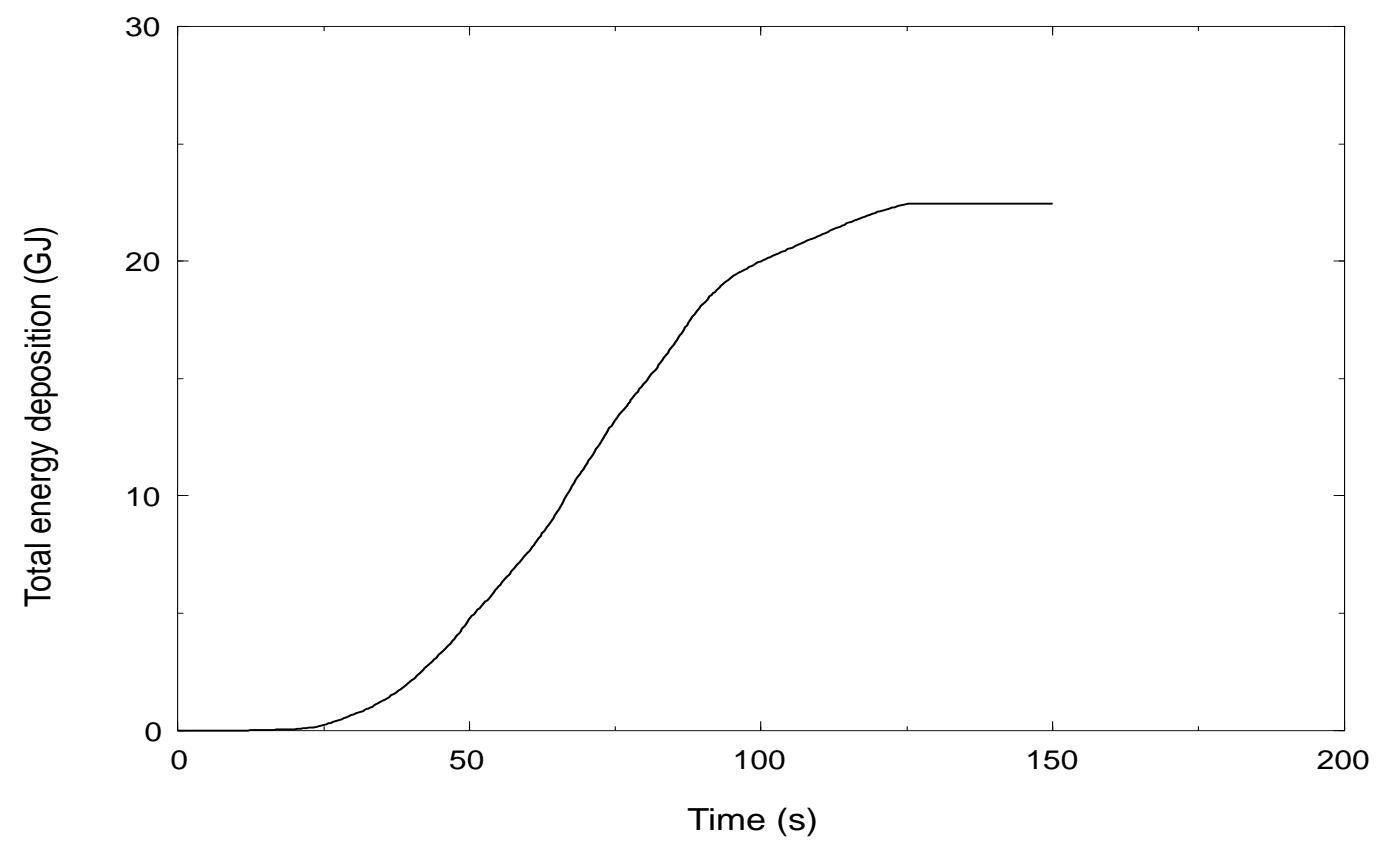

Figure 19. Total energy (resistive + arc) deposited in magnet predicted for the base case unmitigated quench event.

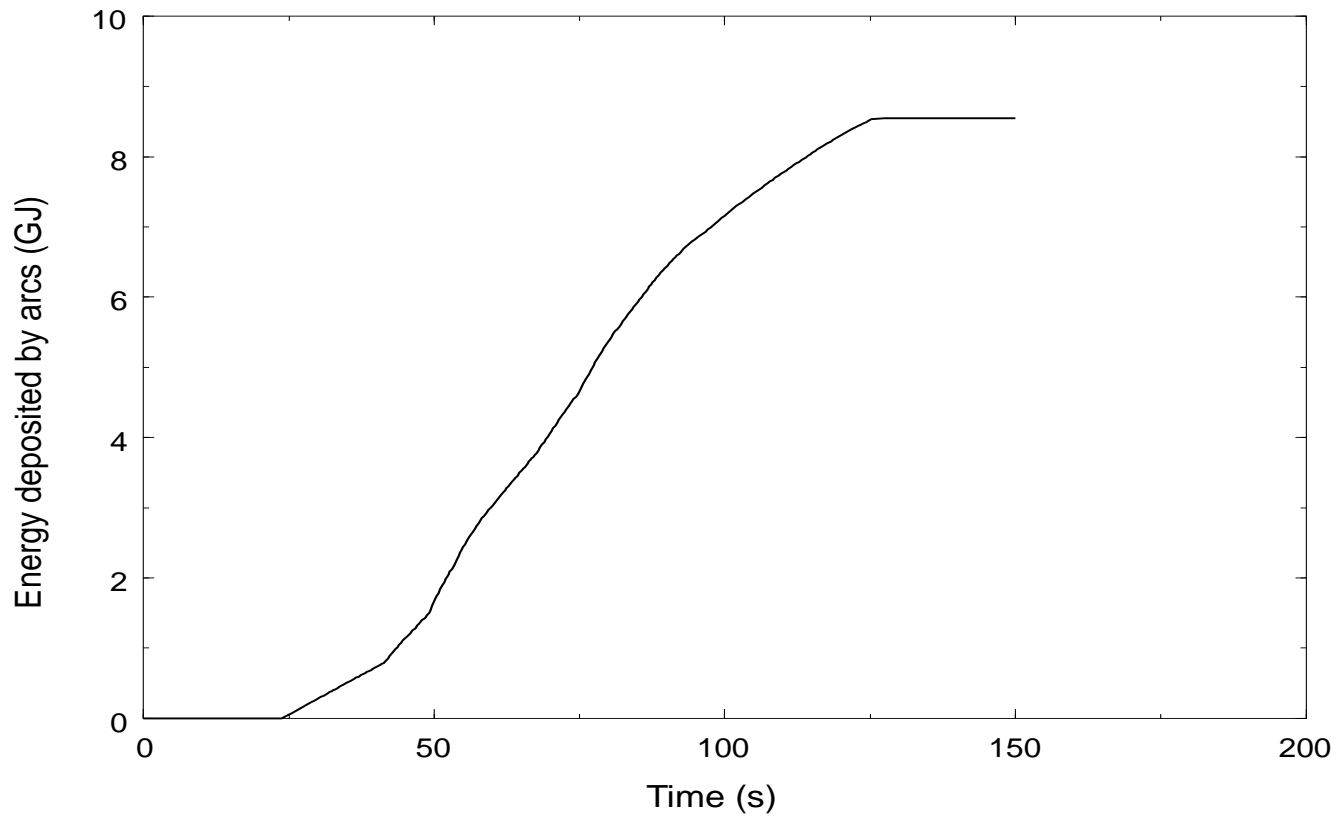

Figure 20. Arc energy deposited in magnet predicted for the base case unmitigated quench event. 


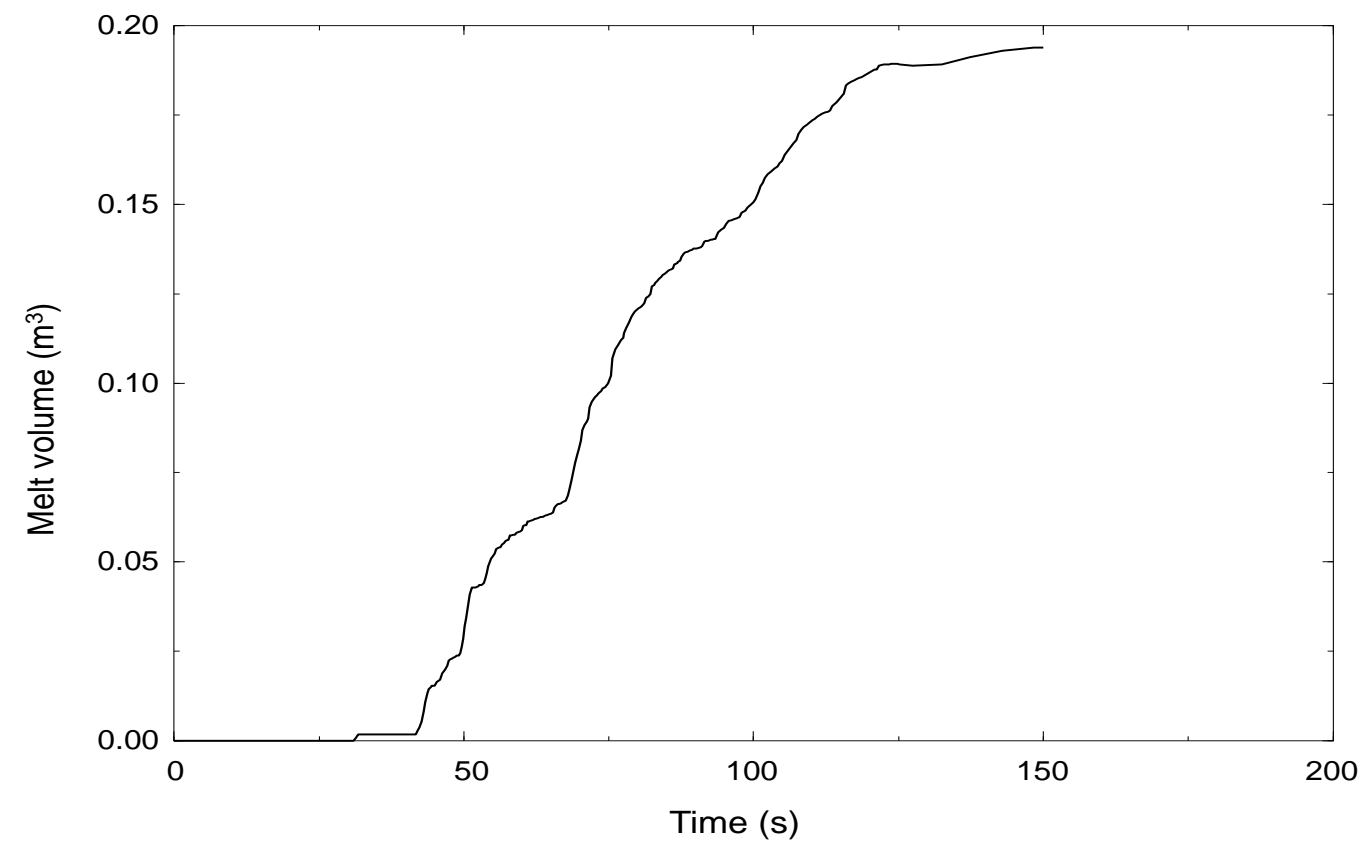

Figure 21.Total melt volume predicted for the base case unmitigated quench event.

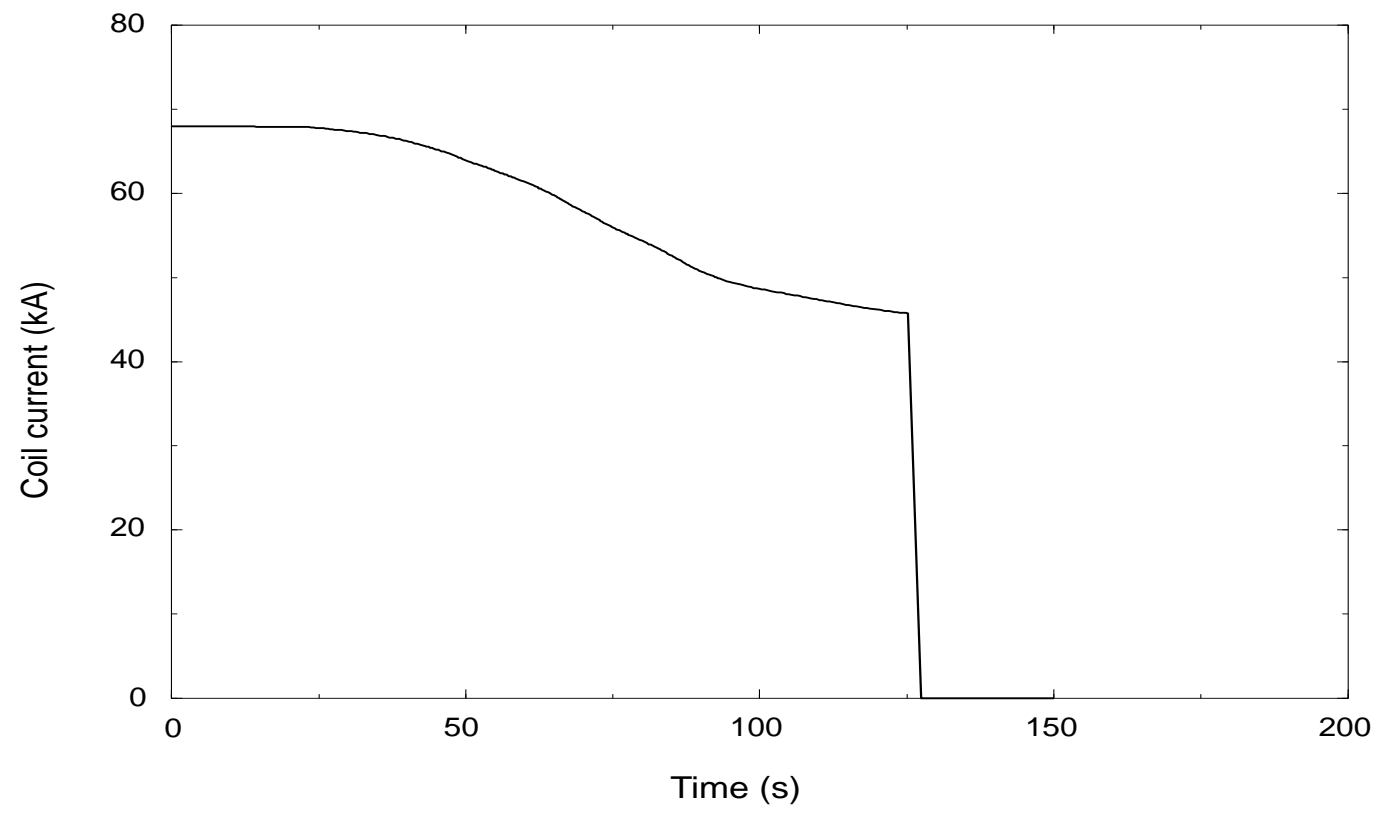

Figure 22. Magnet current predicted for the base case unmitigated quench event. 


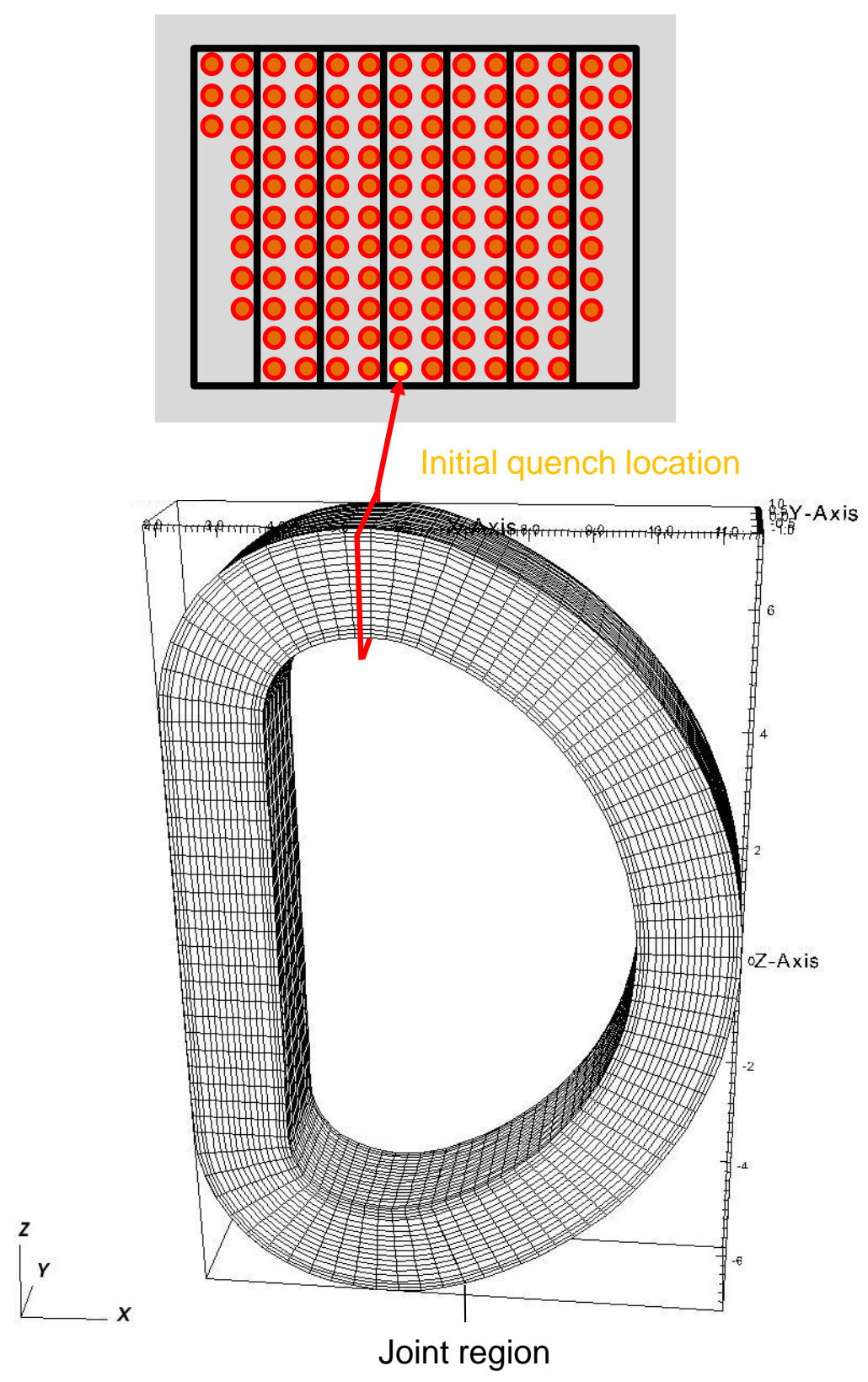

Figure 23. MAGARC Cartesian grid mapped to ITER Engineering Design Activity toroidal field coil coordinates, but with the radial and toroidal widths magnified by a factor of two for easier visualization. 


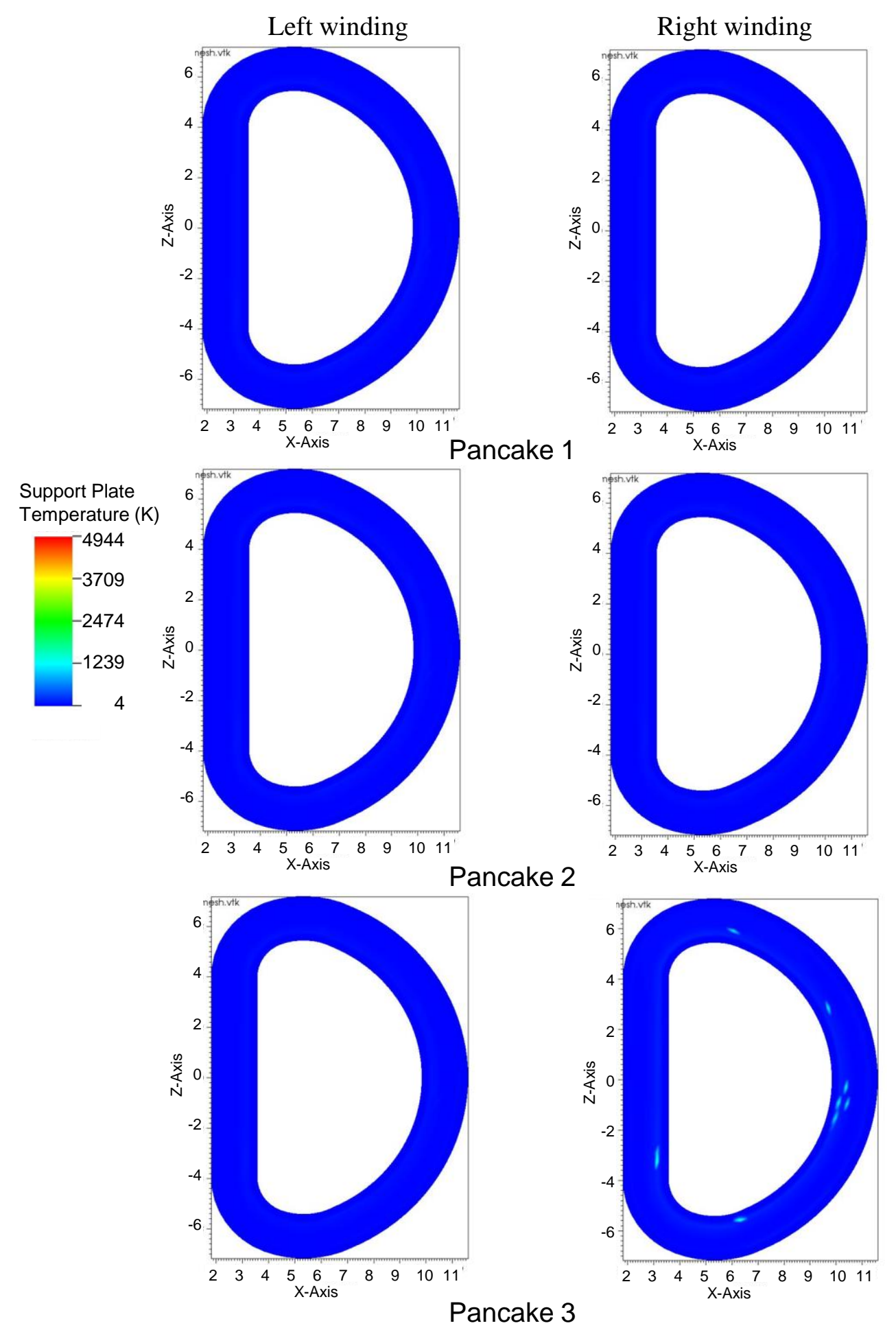

Figure 24. MAGARC predicted support plate temperatures at $50 \mathrm{~s}$ for radial cuts through pancakes 1 through 3. 

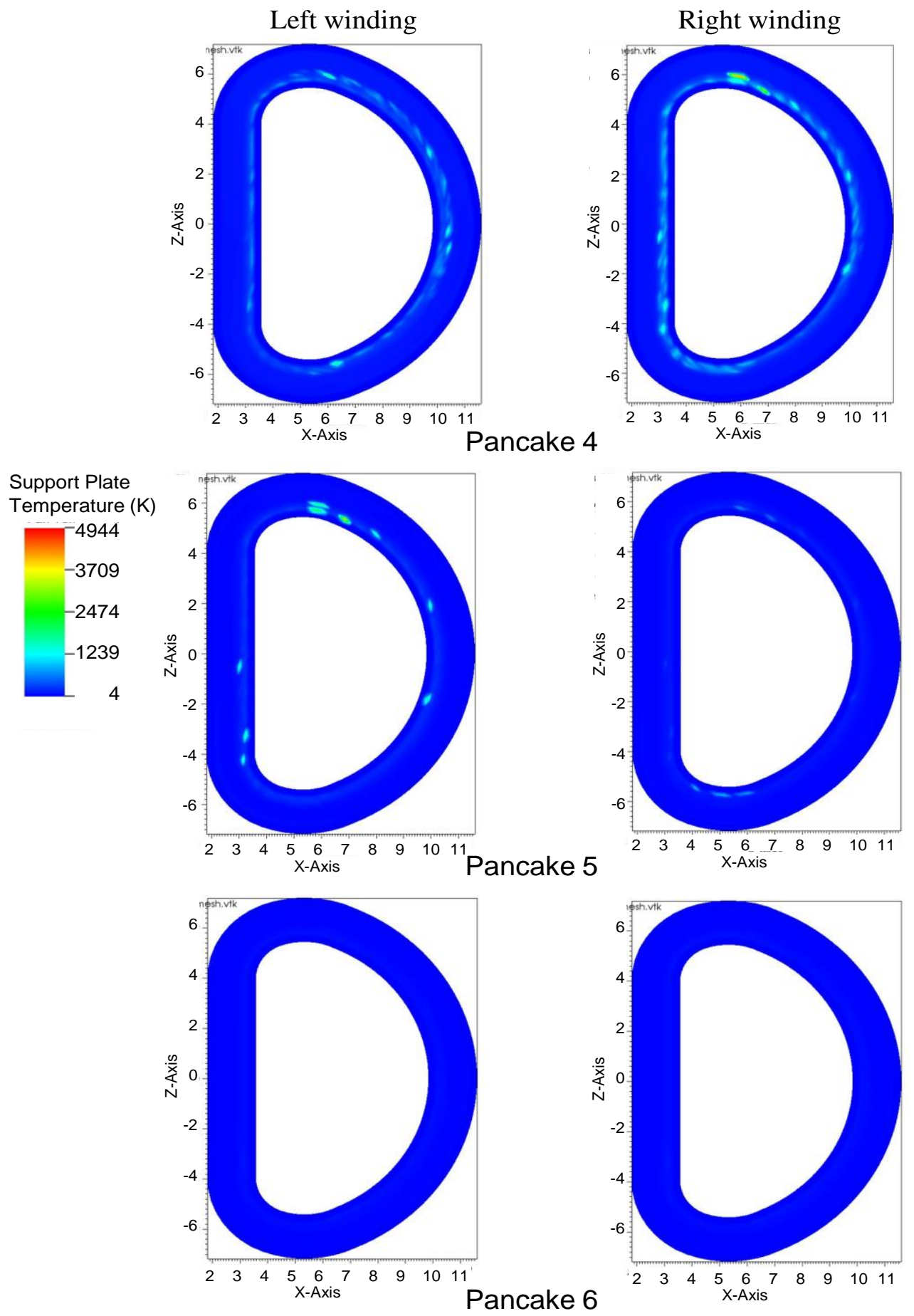

Figure 25. MAGARC predicted support plate temperatures at $50 \mathrm{~s}$ for radial cuts through pancakes 4 through 6. 

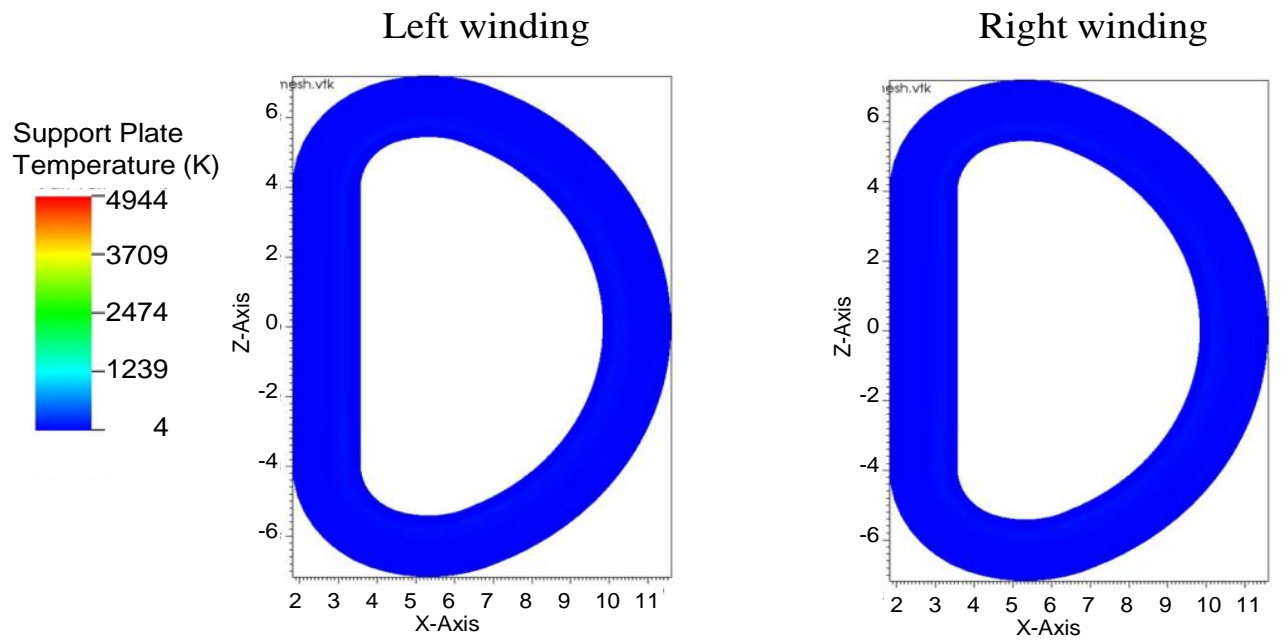

Pancake 7
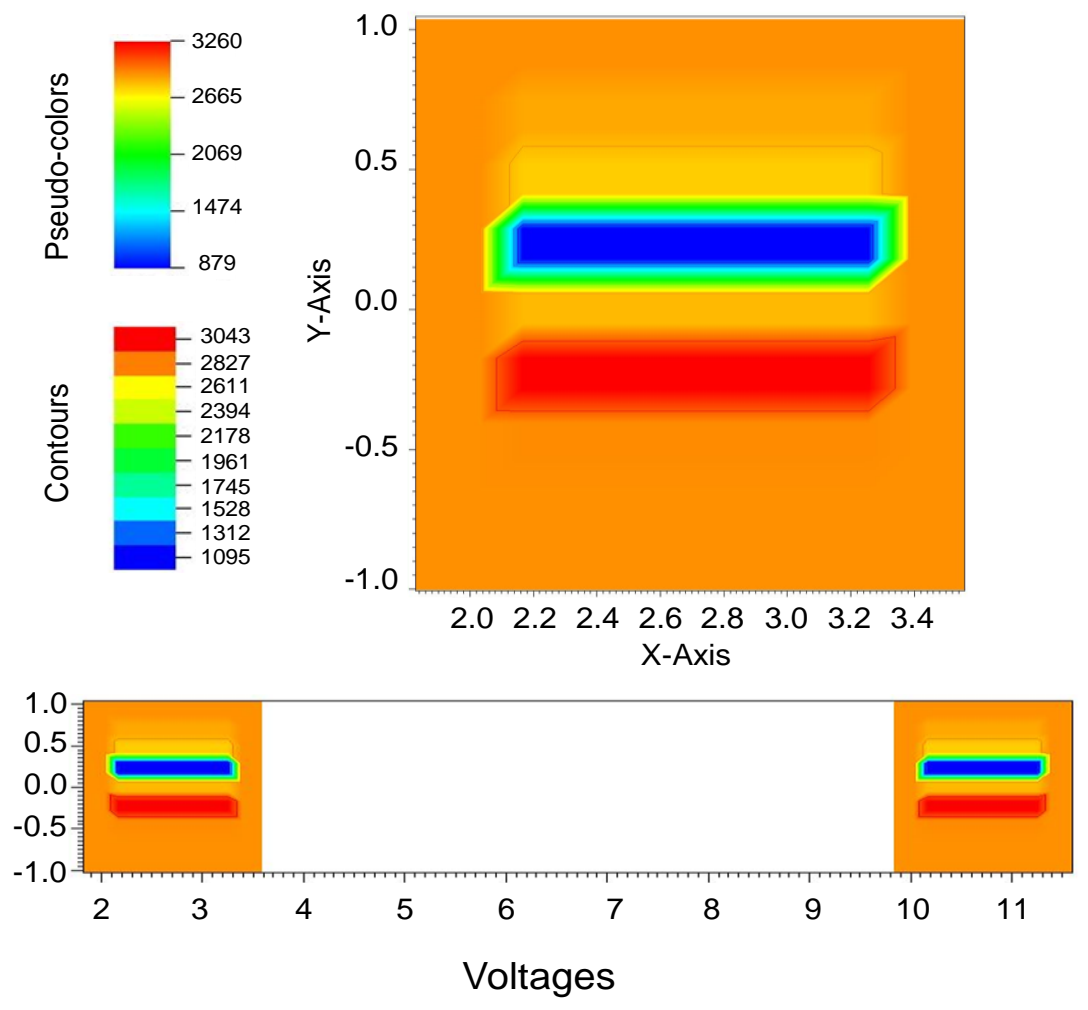

Figure 26. MAGARC predicted support plate temperatures at $50 \mathrm{~s}$ for radial cuts through pancake 7 and voltages for axial cut through magnet midplane. 

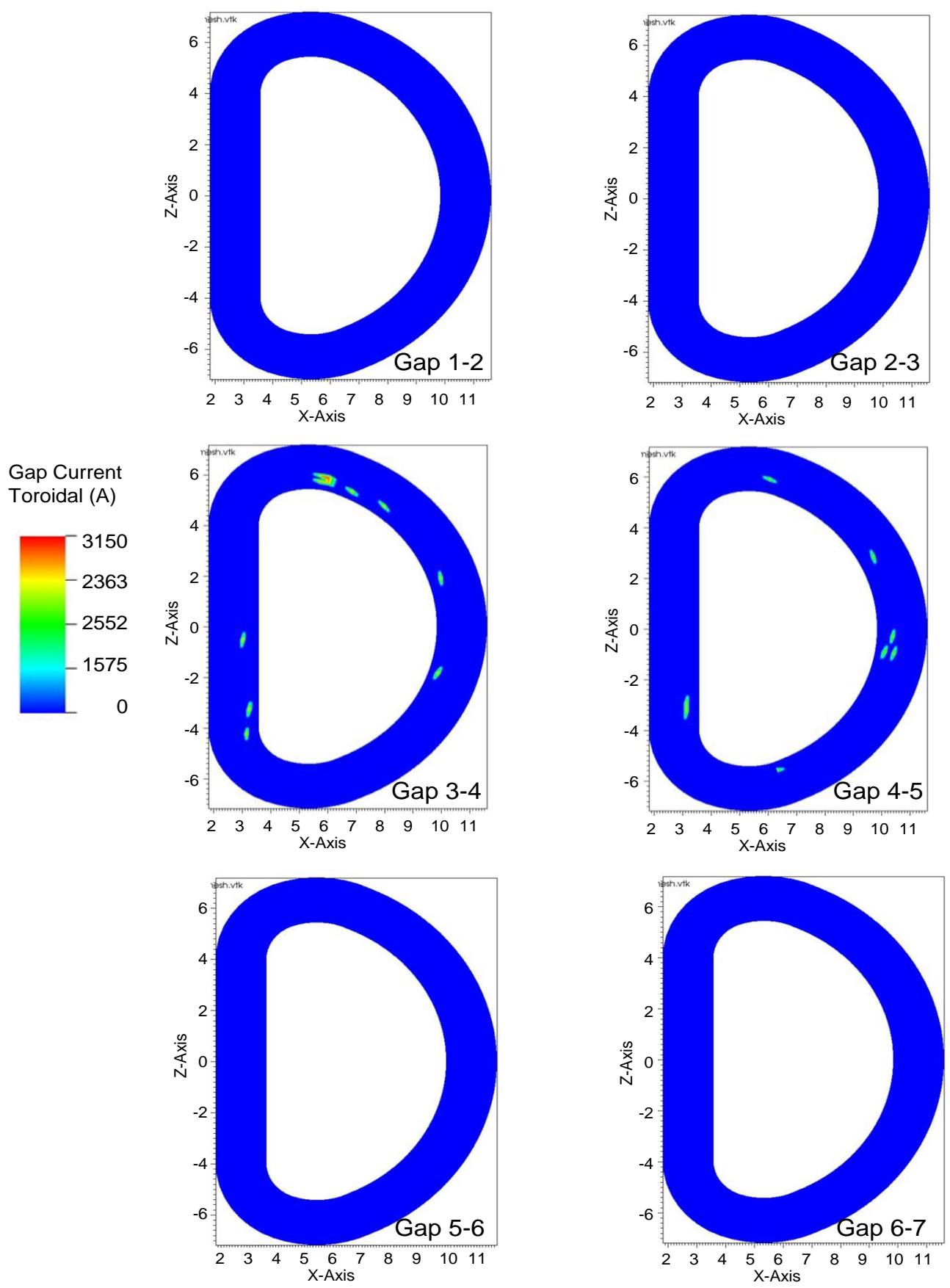

Figure 27. MAGARC predicted toroidal gap currents between magnet pancakes at $50 \mathrm{~s}$. 

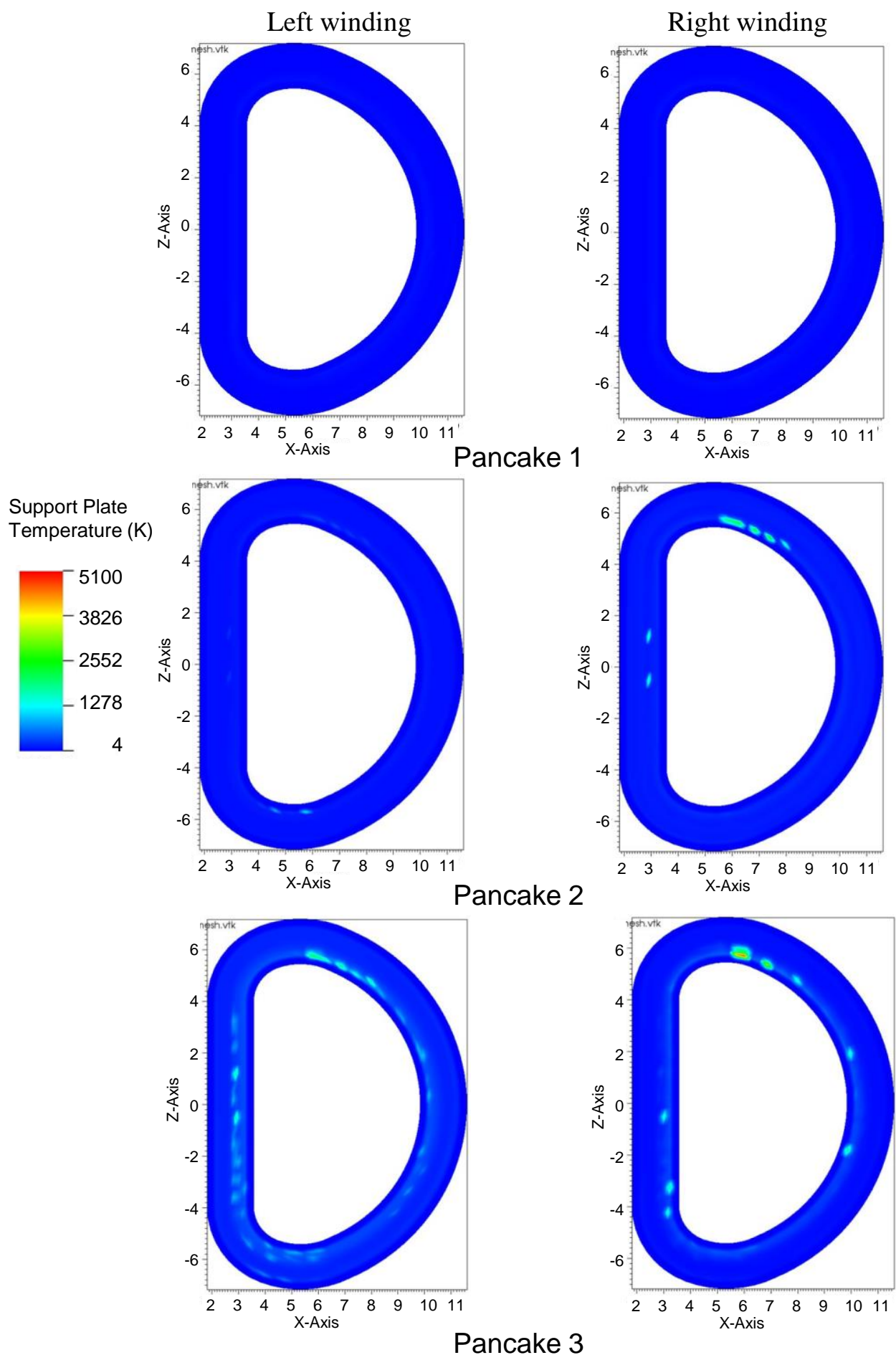

Figure 28. MAGARC predicted support plate temperatures at $75 \mathrm{~s}$ for radial cuts through pancakes 1 through 3 . 

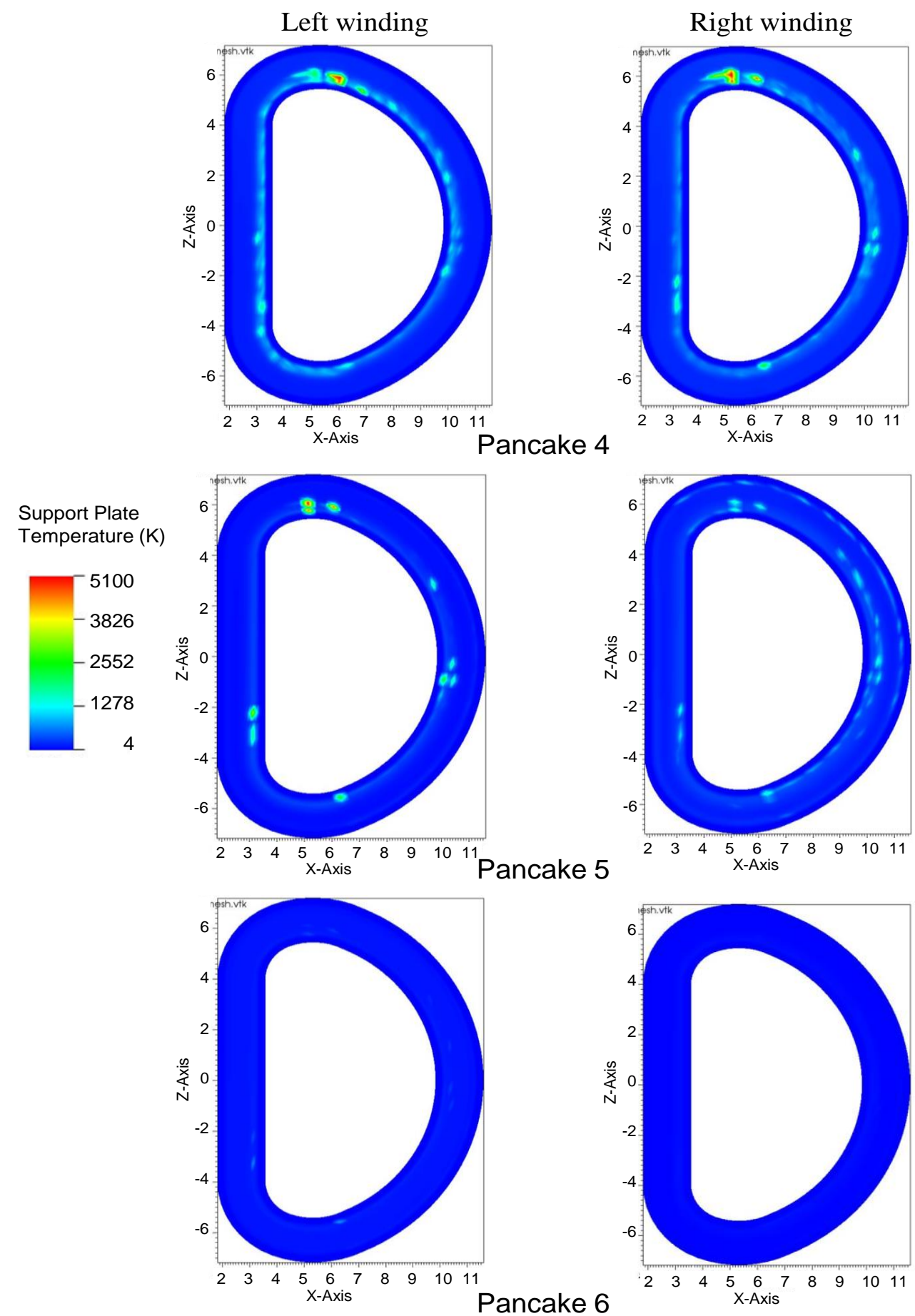

Figure 29. MAGARC predicted support plate temperatures at $75 \mathrm{~s}$ for radial cuts through pancakes 4 through 6 . 

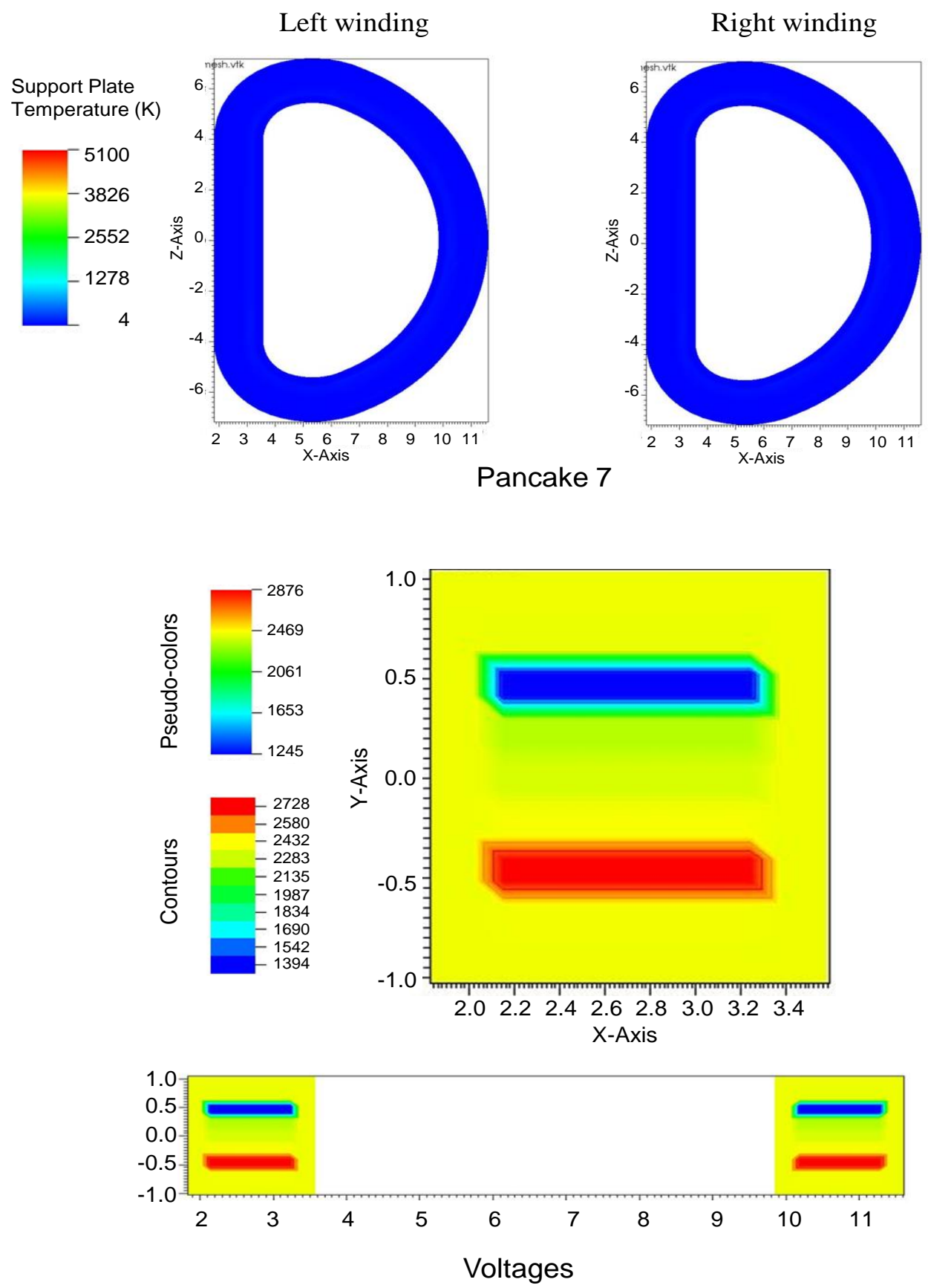

Figure 30. MAGARC predicted support plate temperatures at $75 \mathrm{~s}$ for radial cuts through pancake 7 and voltages for axial cut through magnet midplane. 

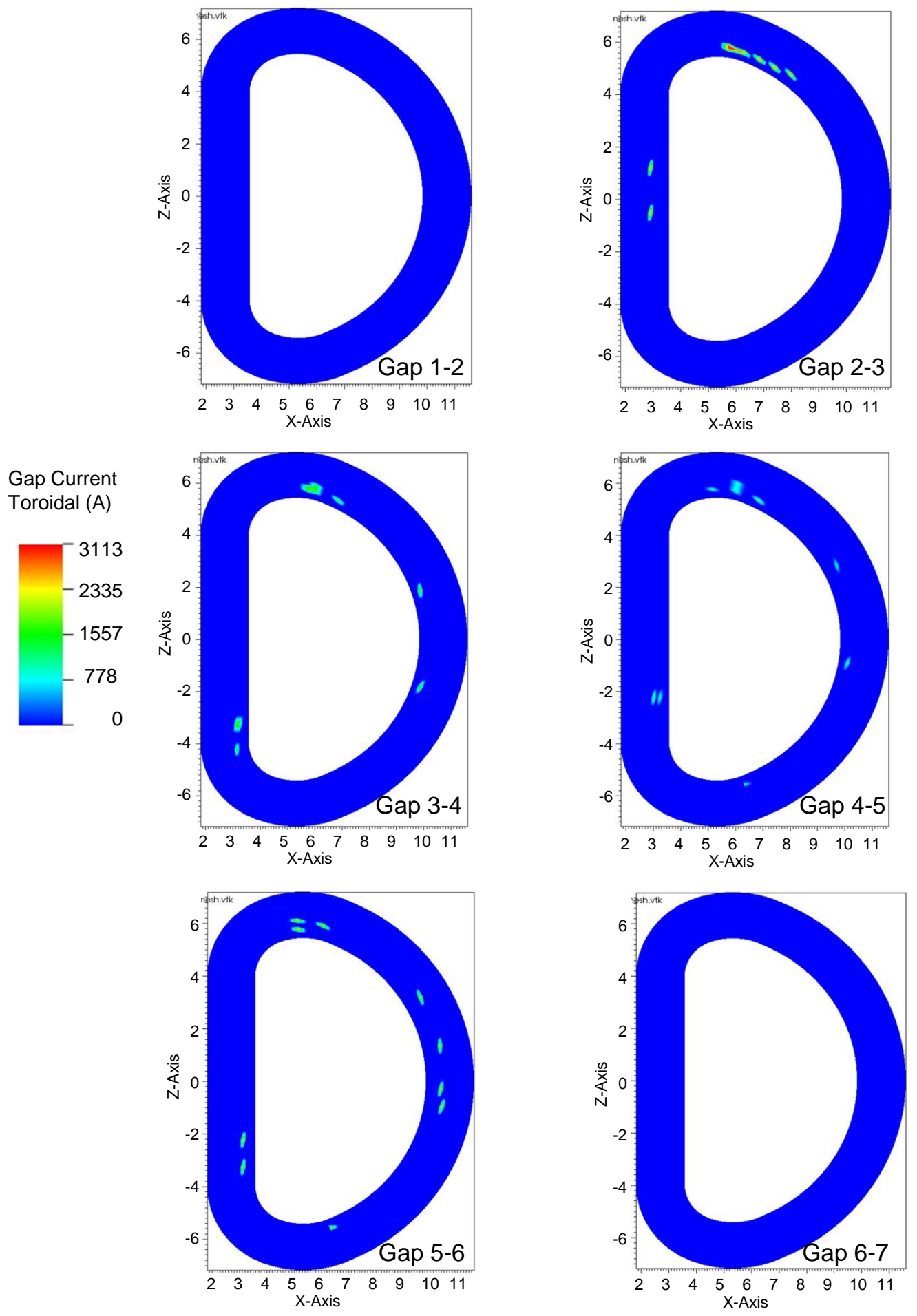

Figure 31. MAGARC predicted toroidal gap currents between magnet pancakes at $75 \mathrm{~s}$. 

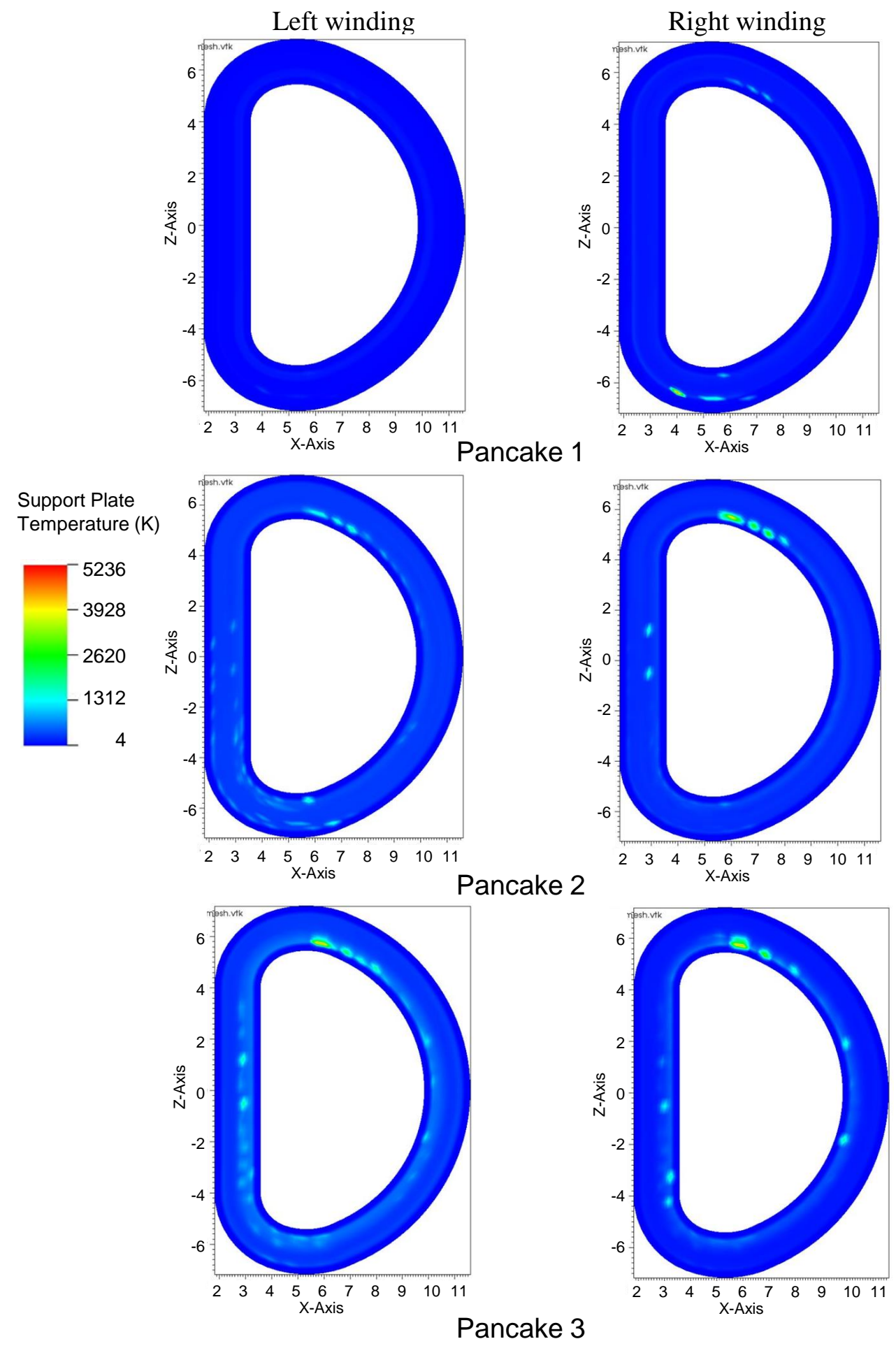

Figure 32. MAGARC predicted support plate temperatures at $100 \mathrm{~s}$ for radial cuts through pancakes 1 through 3. 

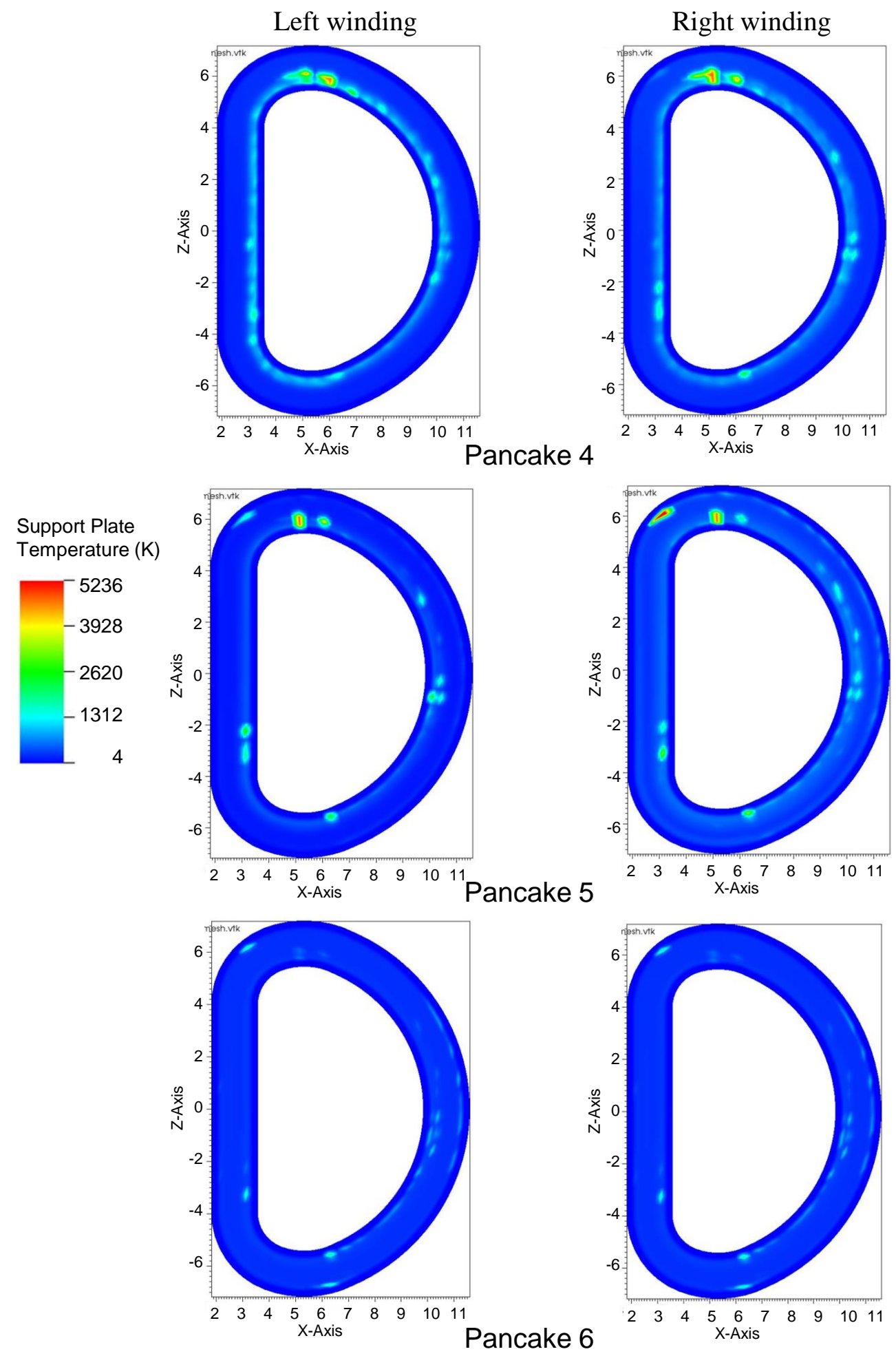

Figure 33. MAGARC predicted support plate temperatures at $100 \mathrm{~s}$ for radial cuts through pancakes 4 through 6. 

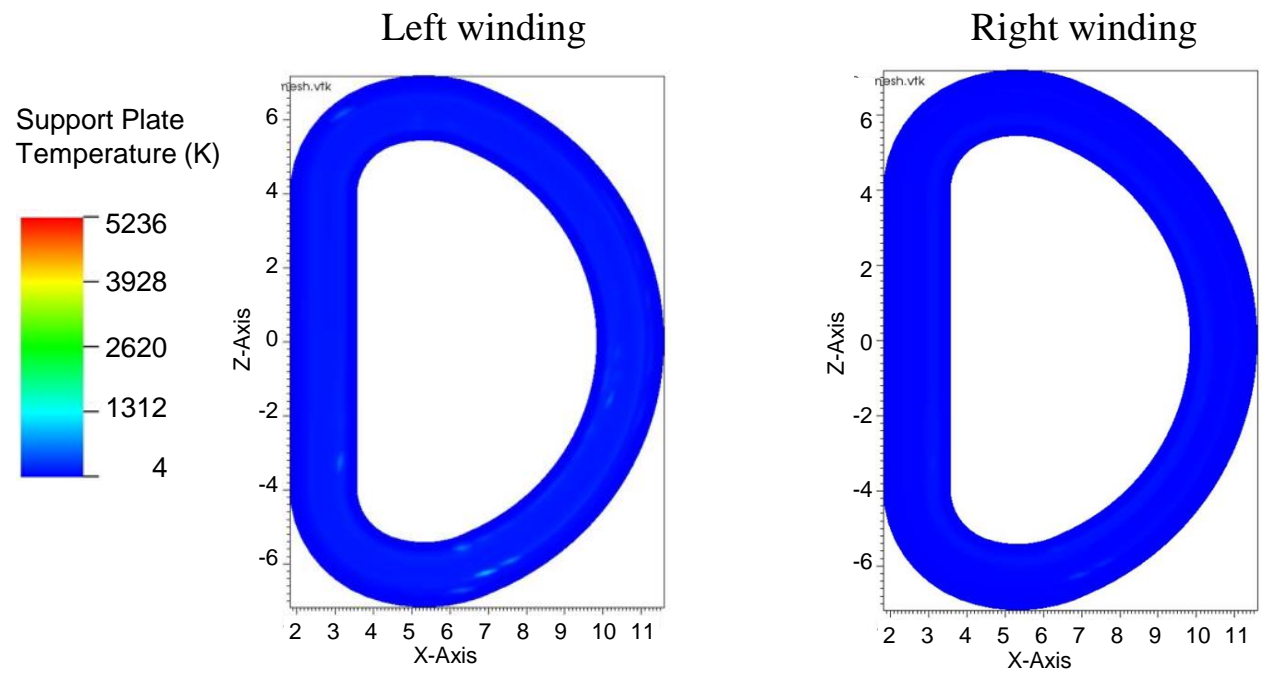

Pancake 7
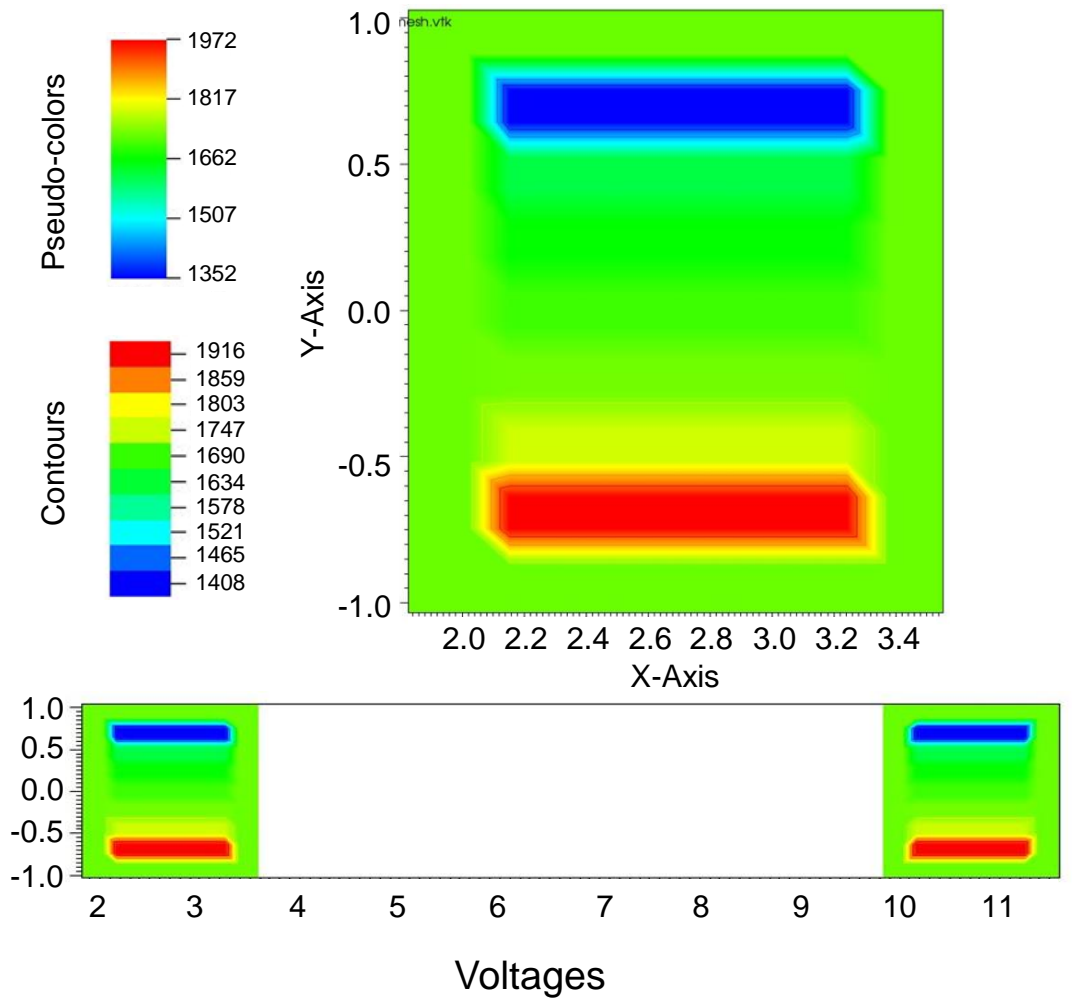

Figure 34. MAGARC predicted support plate temperatures at $100 \mathrm{~s}$ for radial cuts through pancake 7 and voltages for axial cut through magnet midplane. 

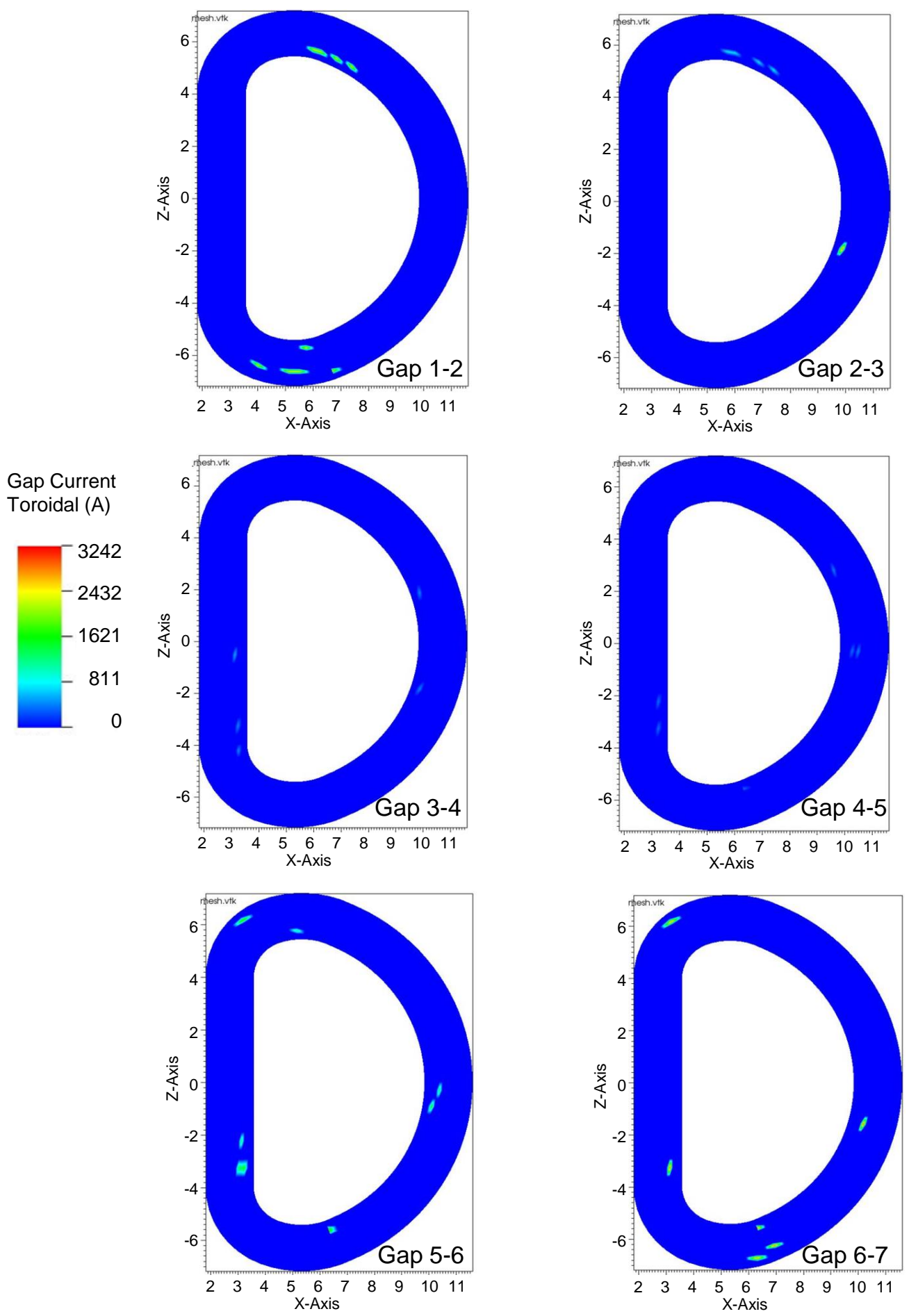

Figure 35. MAGARC predicted toroidal gap currents between magnet pancakes at $100 \mathrm{~s}$. 

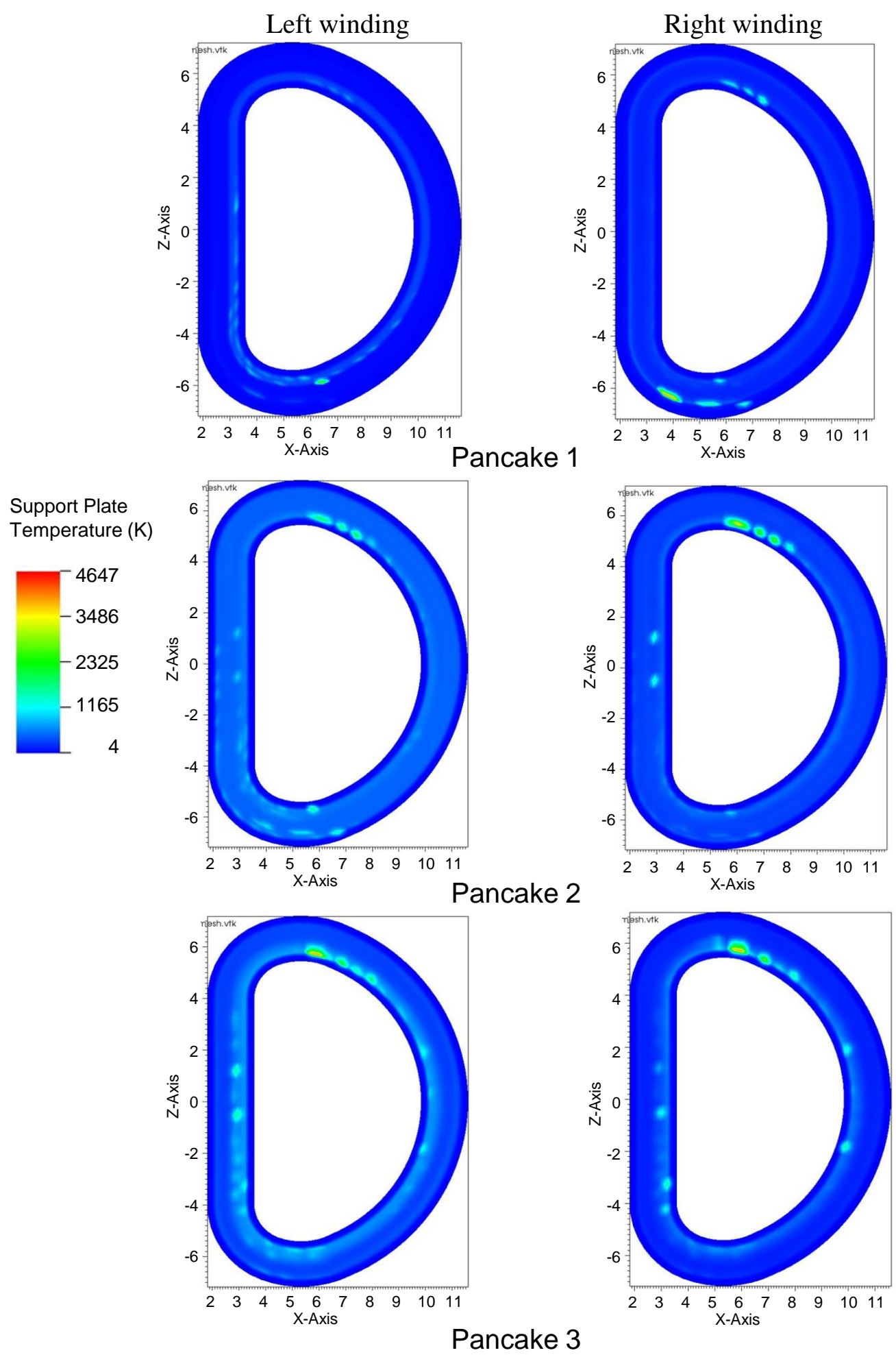

Figure 36. MAGARC predicted support plate temperatures at $125 \mathrm{~s}$ for radial cuts through pancakes 1 through 3. 

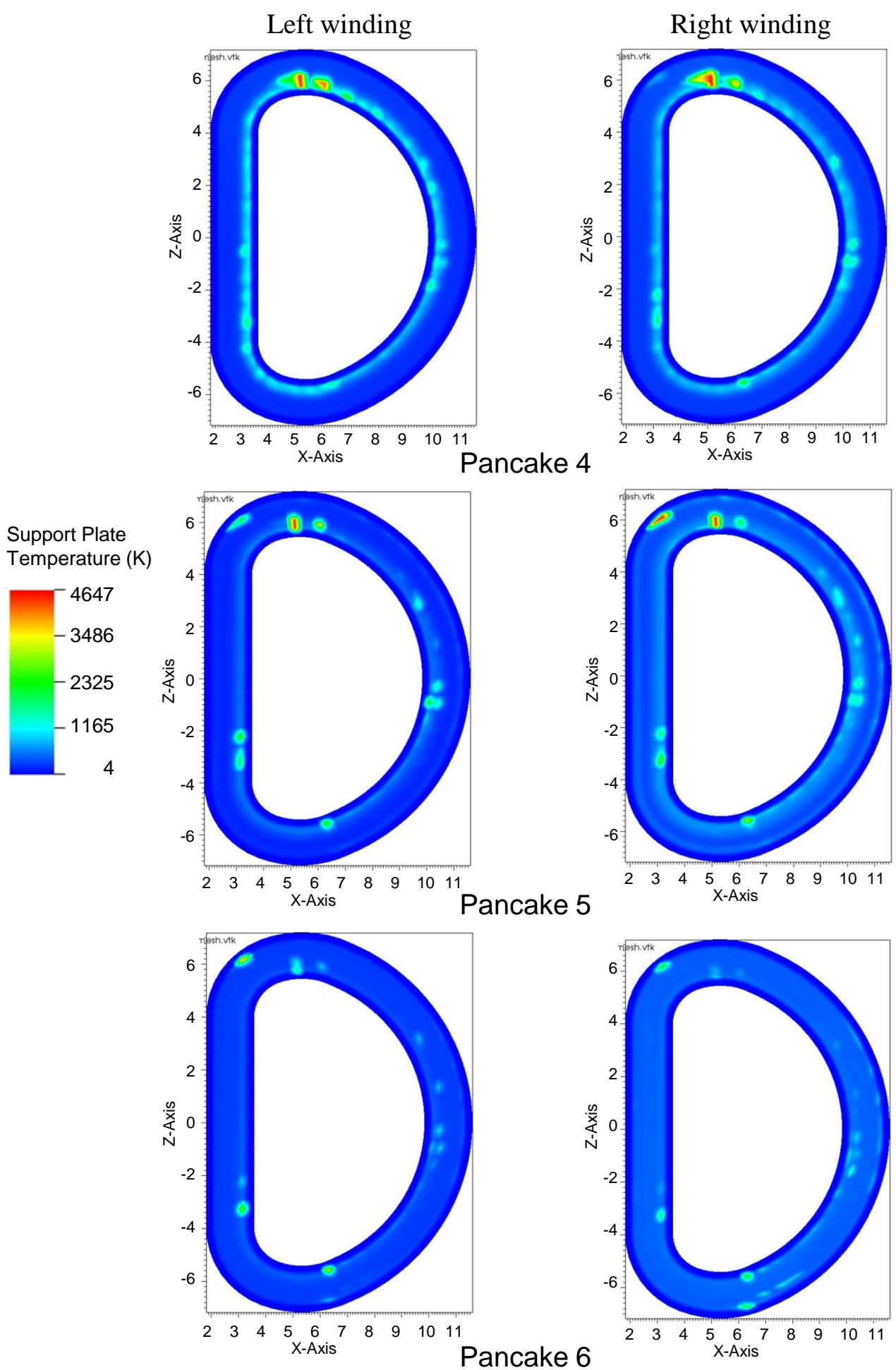

Figure 37. MAGARC predicted support plate temperatures at $125 \mathrm{~s}$ for radial cuts through pancakes 4 through 6. 

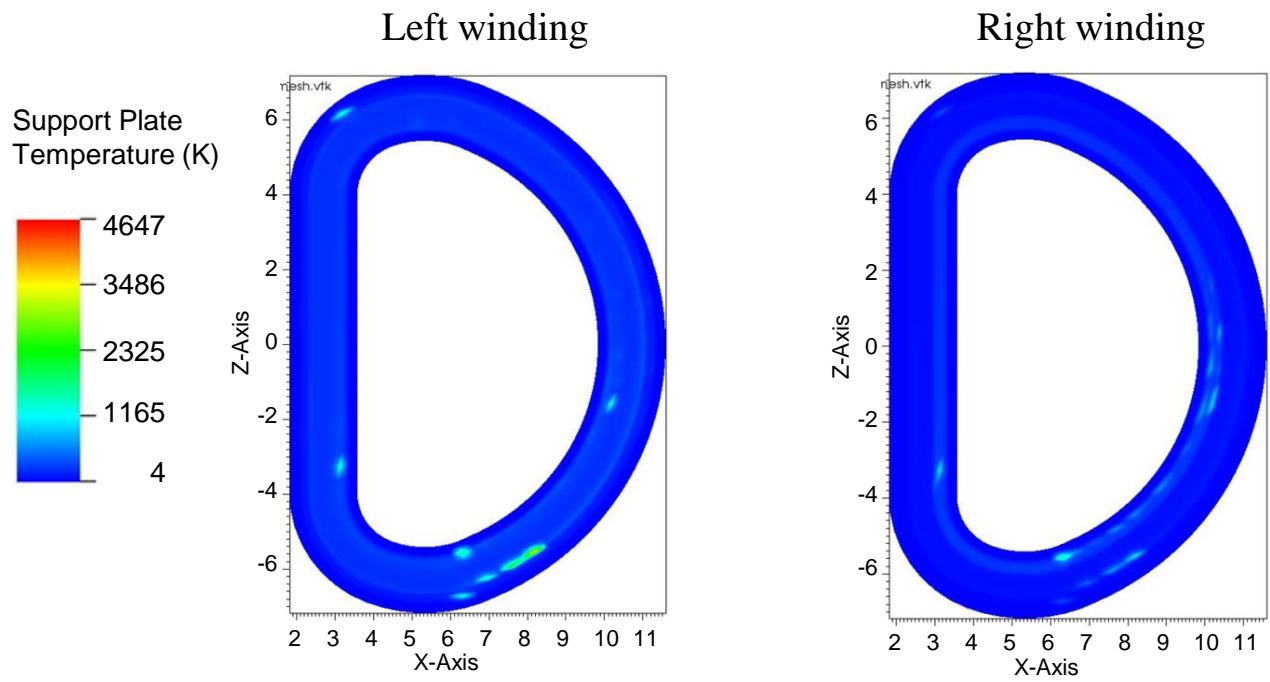

Pancake 7
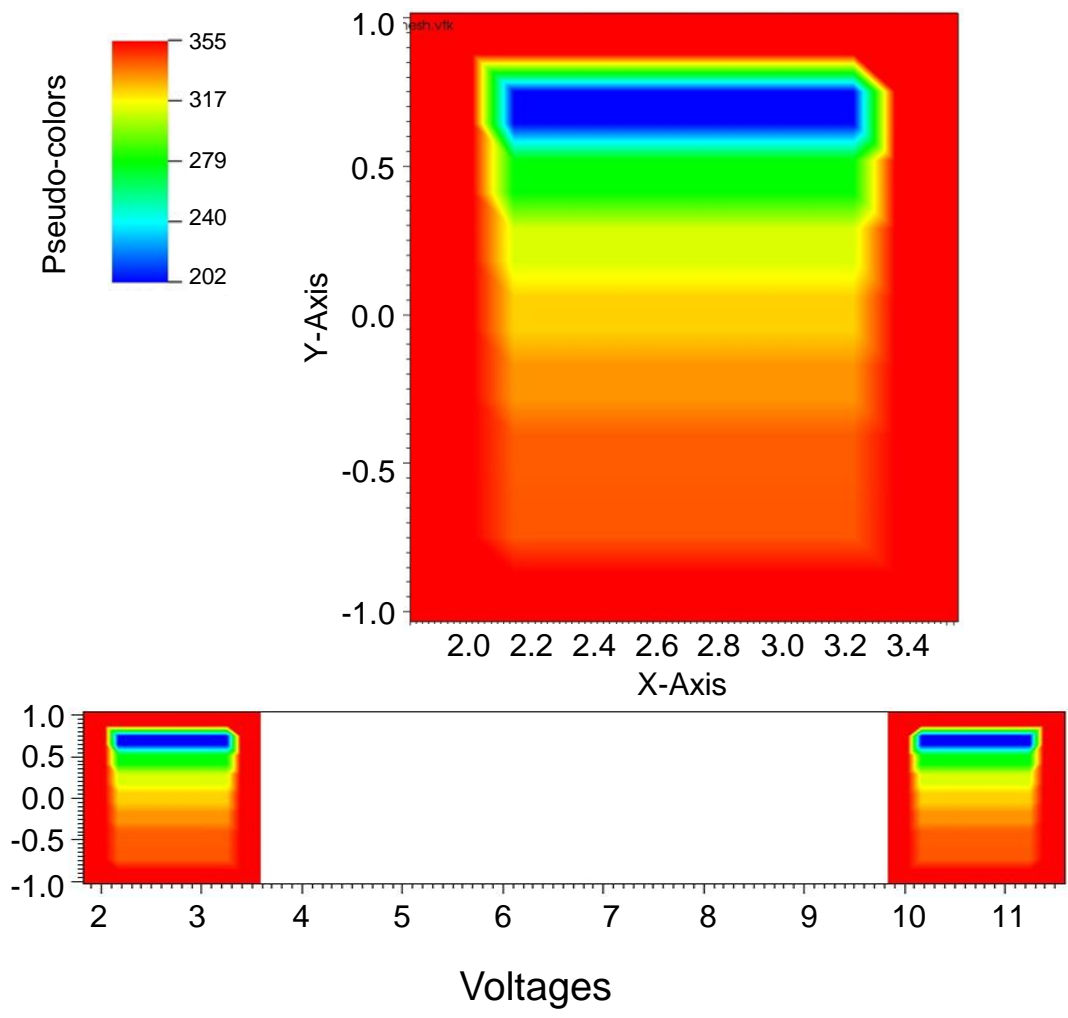

Figure 38. MAGARC predicted support plate temperatures at $125 \mathrm{~s}$ for radial cuts through pancake 7 and voltages for axial cut through magnet midplane. 

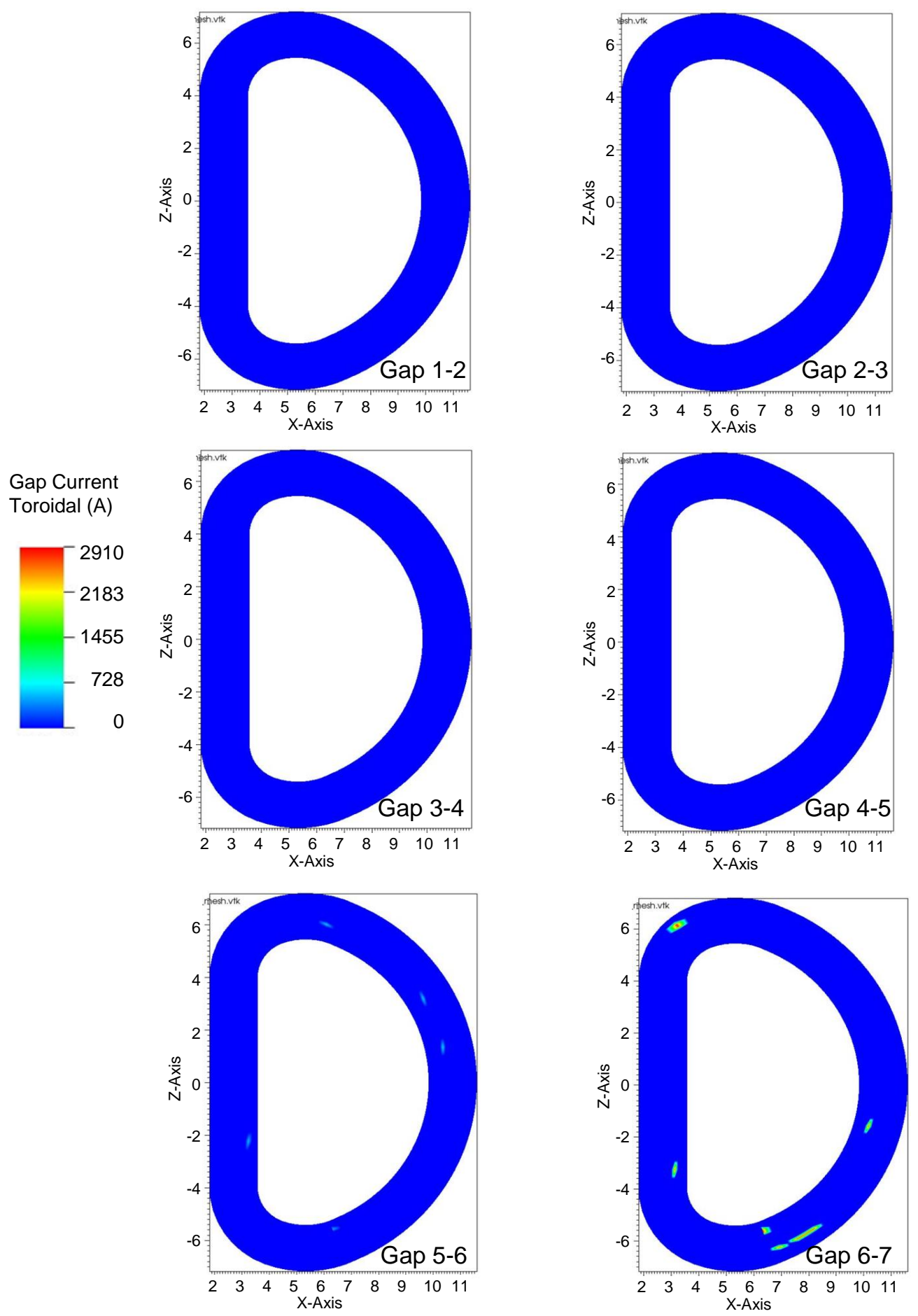

Figure 39. MAGARC predicted toroidal gap currents between magnet pancakes at $125 \mathrm{~s}$. 


\section{Summary}

During the completion of this contract the following products and accomplishments were completed by the Contractor:

1. A work plan was developed by the Contractor and presented to, and agreed to by, the Sponsor,

2. Voltage equations numerical convergence problems were solved by coupling the Generalized Minimum Residual (GMRES) method to the BiConjugate Gradient iterative method if the latter method fails to converge on a solution at a given time step,

3. Electromagnetic grid variables properly stored at the beginning of each time step so that MAGARC correctly repeats a given time step at a lower value when non-convergence occurs for the voltage grid,

4. The CCFE time step size sensitivity study was repeated and reported,

5. A new arc characteristics model was developed that harmonized the Kronhardt model [5] and the data presented by Raeder [13] for unconfined arcs,

6. Gap arc current is now limited to the minimum current for such arcs in a common gap,

7. A complete side-by-side comparison of the MAGARC and CCFE analysis package was presented,

8. Comparison data was developed for a unmitigated quench event for the TF magnet that includes both global and 2D presentations of this data,

9. The Contractor attended two progress meetings, gave progress reports at each meeting, and issued both a preliminary progress and final progress report,

10. Send MAGARC to Sponsor at contract termination.

This list of accomplishments demonstrates that the Contractor has fulfilled the work scope required by this contract.

Table 7. Contractor list of required deliverables due after contract effective date of Oct. $16^{\text {th }} 2015$.

\begin{tabular}{|c|l|c|c|}
\hline $\begin{array}{l}\text { Deliverable } \\
\text { Reference } \\
\text { Number }\end{array}$ & \multicolumn{1}{|c|}{ Deliverable } & Due date & Date Completed \\
\hline 1 & $\begin{array}{l}\text { A PowerPoint presentation at a monthly conference call } \\
\text { describing the work plan, resource distribution and } \\
\text { deliverables }\end{array}$ & $\begin{array}{c}\text { Nov. 16 } \\
2015\end{array}$ & Dec. $14^{\text {th }} 2015$ \\
\hline 2 & Preliminary progress report & $\begin{array}{c}\text { Mar. 16 } \\
2016\end{array}$ & Jan. 31 2016 \\
\hline 3 & Final summary report on investigation findings & $\begin{array}{c}\text { Aug. } 16^{\text {th }} \\
2016\end{array}$ & Jun. 30 2016 \\
\hline 4 & $\begin{array}{l}\text { Data file (text format) of MAGARC code predictions } \\
\text { during a un-mitigate quench accident for CCFE } \\
\text { comparison and provide update version of MAGARC to } \\
\text { Sponsor }\end{array}$ & $\begin{array}{c}\text { Oct. 16 } \\
2016\end{array}$ & $\begin{array}{l}\text { Code and data to } \\
\text { be delivered at } \\
\text { contract } \\
\text { closeout }\end{array}$ \\
\hline
\end{tabular}




\section{References}

1) B. J. Merrill, Modeling an unmitigated quench event in an ITER toroidal field magnet, Fusion Technology, 37 (2000) 231-246.

2) B. J. Merrill, Final report on ITER task agreement 81-10, Idaho National Laboratory Report, INL/EXT-09-15292. (2009).

3) B. J. Merrill, "Modeling an unmitigated thermal quench event in a large field magnet in a DEMO reactor," Fusion Engineering and Design, 98-99 (2015) 2196-2200.

4) Progress \& Status by 12sept2014, Culham Centre for Fusion Energy (CCFE), ITER_D_NPBMC5 v1.0, September (2014).

5) H. Kronhardt, "The Impact of Short-Circuits and Electric Arcs on the Safety of Magnet Systems," Karlsruhe Nuclear Research Centre Report, 5096, May (1993) 27 (English translation).

6) Fong, Kirby W.; Jefferson, Thomas H.; Suyehiro, Tokihiko; Walton, Lee, "Guide to the SLATEC Common Mathematical Library", can be obtained from http://www.netlib.org/slatec/guide, July (1993).

7) R. Meyder, V. Pasler, "Analysis of an unmitigated quench in a poloidal field coil of ITER," Fusion Engineering and Design, 66-68 (2003) 1029-1033.

8) A. Shajii, "Theory and Modeling of Quench in Cable-In-Conduit Superconducting Magnets," Plasma Fusion Center, Massachusetts Institute of Technology Report, PFC/RR-94-5, (1994).

9) G. Schmidt, R. Meyder, "Final Report on Thermal Insulation Experiments," FZR-IRS Report, GB8-SEA5A (Sept01), September 2001.

10) R. Hultgren, et al., "Selected values of the thermodynamic properties of elements," American Society of Metals, Metals Park, Ohio (1973).

11) G. Schmidt, R. Meyder, "Final Report on Electrical Insulation Experiments," FZR-IRS Report, GB8-SEA5A (DEC00), January 2001.

12) D. Klimenko and V. Pasler, "Safety of fusion magnets: Model experiments to high current arcs at ITER busbars and feeder lines,” Fusion Engineering and Design, 87 (2012) 675-679.

13) J. Raeder, "Electric arcs external to ITER magnet coils - synthesis of model," ITER Document, IDOMS: G 83 MD5 02-10-14 W.1.

14) S. Mcintosh, Integrated ANSYS modelling for ITER superconducting magnets: quench, electric, and arc," ITER Report, Q9NKBL.v1, December 31 (2014). 


\section{Appendix A}

Work Plan for the ITER Electromagnetic Assessments of ITER Magnets in Safety-Related Fault Conditions 


\section{Magnet Arcing (MAGARC) WFO Work Plan}

ITER: Electromagnetic Assessments of ITER Magnets in Safety-Related Fault Conditions

Culham Center for Fusion Energy

December $14^{\text {th }} 2015$

Brad J. Merrill

Fusion Safety Program Staff

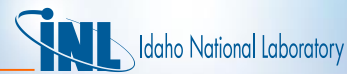

\section{Work plan and resource allocation overview (1/1)}

There are three tasks defined under this contract

- Task 1: Perform sensitivity study to investigate the convergence issues of the MAGARC code identified by Culham Center for Fusion Energy (CCFE)

- Task 2: Implement additional updates/modifications to the MAGARC code, including those required to model present ITER TF magnets, and produce a summary report comparing MAGARC capabilities with those of CCFE's magnet safety system

- Task 3: Consult with CCFE in performing benchmark activity with MAGARC software and supplying MAGARC code output data to CCFE and code to ITER IO 


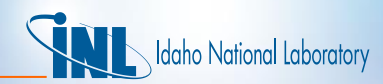

\section{Task 1 work plan and resource allocation (1/3)}

Activities defined under Task 1

Subtask 1: Submit a work containing the resource distribution estimated for each deliverable

- Subtask 2: Travel to Culham Science Centre (Abingdon, United Kingdom) for a meeting. At this one week long meeting, provide CCFE with details on MAGARC code's structure and models

Subtask 3: Perform the required code modifications that remedy the problems identified by the CCFE's sensitivity and produce a preliminary summary report on the improvements and updates to MAGARC software

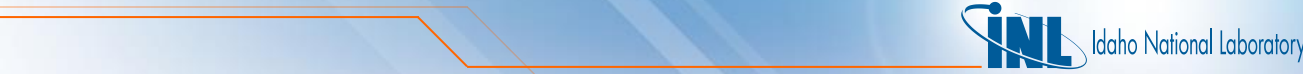

Task 1 work plan and resource allocation (2/3)

Task 1 Approach, Schedule and Estimate (or actual) Cost

- Subtask 1: Proposed Work Plan

- This presentation. Deliverable completed on 11/30/15

- Subtask 2: A presentation detailing MAGARC's capabilities was developed

Presentation at CCFE meeting on 11/30/15 and during follow on discussions the week $11 / 30 / 15$

- Cost $15 \%$ of contract ( $17 \mathrm{~h}$ labor + workshop travel cost), to be completed by $12 / 04 / 15$

- Subtask 3: Code modifications to correct inconsistent results with time-step size reduction and voltage spikes

- The Bi-Conjugate Gradient Krylov iterative method adopted for MAGARC, a powerful iterative solution algorithm for large sets of coupled linear differential equations, is also known to be numerically unstable, which lead to the voltage spikes reported by CCFE

- Problem resolved by coupling this scheme with a second more stable, but slower, Krylov algorithm known as the Generalized Minimum Residual method 


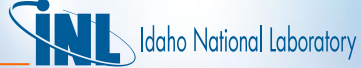

\section{Task 1 work plan and resource allocation (3/3)}

Task 1 Approach, Schedule and Estimate (or actual) Cost

- Subtask 3: Inconsistent results with time-step size reduction and voltage spikes (cont.)

- Variations with time step size is the result of time damping of resistivity changes during start of arcs $(90 \%$ old time $+10 \%$ new) and incomplete restoration of variables prior to repeating a given time step at a reduced value

The identified problems/changes have been completed to MAGARC $11 / 20 / 15$ and the CCFE sensitivity is underway

- Cost is $25 \%$ of contract ( $42 \mathrm{~h}$ labor)

Status $65 \%$ complete. Preliminary report by $1 / 30 / 16$.

\section{Task 2 work plan and resource allocation (1/2)}

Activities defined under Task 2

- Subtask 1: Become familiar with CCFE analysis package capabilities and report to CCFE on how it compares to MAGARC code

Cost $10 \%$ of contract ( $13 \mathrm{~h}$ labor) complete by $12 / 04 / 15$

- Subtask 2: Propose additional updates/modifications to MAGARC \& CCFE software models that would allow a more correct code comparisons

- Subtask 3: Perform the required code updates/modifications necessary to simulate the latest ITER Toroidal Field magnet's configuration

Cost $15 \%$ of contract ( $25 \mathrm{~h}$ labor) complete by $04 / 30 / 16$

- Subtask 4: Produce a final summary comparing MAGARC software and CCFE magnet safety analysis package capabilities, and detailing resulting MAGARC code improvements and updates

Cost is $20 \%$ of contract (32 h labor) to be completed 6/30/16 


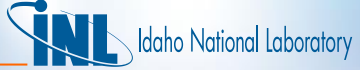

\section{Task 3 work plan and resource allocation (1/2)}

Activities defined under Task 3 (15\% of contract funding- $25 \mathrm{~h}$ labor)

- Subtask 1: Apply the updated MAGARC code to produce results (code output data) to be used by CCFE to benchmark their magnet analysis package

- Subtask 2: Provide an updated/modified version of MAGARC software to the ITER IO

\section{Task 3 work plan and resource allocation (2/2)}

Task 3 Approach, Schedule and Estimate (or actual) Cost

- Subtask 1: Apply the updated MAGARC code to produce results (code output data) to be used by CCFE to benchmark their magnet analysis package

- Cost $10 \%$ of contract (15 h labor) to completed prior to $3 / 31 / 16$

- Subtask 2: Subtask 2: Provide an updated/modified version of MAGARC software to the ITER IO and remotely attend a closeout meeting

Cost $5 \%$ of contract ( $10 \mathrm{~h}$ labor) to completed prior to $06 / 30 / 16$ 


\section{Costs \& Schedule of MAGARC WFO}

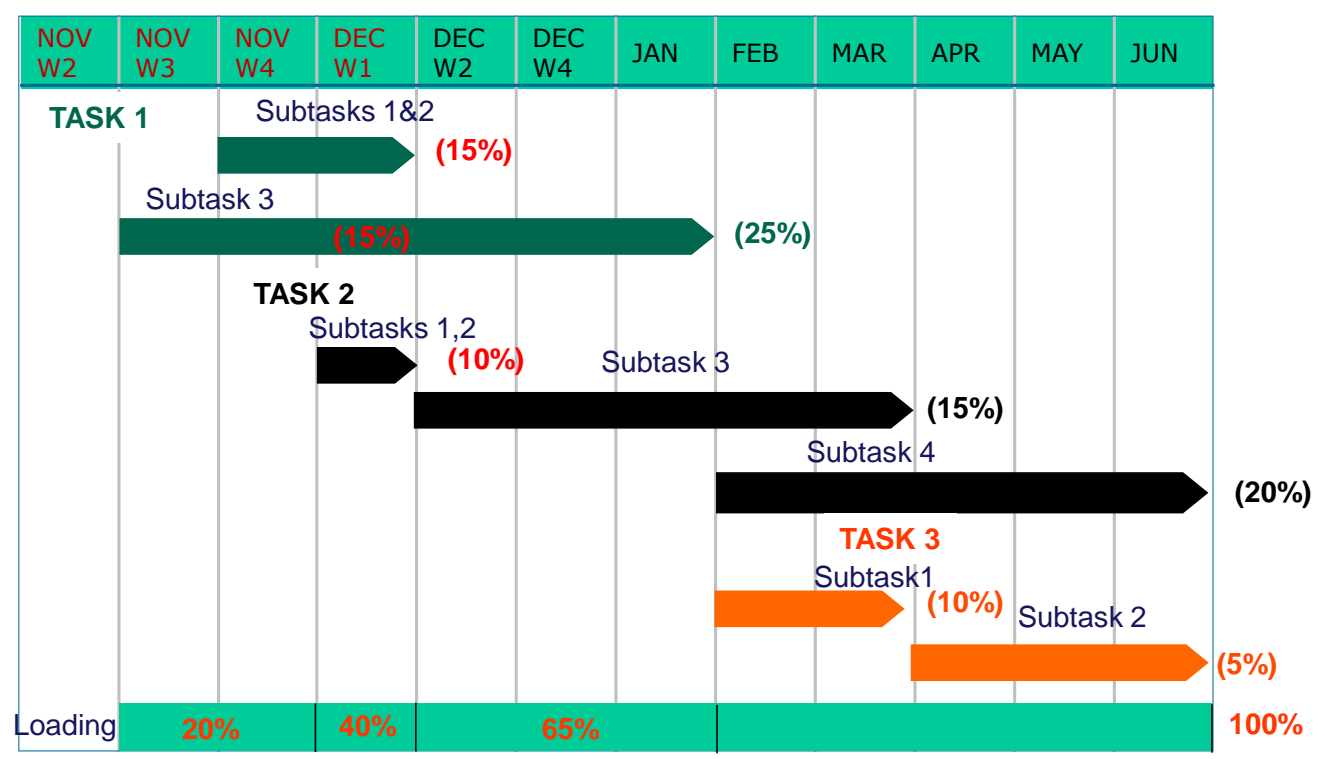

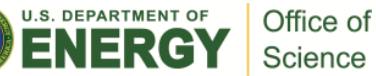


Appendix B

Overview of the Magnet Arcing (MAGARC) Computer Code for Toroidal Field Coils Capabilities 


\section{Magnet Arcing (MAGARC) Computer Codes Capabilities}

ITER: Electromagnetic Assessments of ITER Magnets in Safety-Related Fault Conditions

Culham Center for Fusion Energy November $30^{\text {th }}, 2015$

Brad J. Merrill

INL Fusion Safety Program, Idaho Falls, ID USA

\section{Presentation Outline}

- MAGARC heat conduction equations

- Thermal properties

- Thermal model validation

- MAGARC electromagnetic equations

- Electrical properties

- EM model validation

- Arc modeling: voltages, area, progression, limits on gap arcs

- Applications of MAGARC to ITER-FEAT TF Magnet Coil 


\section{MAGARC Heat Conduction Model}

- Conductor thermal model

$$
\rho c_{p} \frac{\partial T}{\partial t}=\frac{1}{r} \frac{\partial}{\partial r}\left(r k \frac{\partial T}{\partial r}\right)+\frac{\partial}{\partial z}\left(k \frac{\partial T}{\partial z}\right)+q
$$

- Finite difference (1-1/2 D) applied to windings of all pancakes in the direction of current flow

$\int_{k} \rho c_{p} \frac{\partial T}{\partial t} 2 \pi r d r d z \approx\left(\rho_{c u_{k}} c_{p_{c u_{k}}} V_{c u_{k}}+\rho_{s c_{k}} c_{p_{s c_{k}}} V_{s c_{k}}\right) \frac{T_{c+k}^{n+1}-T_{c c_{k}}^{n}}{t^{n+1}-t^{n}}$

$\int_{k}^{1} \frac{1}{r} \frac{\partial}{\partial r}\left(r k_{r} \frac{\partial T}{\partial r}\right) 2 \pi r d r d z \approx-\frac{2 \pi\left(z_{k+1 / 2}-z_{k-1 / 2}\right)\left(\left(_{c r_{k}}^{n+1}-T_{i j k}^{n}\right)\right.}{\left[\ln \left(\frac{r_{j k t}}{r_{c u}}\right) / k_{j k t}+\ln \left(\frac{r_{i n}}{r_{j k t}}\right) / k_{i n}\right]}$

$\int_{k} \frac{\partial}{\partial z}\left(k \frac{\partial T}{\partial z}\right) 2 \pi r d r d z \approx A_{c u}\left[k_{c u_{k+1 / 2}}\left(\frac{T_{c_{k+1}^{+1}}^{n+1}-T_{c c_{k}}^{n+1}}{z_{k+1}-z_{k}}\right)-k_{c u_{k-1 / 2}}\left(\frac{T_{c_{k}}^{n+1}-T_{c r_{k-1}}^{n+1}}{z_{k}-z_{k-1}}\right)\right]$

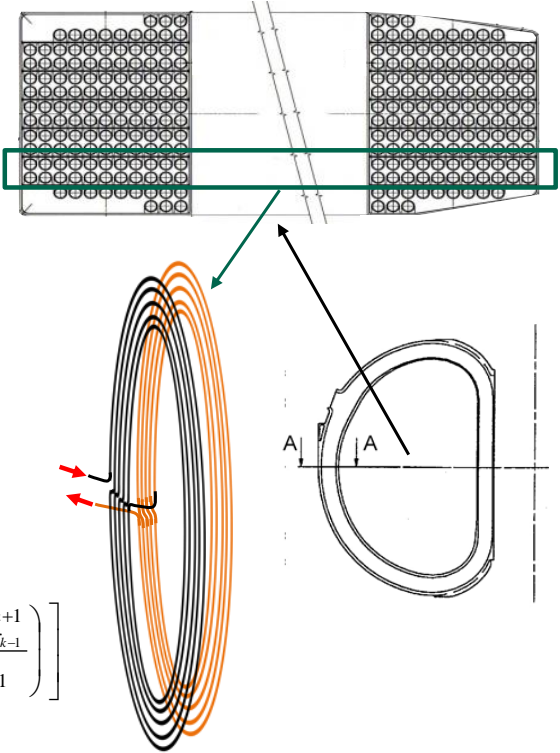

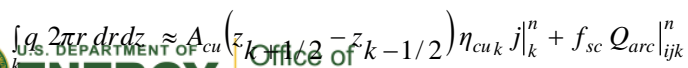

ENERCY Science

Pancake windings

Fusion Safety Program

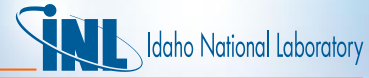

\section{MAGARC Heat Conduction Model (cont.)}

- Structure model (radial plates/coil case)

$$
\rho c_{p} \frac{\partial T}{\partial t}=\frac{\partial}{\partial x}\left(k \frac{\partial T}{\partial x}\right)+\frac{\partial}{\partial y}\left(k \frac{\partial T}{\partial y}\right)+\frac{\partial}{\partial z}\left(k \frac{\partial T}{\partial z}\right)+q
$$

- Finite difference in Cartesian coordinates

$$
\rho_{i j k} c_{p_{i j k}}\left(\frac{T_{i j k}^{n+1}-T_{i j k}^{n}}{t^{n+1}-t^{n}}\right)=\frac{1}{x_{i+1 / 2}-x_{i-1 / 2}}\left(k_{i+1 / 2} \frac{T_{i+1 j k}^{n+1}-T_{i j k}^{n+1}}{x_{i+1}-x_{i}}-k_{i-1 / 2} \frac{T_{i j k}^{n+1}-T_{i-1 j k}^{n+1}}{x_{i}-x_{i-1}}\right)
$$

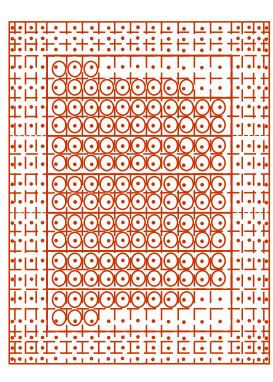

$$
+\frac{1}{y_{j+1 / 2}-y_{j-1 / 2}}\left(k_{j+1 / 2} \frac{T_{i j+1 k}^{n+1}-T_{i j k}^{n+1}}{y_{j+1}-y_{j}}-k_{j-1 / 2} \frac{T_{i j k}^{n+1}-T_{i j-1 k}^{n+1}}{y_{j}-y_{j-1}}\right)
$$$$
+\frac{1}{z_{k+1 / 2}-z_{k-1 / 2}}\left(k_{k+1 / 2} \frac{T_{i j k+1}^{n+1}-T_{i j k}^{n+1}}{z_{k+1}-z_{k}}-k_{k-1 / 2} \frac{T_{i j k}^{n+1}-T_{i j k-1}^{n+1}}{z_{k}-z_{k-1}}\right)+q_{i j k}
$$

$q_{i j k} V_{i j k}=\frac{2 \pi\left(z_{k+1 / 2}-z_{k-1 / 2}\right)\left(T_{c_{k}}^{n+1}-T_{i j k}^{n}\right)}{\left[\ln \left(\frac{r_{j k t}}{r_{c u}}\right) / k_{j k t}+\ln \left(\frac{r_{i n}}{r_{j k t}}\right) / k_{i n}\right]}+\left.\left(1-f_{s c}\right) Q_{a r c}\right|_{i j k}+\left.Q_{r e s}\right|_{i j k}$

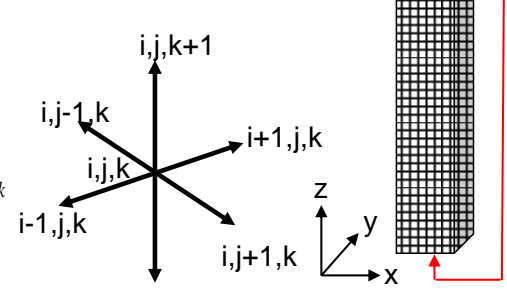

$\mathrm{i}, \mathrm{j}, \mathrm{k}-1$

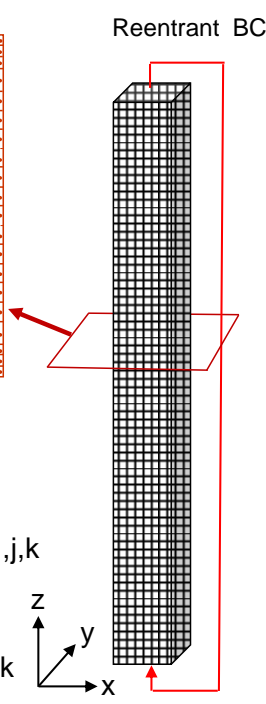




\section{MAGARC Thermal Properties}

- The $\mathrm{Nb}_{3} \mathrm{Sn}$ specific heat capacity in MAGARC is volume weighted with the SS conduit

- Cu and SS heats of fusion are added over $1 \mathrm{~K}$ to specific heat capacities at melting [Cu 205 $\mathrm{kJ} / \mathrm{kg}(356 \mathrm{~K}), \mathrm{SS} 270 \mathrm{~kJ} / \mathrm{kg}$ (1643)]

- Cu and SS heats of vaporization are added over $1 \mathrm{~K}$ to specific heat capacities at $4500 \mathrm{~K}$ (approximate liquid $\mathrm{Fe} \mathrm{T}_{\text {sat }}$ at Kronhardt measured pressure of $120 \mathrm{bar}$ of $\mathrm{Cu} 4790 \mathrm{~kJ} / \mathrm{kg}$ and $\mathrm{Fe} 7440 \mathrm{~kJ} / \mathrm{kg}$

- There is no $\mathrm{Nb}_{3} \mathrm{Sn}$ thermal conductivity used in MAGARC. The value plotted could be the conduction shape factor times SS thermal conductivity

- GE thermal conductivity is from: G. Schmidt, R. Meyder, "Final Report on Thermal Insulation Experiments," FZR-IRS, GB8SEA5A (Sept01) 2001 (includes the dip at $600 \mathrm{~K}$ )

(2) U.S. DEPARTMENT OF

\section{ENERGY}

$q_{x}=$

Sumine

\section{Material properties comparison}

\section{- Thermal}
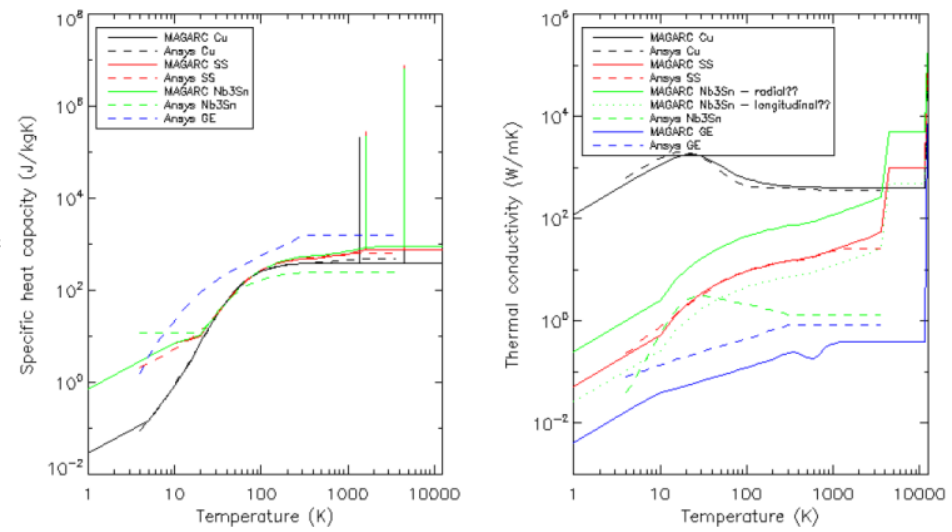

$\$$ CCFE

\section{Benchmarking of MAGARC Heat Conduction Model}

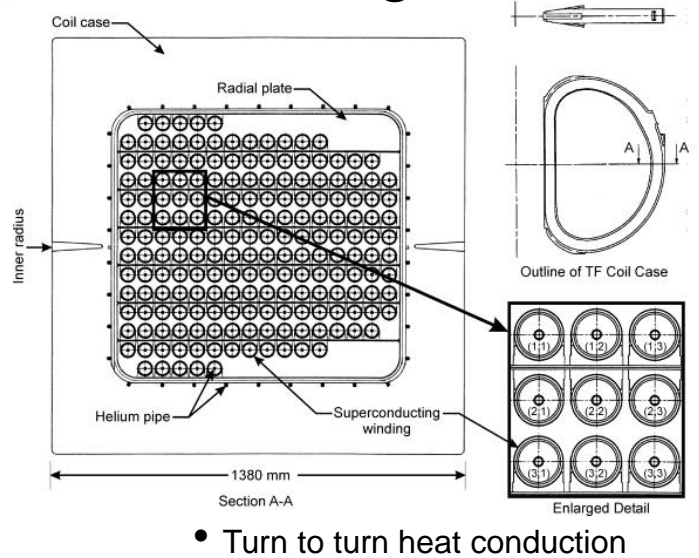

Table 1. Finite element model (FEM) benchmark of INL unmitigated TF magnet quench model (MAGARC)

\begin{tabular}{|c|c|c|c|c|}
\hline \multirow[b]{2}{*}{$\begin{array}{l}\text { Cable Space } \\
\text { Temperature }\end{array}$} & \multirow[b]{2}{*}{ Model } & \multicolumn{3}{|c|}{ Cable Space Indicator } \\
\hline & & $\begin{array}{c}(2,1) \&(2,3) \\
W / m\end{array}$ & $\begin{array}{l}(1,2) \\
W / m\end{array}$ & $\begin{array}{c}(3,2) \\
W / m\end{array}$ \\
\hline \multirow[b]{2}{*}{$50 \mathrm{~K}$} & FEM & 40 & 33 & 19 \\
\hline & MAGARC & 40.8 & 34.2 & 19.1 \\
\hline \multirow[b]{2}{*}{$150 \mathrm{~K}$} & FEM & 215 & 180 & 90 \\
\hline & MAGARC & 200.1 & 177.4 & 108.0 \\
\hline
\end{tabular}

(2) U.S. DEPARTMENT OF Office of
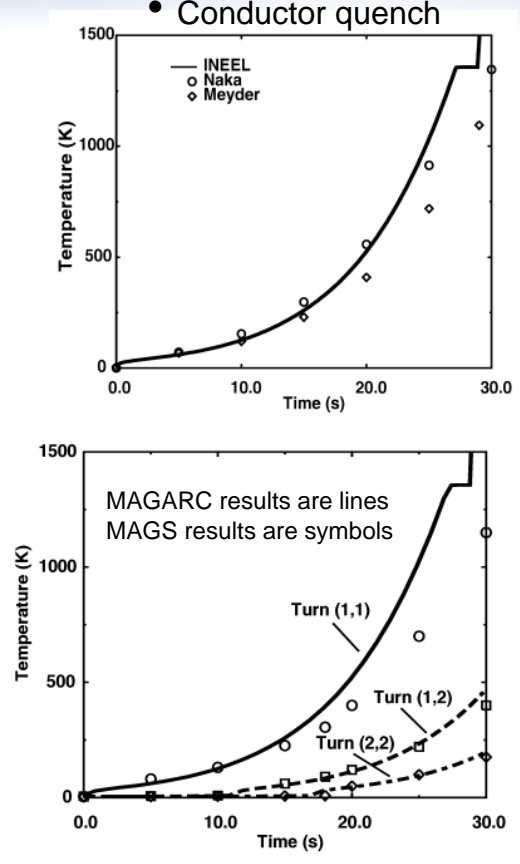


\section{Vector Potential form of Maxwell Equations for Low Frequency Applications}

$$
\text { Assumes: } \frac{\partial \vec{E}}{\partial t}=0 \quad \overrightarrow{\mathrm{E}}=-\nabla \phi-\frac{\partial \overrightarrow{\mathrm{A}}}{\partial \mathrm{t}}
$$

Magnetic vector potentials

$$
\nabla^{2} \overrightarrow{\mathrm{A}}-\nabla(\nabla \cdot \overrightarrow{\mathrm{A}})=\mu \sigma\left(\nabla \phi+\frac{\partial \overrightarrow{\mathrm{A}}}{\partial \mathrm{t}}\right)-\mu \overrightarrow{\mathrm{j}}_{\mathrm{a}}
$$

Scalar potential (voltage) from conservation of current

$$
\nabla \cdot \sigma \nabla \phi=\nabla \cdot \overrightarrow{\mathrm{j}}_{\mathrm{a}}
$$

\section{Vector Potential form of Maxwell Equations for Low Magnetic Reynolds Number (cont.)}

Applying the Divergence Theorem $\iiint_{\mathrm{V}} \nabla \cdot \overrightarrow{\mathrm{F}} \mathrm{dv}=\oiint_{S} \vec{F} \cdot \hat{n} d s$ to

$\nabla \cdot \sigma \nabla \phi=\nabla \cdot \overrightarrow{\mathrm{j}}_{\mathrm{a}}$

$\iiint_{\mathrm{V}}\left(\nabla \cdot \sigma(\nabla \phi)-\nabla \cdot \overrightarrow{\mathrm{j}}_{\mathrm{a}}\right) \mathrm{dv}=$

$\left.\frac{\sigma_{x} a_{x} \Delta \phi}{\Delta x}\right|_{+}-\left.\frac{\sigma_{x} a_{x} \Delta \phi}{\Delta x}\right|_{-}+\left.\frac{\sigma_{y} a_{y} \Delta \phi}{\Delta y}\right|_{+}-\left.\frac{\sigma_{y} a_{y} \Delta \phi}{\Delta y}\right|_{-}+\left.\frac{\sigma_{z} a_{z} \Delta \phi}{\Delta z}\right|_{+}-\left.\frac{\sigma_{z} a_{z} \Delta \phi}{\Delta z}\right|_{-}$

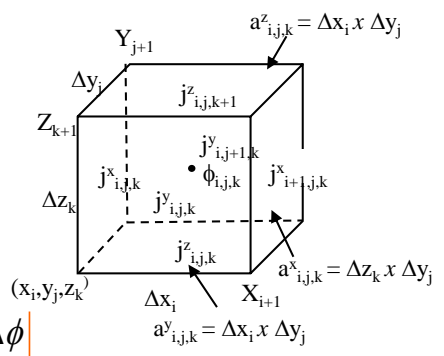

$+\left.a_{x} j_{x}^{a}\right|_{+}-\left.a_{x} j_{x}^{a}\right|_{-}+\left.a_{y} j_{y}^{a}\right|_{+}-\left.a_{y} j_{y}^{a}\right|_{-}+\left.a_{z} j_{z}^{a}\right|_{+}-\left.a_{z} j_{z}^{a}\right|_{-}=0$

This is the original MAGARC node voltage formulation, e.g.

$R_{z}=\Delta z / \sigma_{z} a_{z}$, where $j_{x}{ }^{a}$ and $j_{y}{ }^{a}=0$ and $j_{z}{ }^{a}$ is the applied current densities resulting from bypass arcs out of or into the superconductor

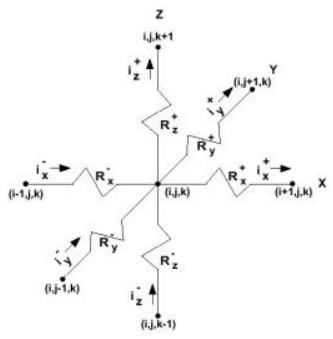




\section{Vector Potential form of Maxwell Equations for Low Magnetic Reynolds Number (cont.)}

Equation solution starts each time step by solving for the electric potential $(\phi)$ based on current arcs into and out of the superconductor. Given $\phi$ the magnetic vector potentials are advanced from the following three system of equations

$$
\begin{aligned}
& \left(\frac{\partial^{2} \mathrm{~A}_{\mathrm{x}}}{\partial x^{2}}+\frac{\partial^{2} \mathrm{~A}_{\mathrm{x}}}{\partial y^{2}}+\frac{\partial^{2} \mathrm{~A}_{\mathrm{x}}}{\partial z^{2}}\right)^{\mathrm{n}+1}-\nabla(\nabla \cdot \overrightarrow{\mathrm{A}})_{x}^{n}=\mu \sigma_{\mathrm{x}}\left(\frac{\partial \phi^{n+1}}{\partial x}+\frac{\partial \mathrm{A}_{x}}{\partial \mathrm{t}}\right) \\
& \left(\frac{\partial^{2} \mathrm{~A}_{\mathrm{y}}}{\partial x^{2}}+\frac{\partial^{2} \mathrm{~A}_{\mathrm{y}}}{\partial y^{2}}+\frac{\partial^{2} \mathrm{~A}_{\mathrm{y}}}{\partial z^{2}}\right)^{\mathrm{n}+1}-\nabla(\nabla \cdot \overrightarrow{\mathrm{A}})_{y}^{n}=\mu \sigma_{\mathrm{y}}\left(\frac{\partial \phi^{n+1}}{\partial y}+\frac{\partial \mathrm{A}_{y}}{\partial \mathrm{t}}\right) \\
& \left(\frac{\partial^{2} \mathrm{~A}_{\mathrm{z}}}{\partial x^{2}}+\frac{\partial^{2} \mathrm{~A}_{\mathrm{z}}}{\partial y^{2}}+\frac{\partial^{2} \mathrm{~A}_{\mathrm{z}}}{\partial z^{2}}\right)^{\mathrm{n}+1}-\nabla(\nabla \cdot \overrightarrow{\mathrm{A}})_{z}^{n}=\mu \sigma_{\mathrm{z}}\left(\frac{\partial \phi^{n+1}}{\partial z}+\frac{\partial \mathrm{A}_{z}}{\partial \mathrm{t}}\right)-\mu \mathrm{j}_{\mathrm{z}}^{\mathrm{sc}}
\end{aligned}
$$

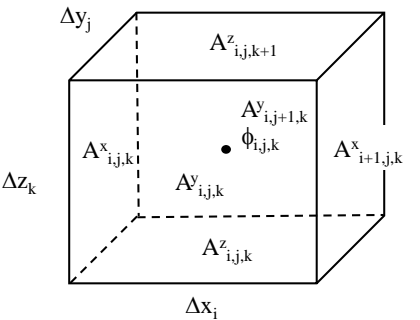

- This formulism was chosen because it allowed for ease in specifying boundary conditions and selecting the Coulomb gauge by setting $\nabla \cdot \vec{A}=\mathbf{0}$ if desired.

- Magnetic vector BCs from Biot-Savart Law

\section{MAGARC Electrical Properties}

\section{Material properties comparison}

\section{- Electric}

- Good match for Cu and SS

- ANSYS model does not have GE resistivity?

- GE thermal conductivity is from: G. Schmidt, R. Meyder, "Final Report on Thermal Insulation Experiments," FZR-IRS, GB8 SEA5A (DECO0) January 2001

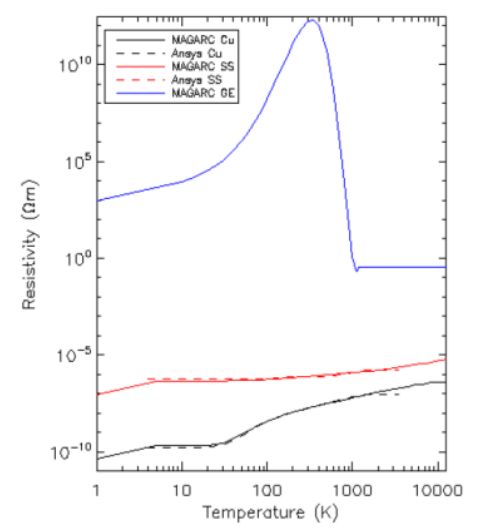




\section{Fusion Safety Program}

PNL Idaho National Laboratory

\section{Test Case - Magnet Startup \\ A Step change in magnet current to $68 \mathrm{kA}$}

- MAGARC current was set at $68 \mathrm{kA}$ and a transient solution executed until an equilibrium was achieved

- The Diagonally Preconditioned Bi-conjugate Gradient method was used to solve the equation set

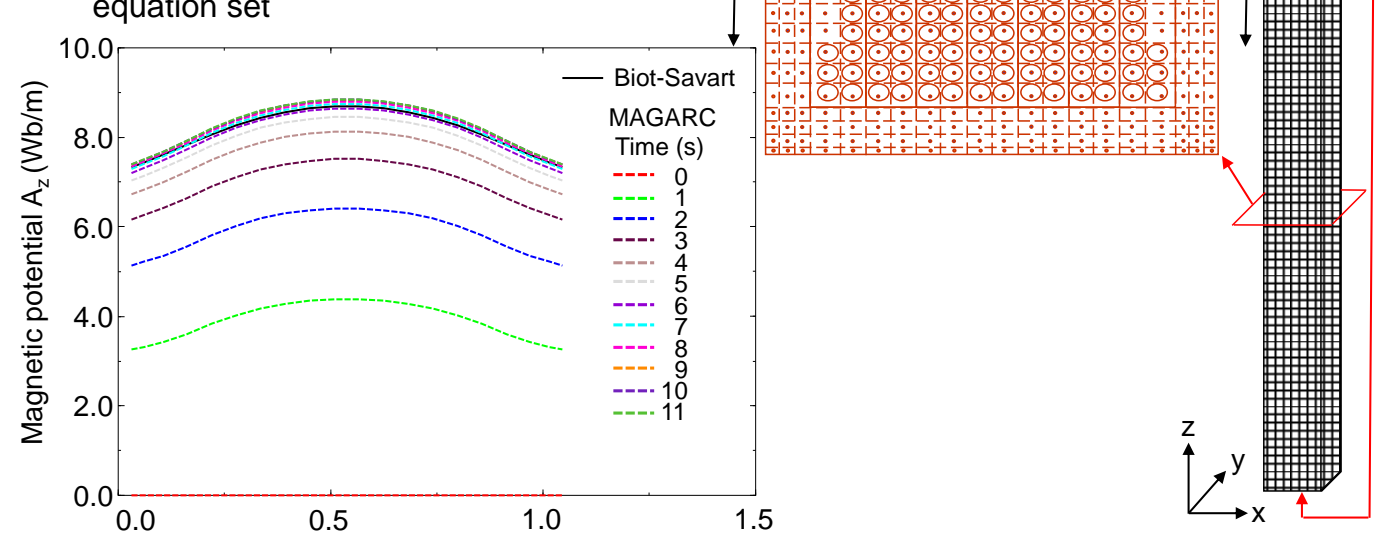

Toroidal or $x$ distance $(m)$
u.s. DEPARTMENT OF Office of

\section{Attempt to Include Magnetic Field from Other}

\section{ITER TF Coils}

Plot Grid schematic

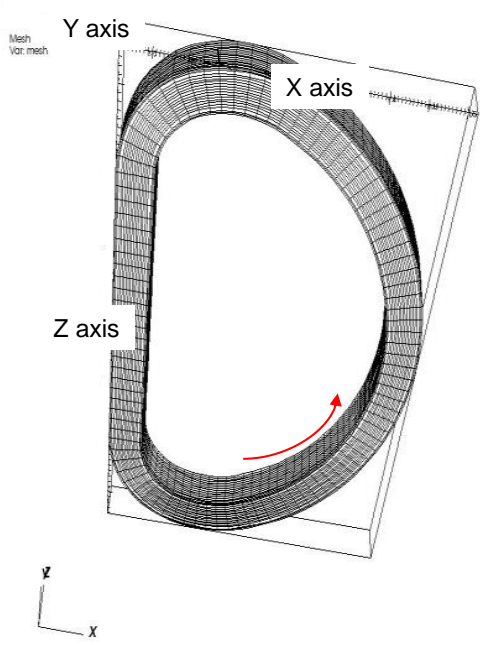

- MAGARC boundary conditions calculated by Biot-Savart law including all of the ITER TF coils

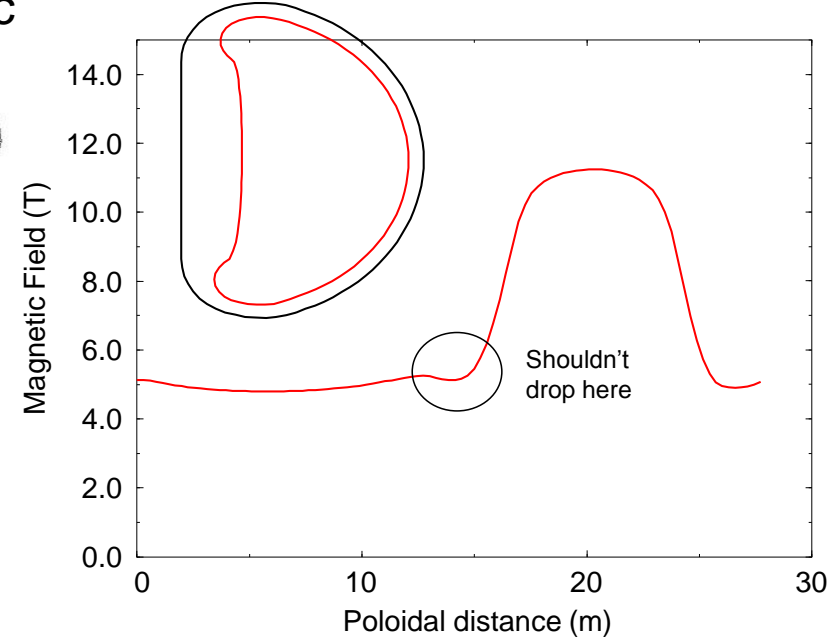

- Encouraging result for a rectilinear grid, if the boundary conditions can be correctly applied, because the magnet quench properties are a function of field strength 


\section{Preliminary Energy Conservation Test}

- Poynting's Theorem

$\frac{\partial}{\partial \mathrm{t}} \int_{\mathrm{V}} \mathrm{udV}+\int_{\mathrm{S}} \mathrm{n} \cdot \mathrm{Pda}+\int_{\mathrm{V}} \mathrm{J} \cdot \mathrm{EdV}=\mathrm{I}_{\mathrm{a}} \mathrm{V}_{\mathrm{a}}$

where

$$
\mathrm{u}=\frac{\mathbf{1}}{\mathbf{2}}\left(\varepsilon_{\mathrm{o}} \mathrm{E}^{2}+\frac{\mathrm{B}^{2}}{\mu_{\mathrm{o}}}\right) ; \mathrm{P}=\frac{\mathbf{1}}{\mu_{\mathrm{o}}} \mathrm{E} \times \mathrm{B}
$$

- Energy error calculated as:

$E_{r}=\mathbf{1} \cdot-\left(\frac{\partial}{\partial t} \int_{V} u d V+\int_{S} n \cdot P d a+\int_{V} J \cdot E d V\right) / I_{a} V_{a}$
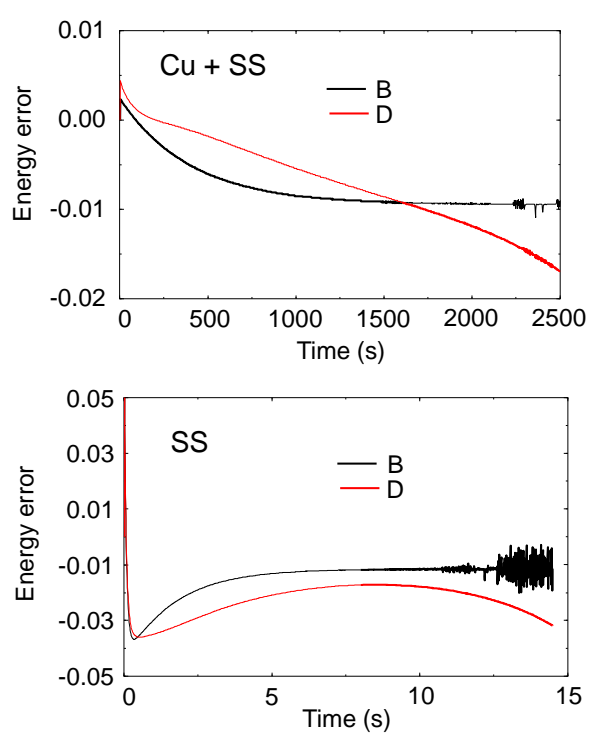

Fusion Safety Program Idaho National Laboratory

\section{MAGARC Internal Arc Model}

- Kronhardt's data - encased superconducting cable with arc currents ranaina from 700 to $5000 \mathrm{~A}$

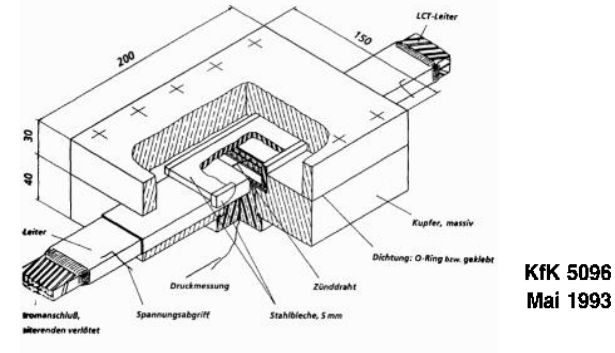

3.4: Druckkammer zur Untersuchung rabumlich eingeschlossener Lichtbōgen.

Einfluß von Kurzschlüssen und Lichtbögen auf die Sicherheit von Magnetsystemen

H. Kronhard Institut für Technische Physik Projekt Kernfusion
$E_{\mathrm{A}}=A+\frac{B}{j^{\mathrm{n}}}=1,75+\frac{0,012}{j^{-1,75}} \quad(\mathrm{~V} / \mathrm{mm})$

(5.4.1a)

bzw.

$U_{\mathrm{A}}=75+\frac{0,24}{j^{-1,75}}(V)$

(5.4.1b)

ITER Relevant

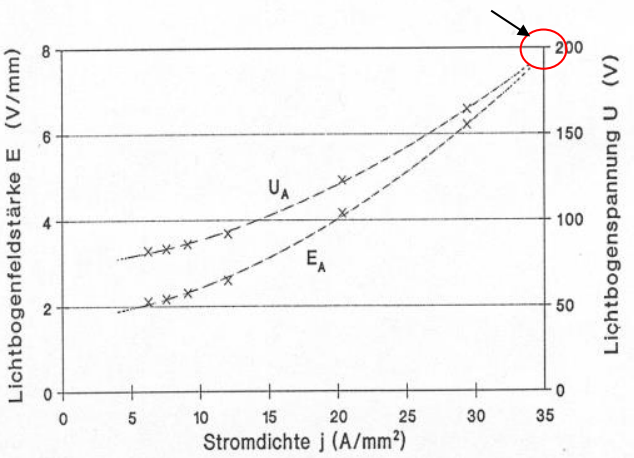

Abb. 5.5: Abhängigkeit der Lichtbogenfeldstärke $\mathrm{E}_{\mathrm{A}}$ und der Anfangsbogenspannung $\mathrm{U}_{\mathrm{A}}$ von der Stromdichte: $\mathrm{x}$ - Meßwerte, --.-- Approximation nach Gl. 5.4.1a,b 


\section{MAGARC Internal Arc Model (cont.)}

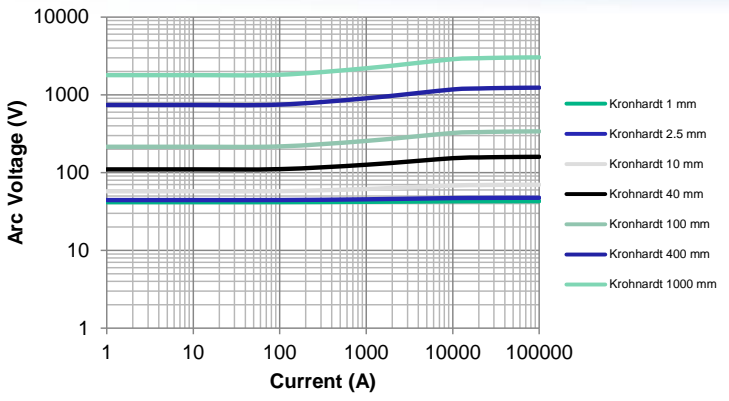

- MAGARC arc voltage vs. gap width and current density (inline or gap arcs)

$\mathrm{V}_{\mathrm{arc}}=\mathrm{V}_{\mathrm{O}}+\Delta_{\mathrm{g}}\left(1.75+0.012 \mathrm{j}^{1.75}\right)$

- MAGARC arc area vs. arc current, derived from Table 5.1 of Kronhardt

$$
\mathrm{A}_{\mathrm{arc}}\left(\mathrm{mm}^{2}\right)=63.8+0.07 \times \mathrm{I}(\mathrm{amps})
$$

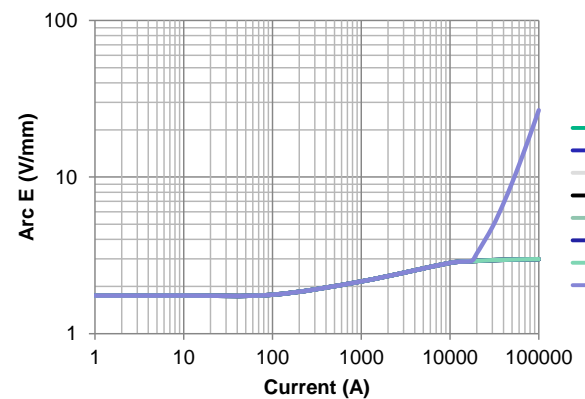

- MAGARC arc resistance

$$
\mathrm{R}_{\mathrm{arc}}=\frac{\mathrm{V}_{\mathrm{arc}}}{\mathrm{A}_{\text {arc }} \mathrm{j}_{\mathrm{arc}}}
$$

- High arc pressures were generated in Kronhardt's tests, implying superheated copper relative to atmospheric conditions

\section{MAGARC Arc Progression Logic}

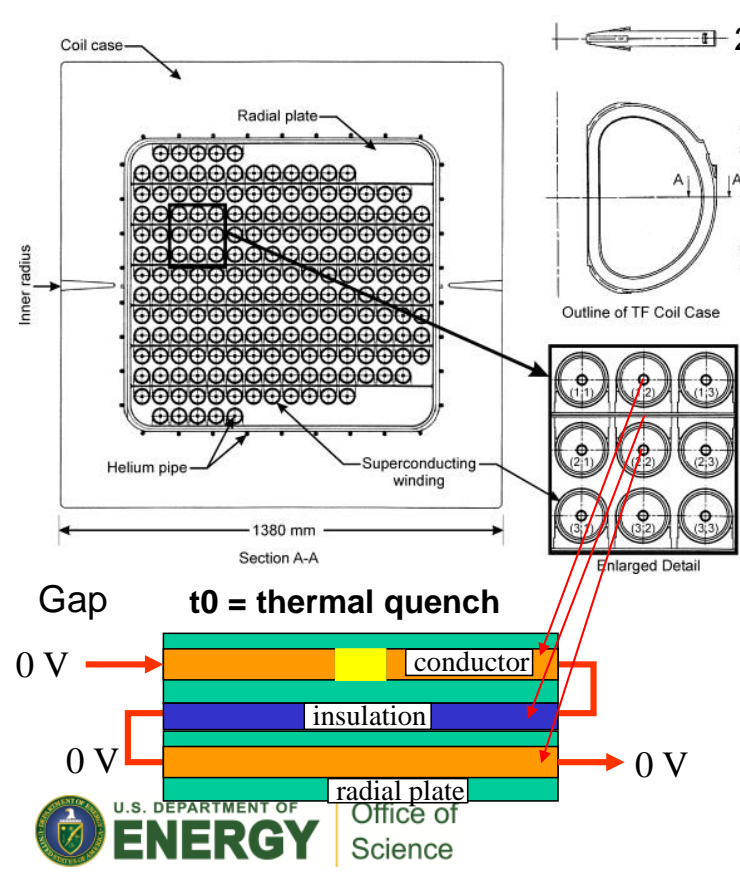

t1 = inline arc

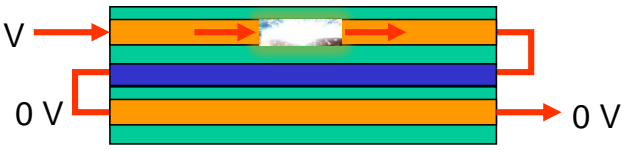

t2 = inline arc grows \& splits into two bypass arcs after voltage exceeds $400 \mathrm{~V}$

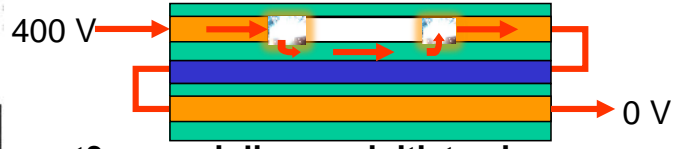

t3 = new inline arc initiates in adjacent pancake, V climbs to $600 \mathrm{~V}$

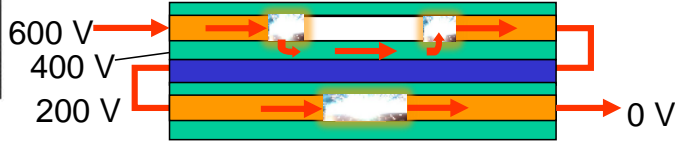

T4 = gap arcs form between pancakes, $\mathrm{V}$ drops from current sharing

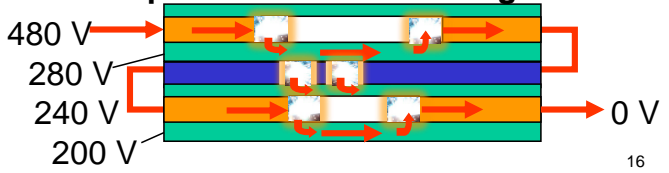




\section{MAGARC Inline and Bypass Arc Search Logic}
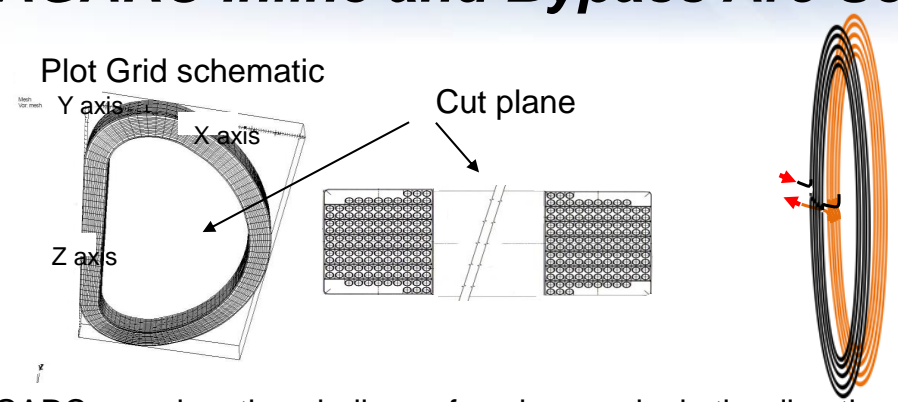

- MAGARC searches the windings of each pancake in the direction of current starting at the inlet and against the current starting at the outlet, storing the locations it first encounters copper melt (arc velocity equals conductor melt progression, Kronhardt arc velocity is an alternative)

- If the two locations are the same in a given pancake, then an inline arc exist for that pancake and if not then two bypass arcs exist

- The first melt location in the direction of the current for pancakes 1-7 and in the direction opposite current in pancakes 7-1 are arc locations where the total current enters and leaves the structural voltage network, respectively

- When adjacent pancakes contain arcs, a "bridge resistor" is applied to represent the intact turns from the arc out location in the first to the arc in location in the second (resistance equals voltage drop of two arcs)

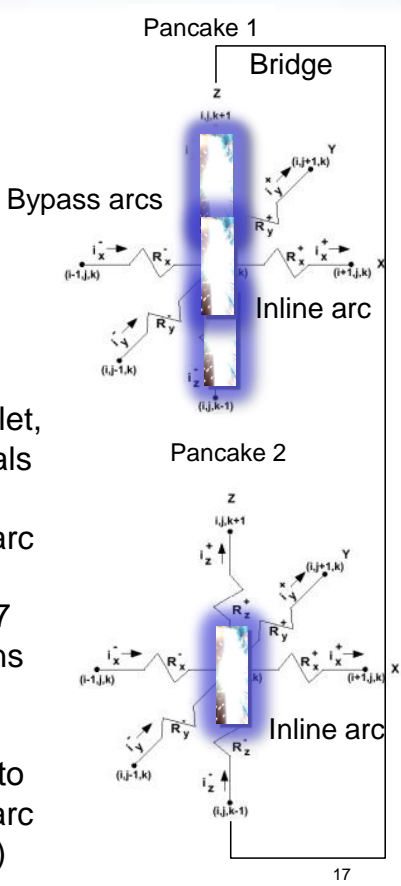

एक

Fusion Safety Program

III Iaho National Laboratory

\section{MAGARC Parallel Gap Arc Limit Logic}

*J. Raeder: Electric arcs external to ITER

magnet coils - synthesis of model

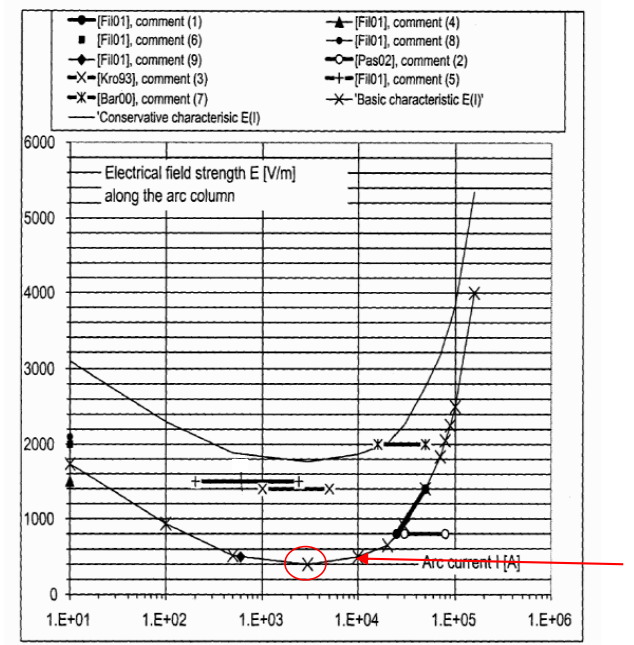

Figure 3-5: 'Conservative characteristic' of an arc (open circles) based on all data in Table 2.1-1. The 'basic characteristic' according to Figure 3-4 and all underlying data are also shown.

*IDOMS: G 83 MD5 02-10-14 W.1

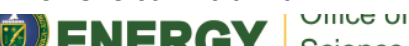

- Gap arcs can form between the adjacent TF radial plates, or between the radial plate and coil case.

- Arcs initiate once the gap temperature exceeds insulation failure temperature $\left(900^{\circ} \mathrm{C}\right)$, provided the gap voltage drop exceeds the user specified minimum, and the number of arcs in this gap does not exceed the number that can be sustained

- The criterion adopted for the number of sustainable arcs is the 'Steenbeck minimum principle' which is that electric arcs have the tendency to minimize their burn voltage

- Raeder's memo proposed that the minimum electric field occurs at a current of $\sim 3 \mathrm{kA}$

- For a given gap, a single arc is first initiated that grows until reaching $6 \mathrm{kA}$, where upon two $3 \mathrm{kA}$ arcs form, until a maximum is obtained for that gap (e.g., if conditions dictate, a magnet current of $68 \mathrm{kA}$ limits a common gap to 22 arcs)

- During arc extinction, the order is first on last out 


\section{MAGARC Applied to ITER-FEAT TF Coil}

Plot Grid schematic

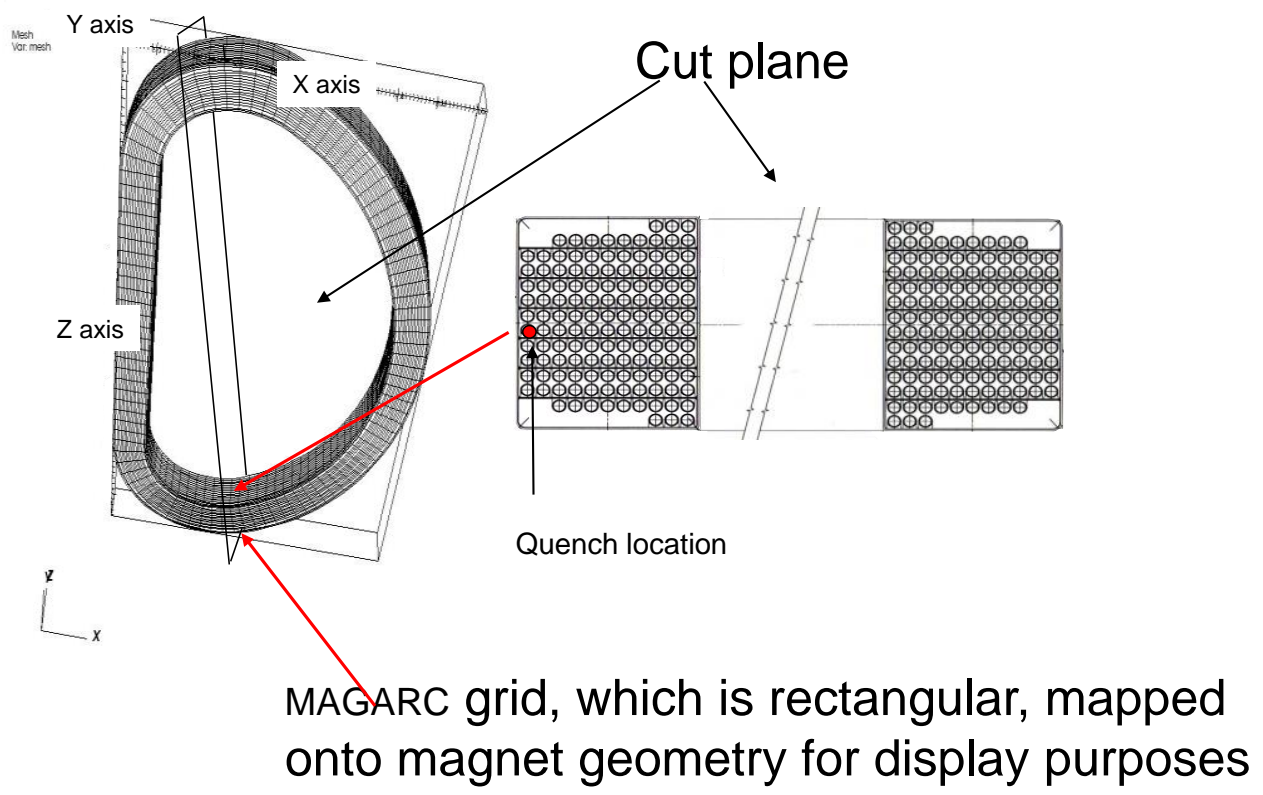
onto magnet geometry for display purposes

\section{u.s. Department of Office of $(40,000$ cells $)$}

\section{Melt Progression During an Unmitigated Quench in a TF Coil}

\section{Plot Grid schematic}

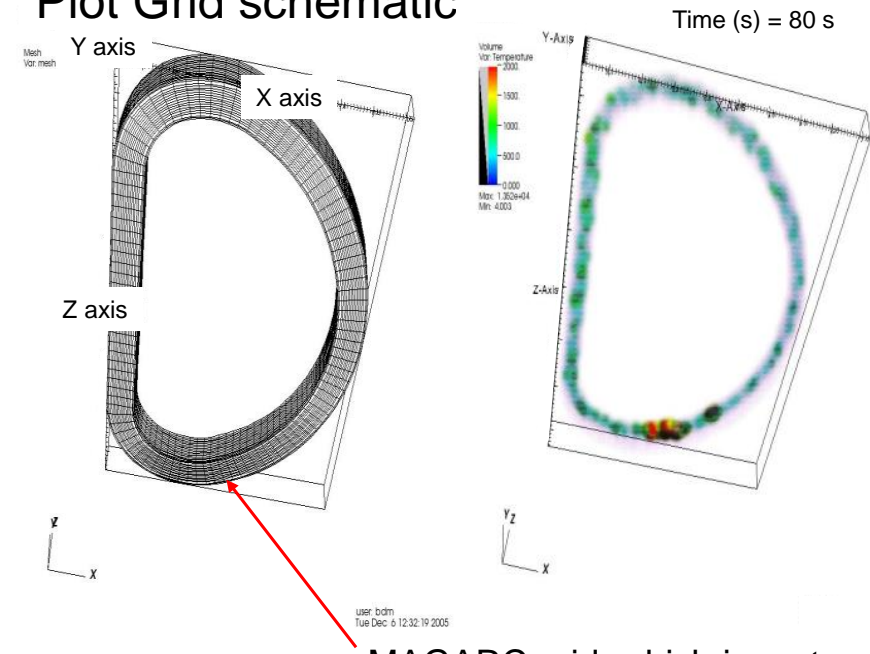

MAGARC grid, which is rectangular, mapped onto magnet geometry for display purposes

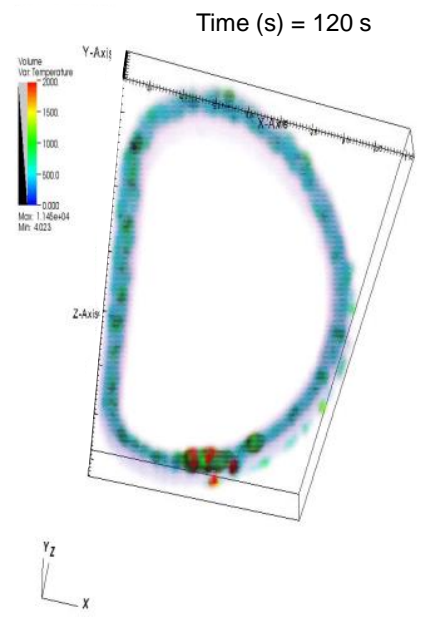


Fusion Safety Program

III daho National Laboratory

\section{Summary Plots - TF Coil Unmitigated Quench}
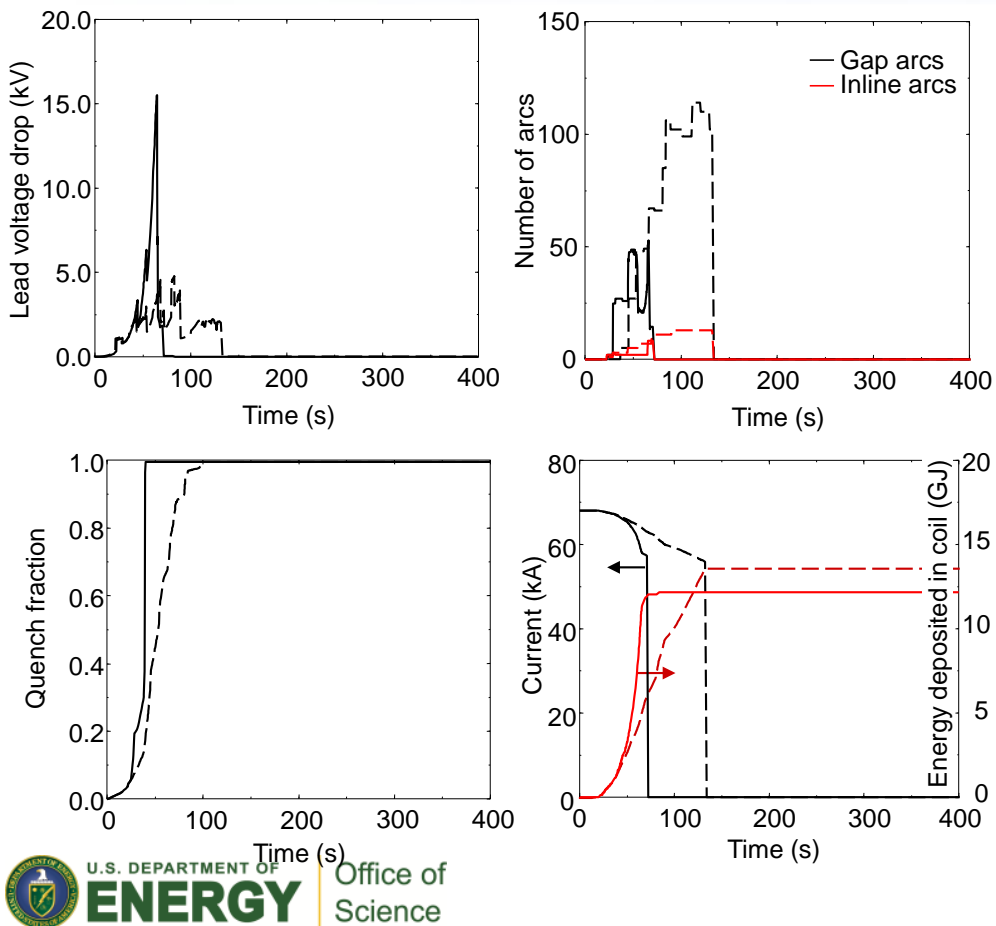

- MAGARC comparison

— with magnetics

-- without magnetics

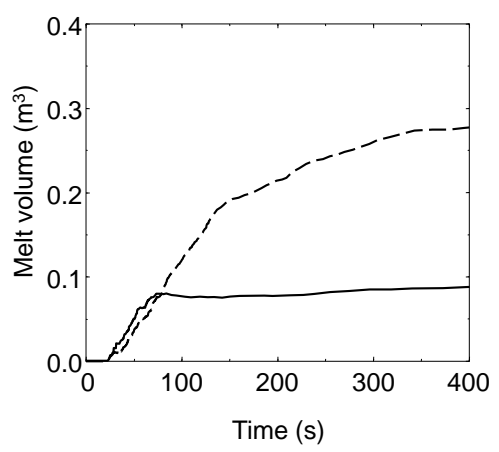

- Primary difference is a faster magnet quench due to induced eddy currents 
Appendix C

\section{MAGARC Computer Code Changes Addressing Time- step Size Sensitivity Problems}




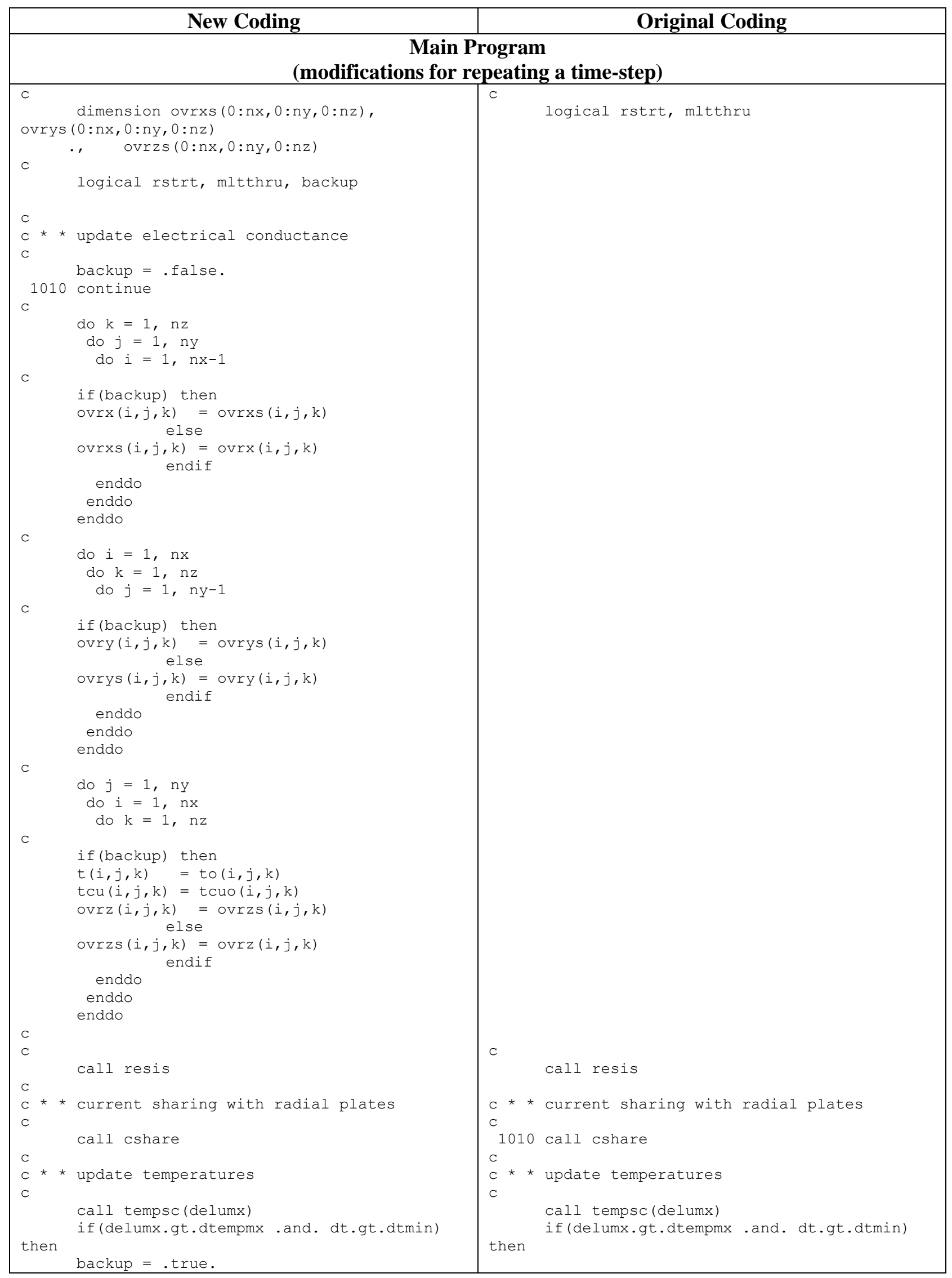




\begin{tabular}{|c|c|}
\hline 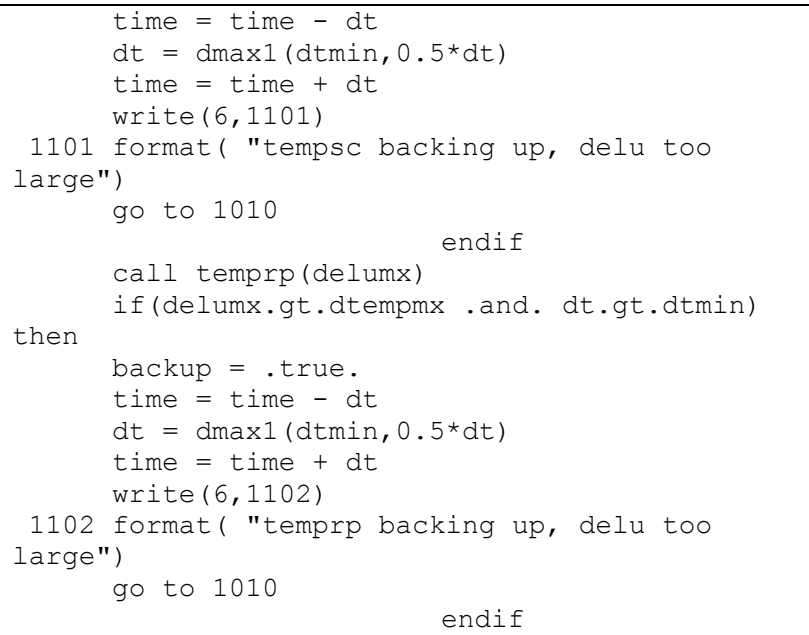 & 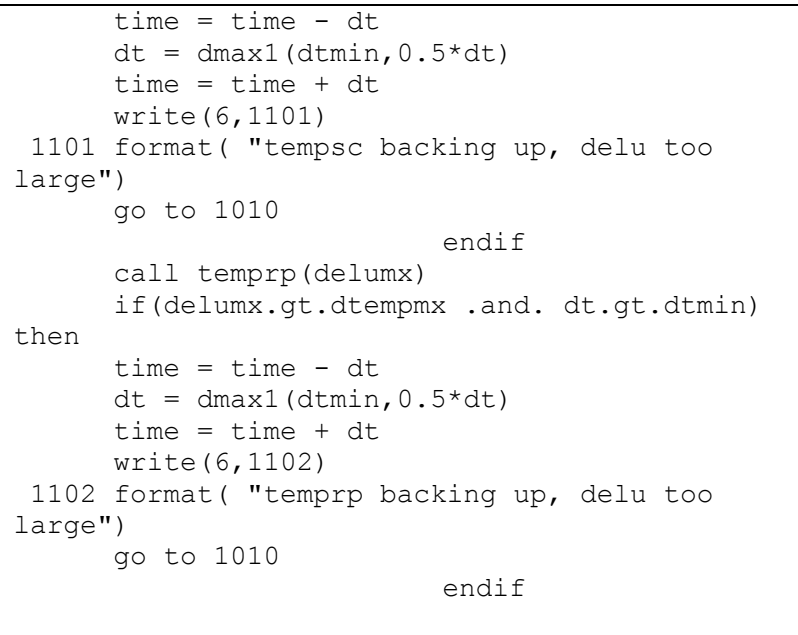 \\
\hline & \\
\hline 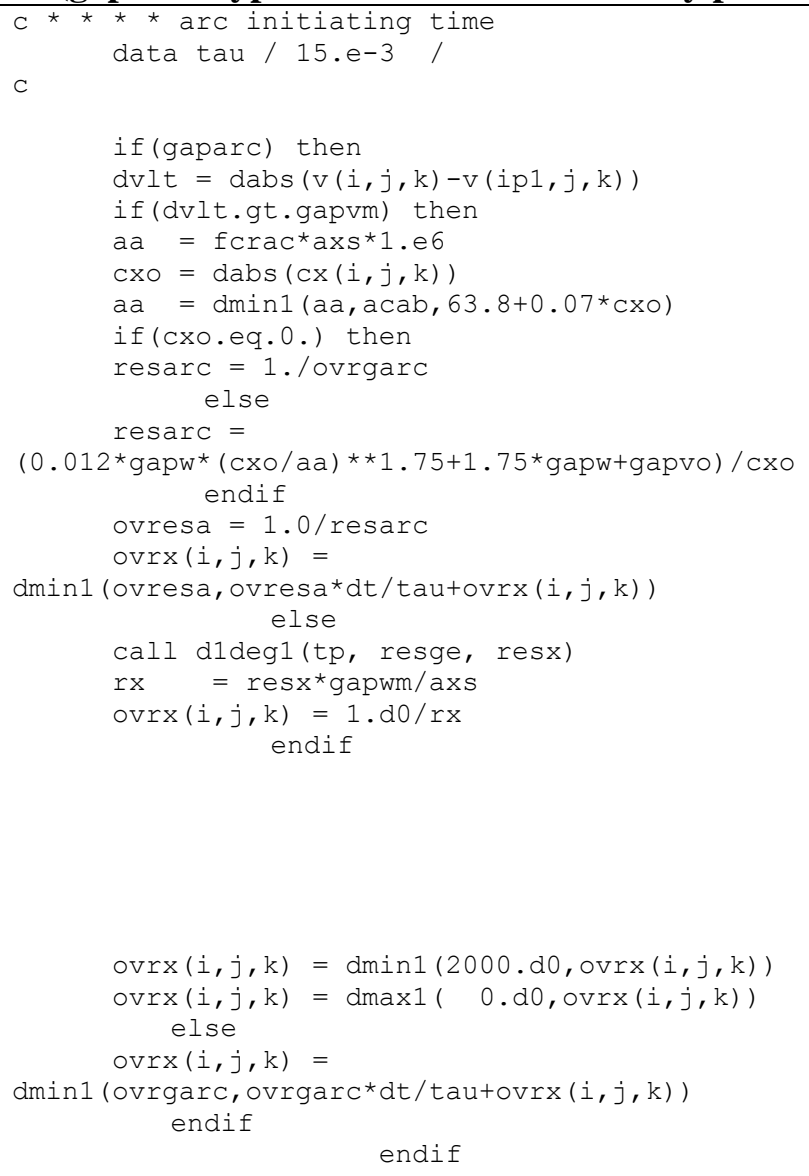 & 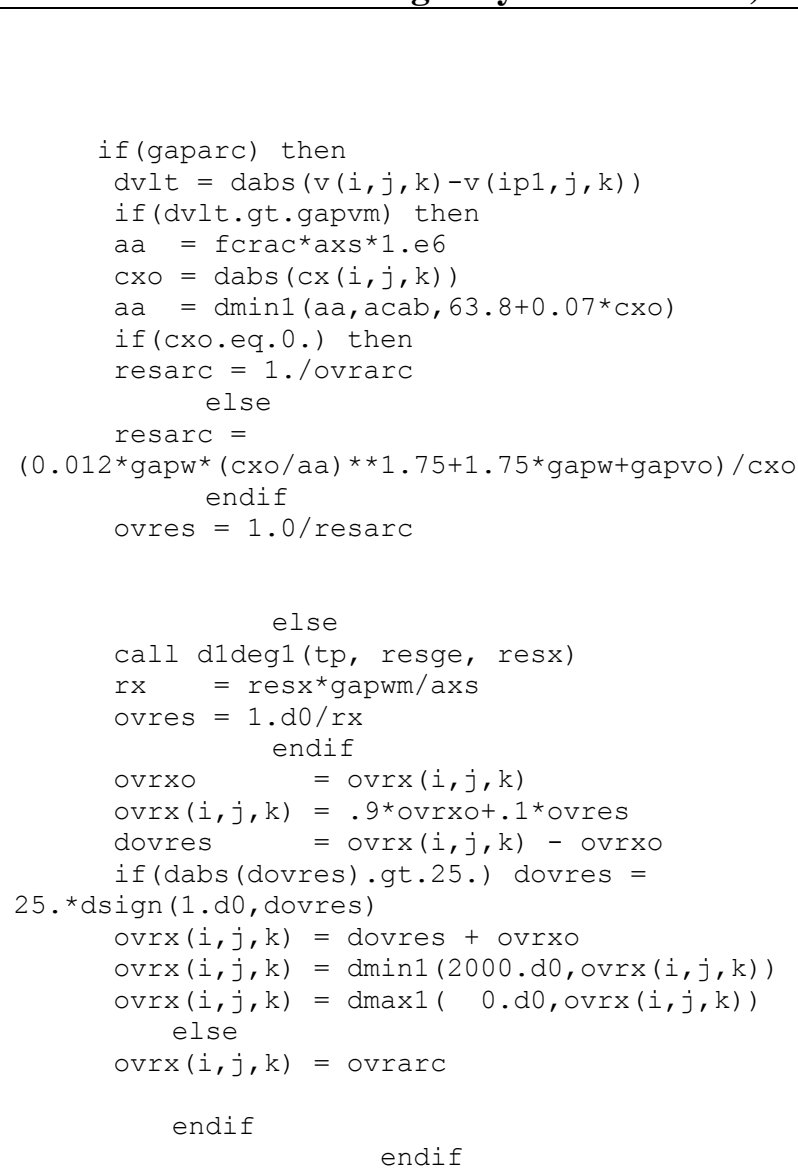 \\
\hline \multicolumn{2}{|c|}{$\begin{array}{l}\text { Subroutine Cshare } \\
\text { (modifications to include calls to Generalized Minimum Residual method when Bi-conjugate } \\
\text { Gradient Squared method fails to converge) }\end{array}$} \\
\hline $\begin{array}{l}\mathrm{c} \text { if(cur.gt.0.) then } \\
c * * \text { voltage } \\
c \quad \text { print *, 'Converging voltages }+++++++++' \\
c \quad \text { nloopmx }=2000\end{array}$ & $\begin{array}{l}\text { c } \quad \text { if(cur.gt.0.) then } \\
c * * \text { voltage }\end{array}$ \\
\hline
\end{tabular}




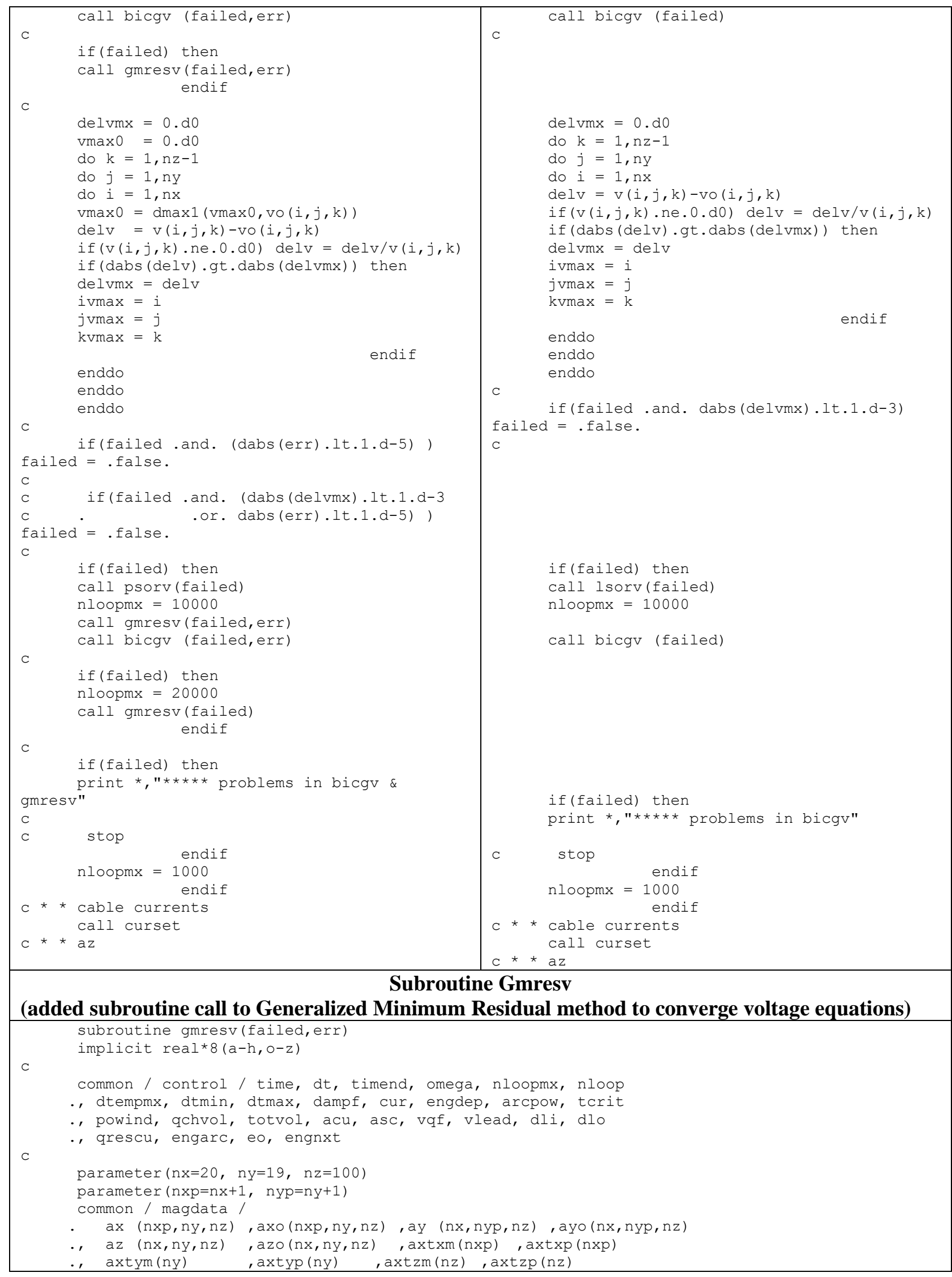




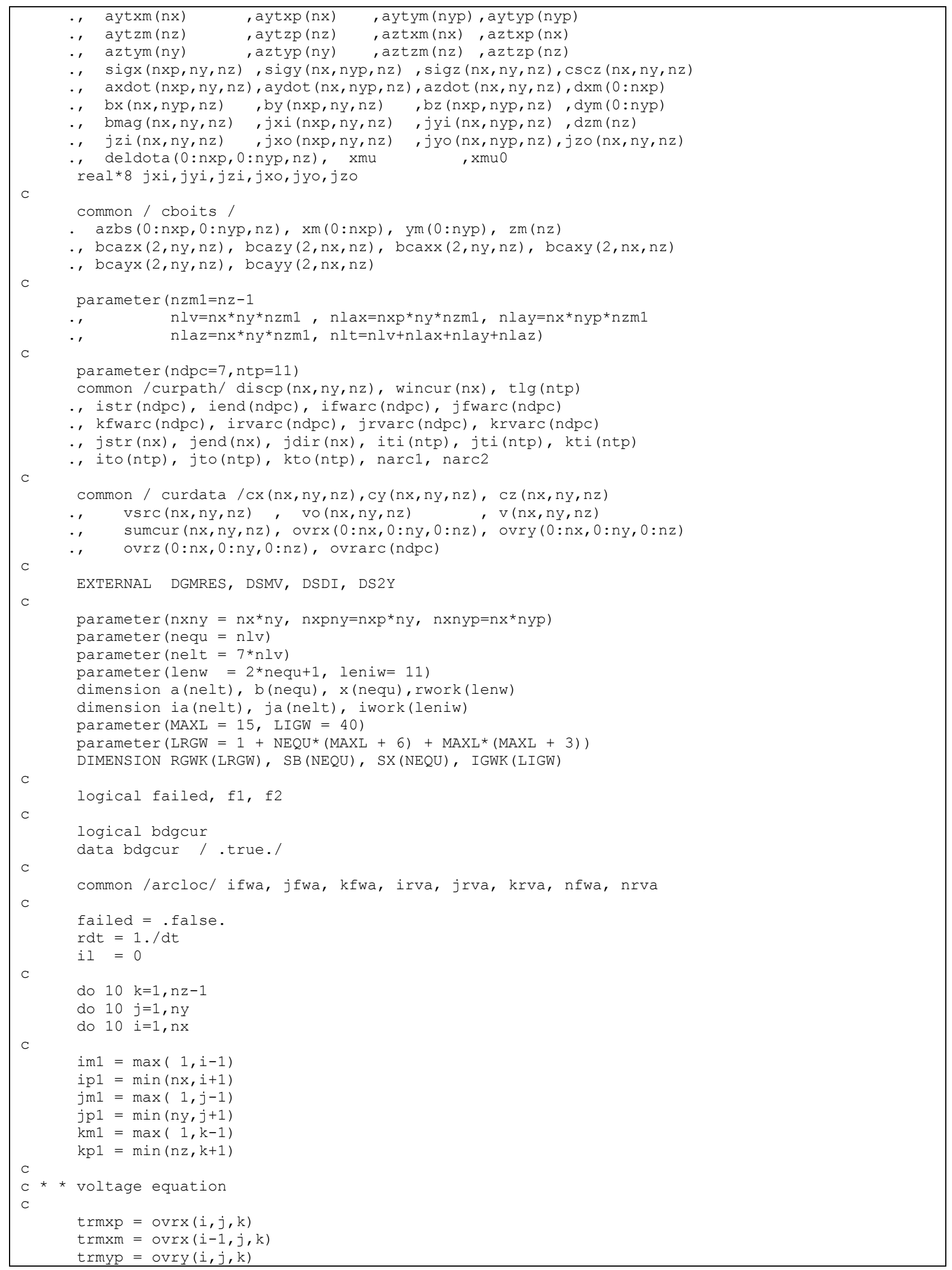




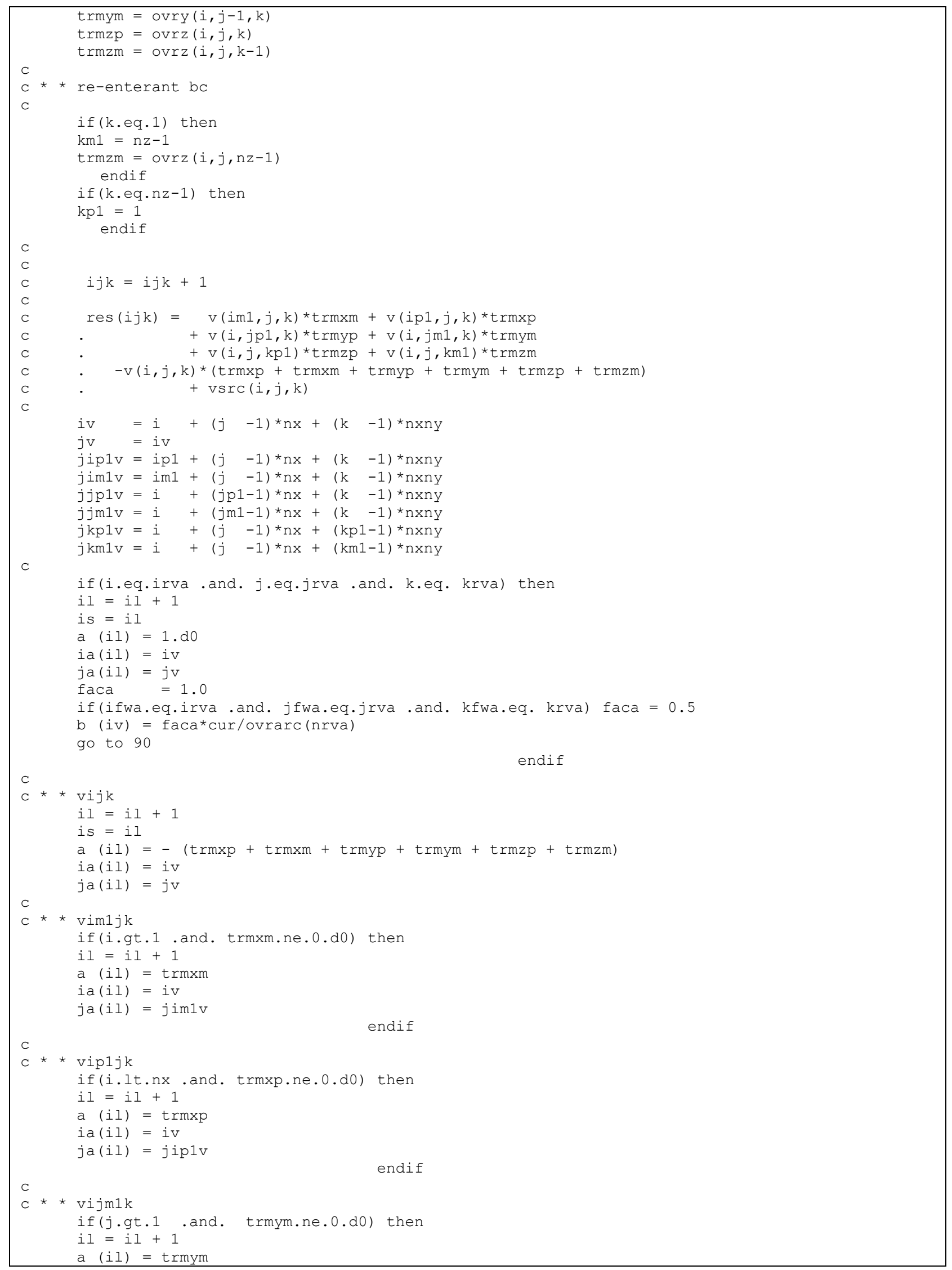




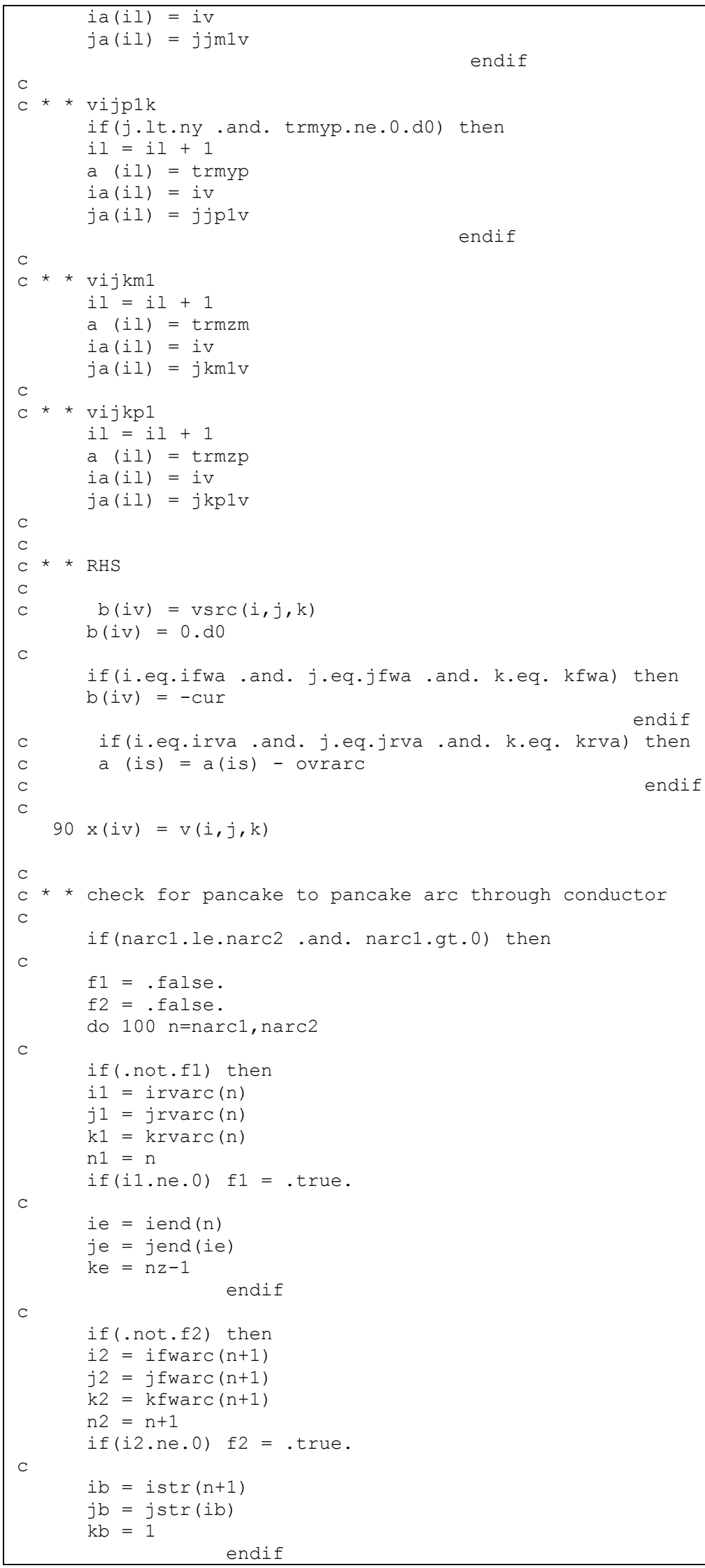




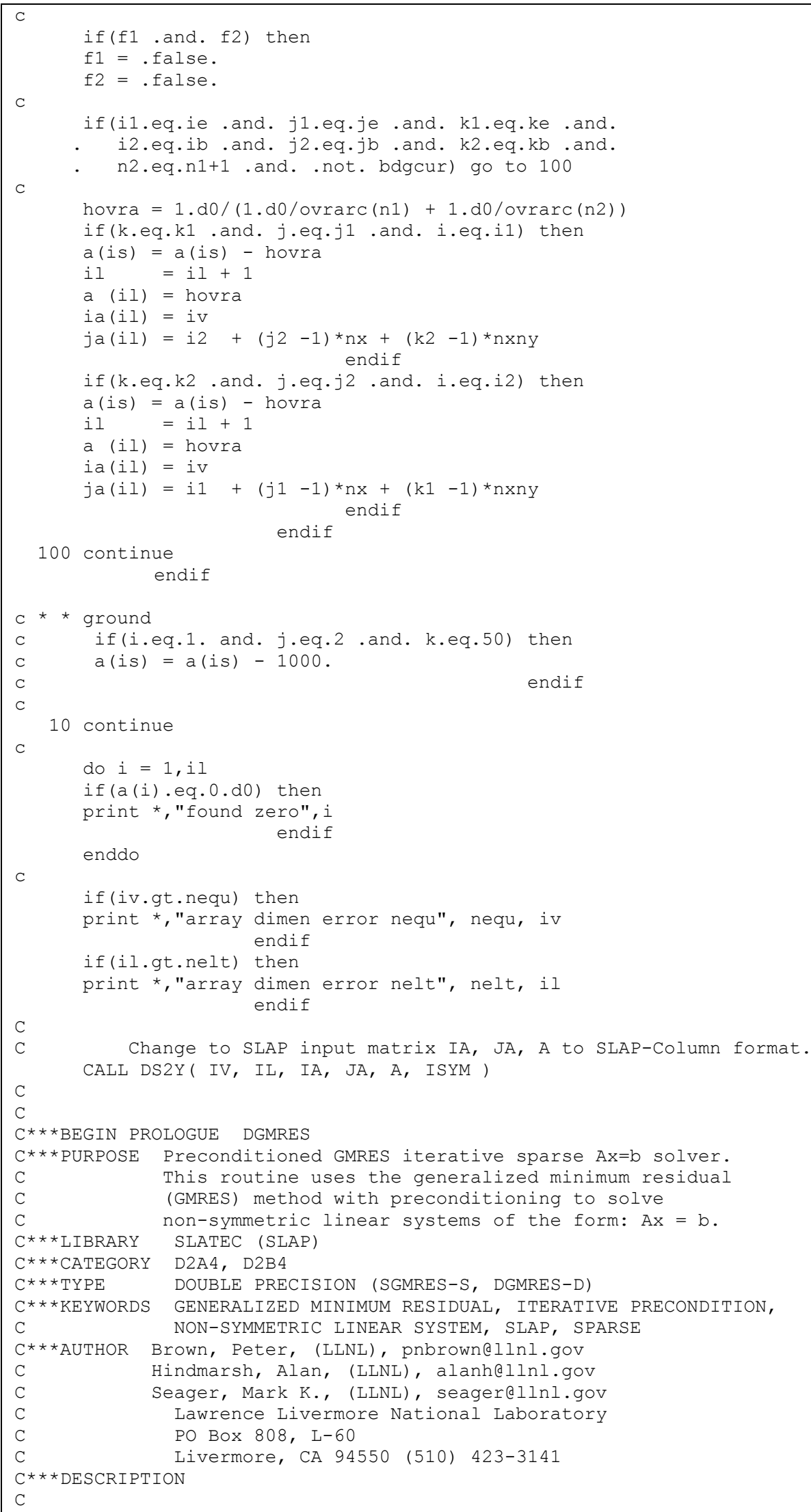




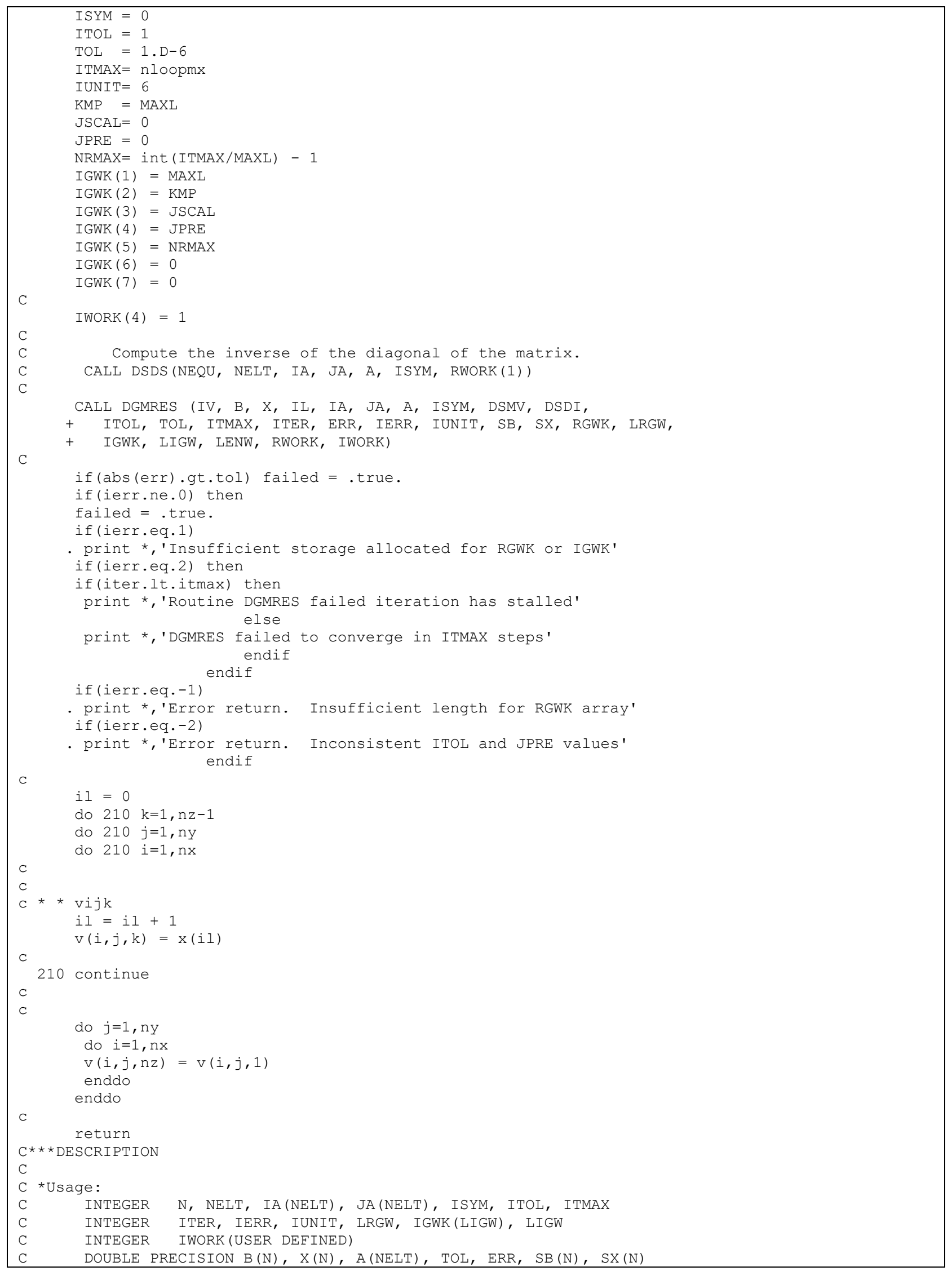




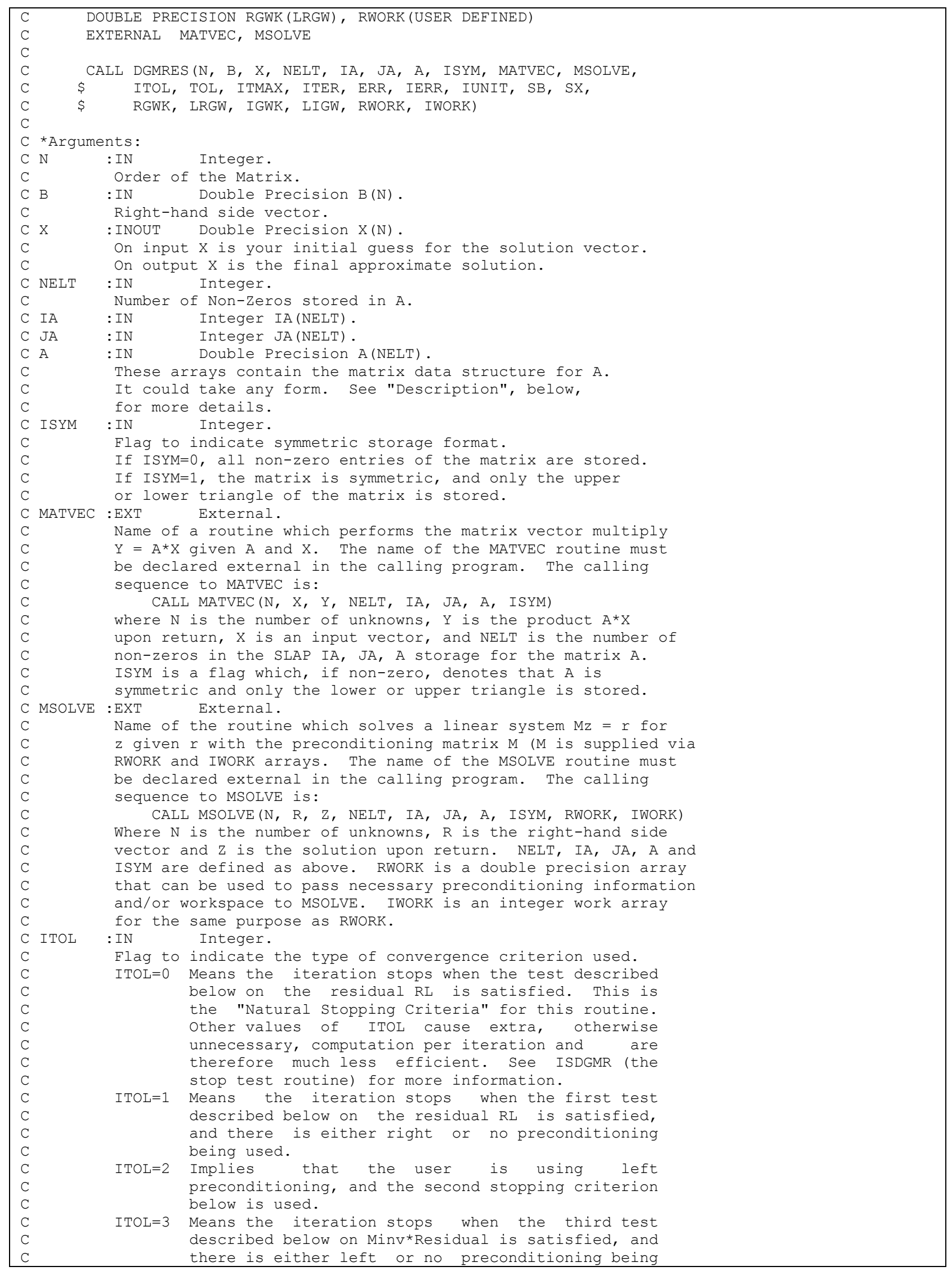




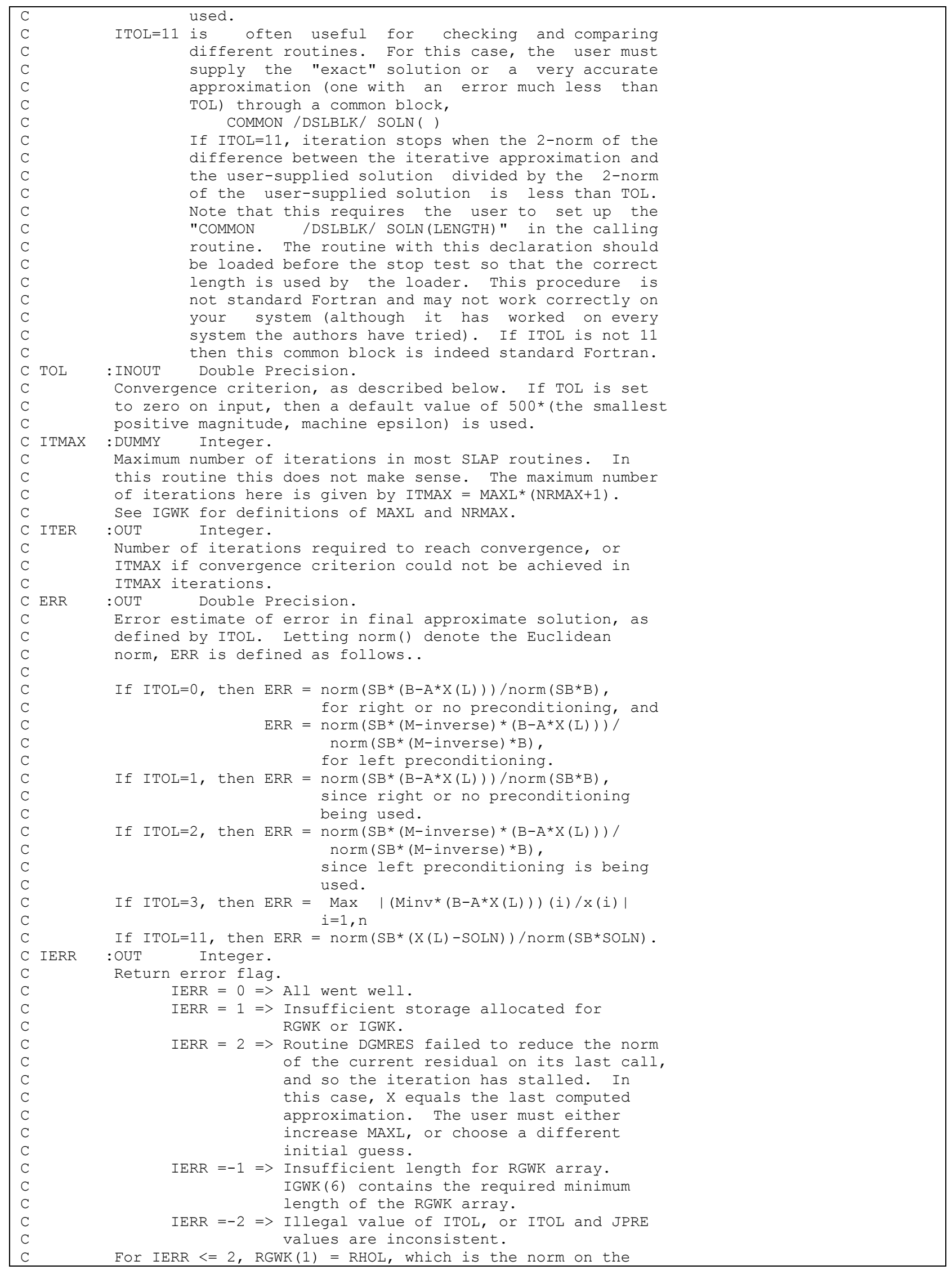




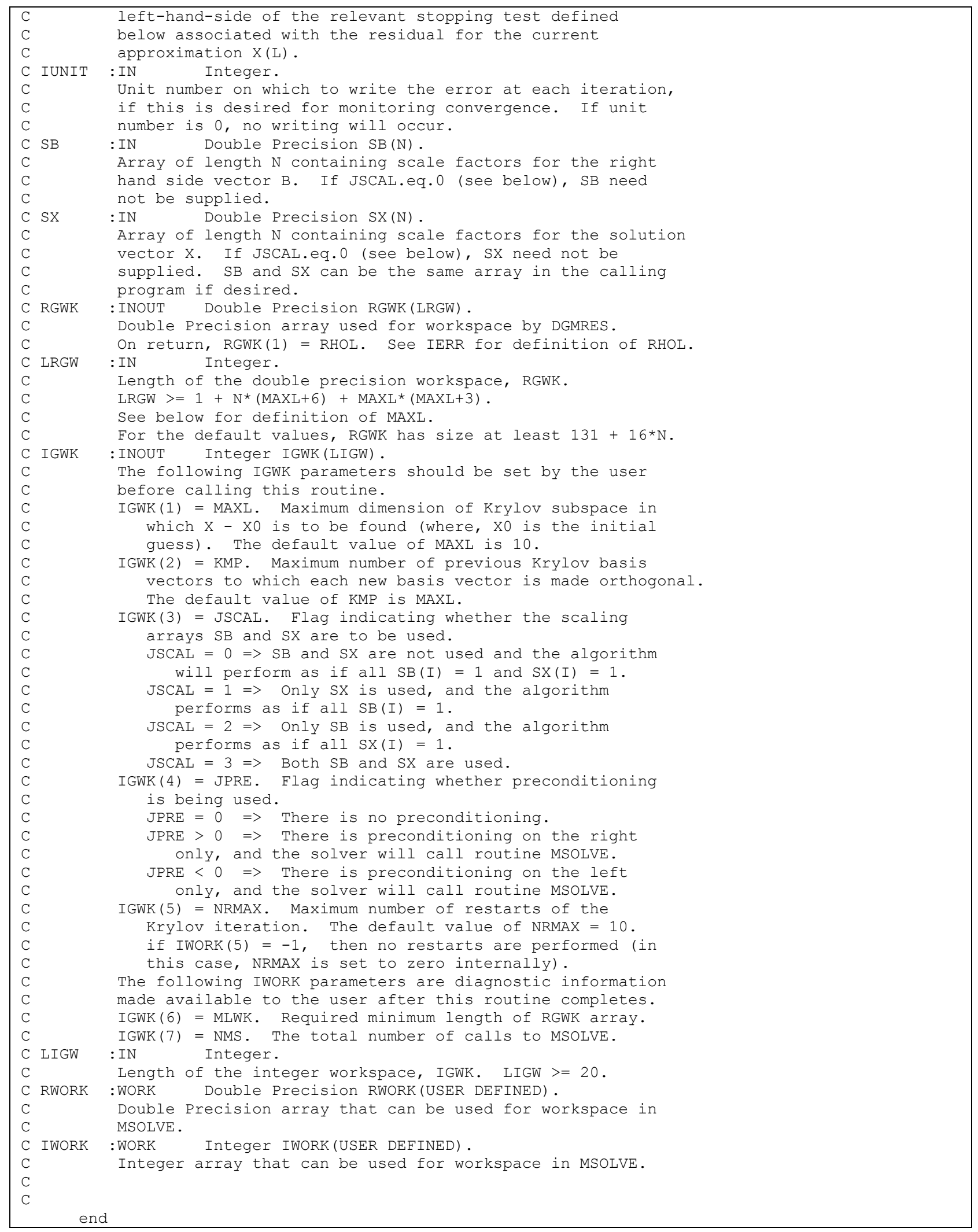

